Article

\title{
The Value-At-Risk Estimate of Stock and Currency-Stock Portfolios' Returns
}

\author{
Jung-Bin Su ${ }^{1, * \mathbb{D}}$ and Jui-Cheng Hung ${ }^{2}$ \\ 1 Department of Finance, China University of Science and Technology, No. 245, Sec. 3, Academia Rd., \\ Nangang Dist., Taipei 11581, Taiwan \\ 2 Department of Banking and Finance, Chinese Culture University, No. 55, Hwa-Kang Rd., Yang-Ming-Shan, \\ Taipei 11114, Taiwan; hung660804@gmail.com \\ * Correspondence: jungbinsu@cc.cust.edu.tw or jungbinsu@gmail.com; Tel.: +886-2-2786-4501 (ext. 16)
}

Received: 14 August 2018; Accepted: 12 November 2018; Published: 16 November 2018

\begin{abstract}
This study utilizes the seven bivariate generalized autoregressive conditional heteroskedasticity (GARCH) models to forecast the out-of-sample value-at-risk (VaR) of 21 stock portfolios and seven currency-stock portfolios with three weight combinations, and then employs three accuracy tests and one efficiency test to evaluate the VaR forecast performance for the above models. The seven models are constructed by four types of bivariate variance-covariance specifications and two approaches of parameters estimates. The four types of bivariate variance-covariance specifications are the constant conditional correlation (CCC), asymmetric and symmetric dynamic conditional correlation (ADCC and DCC), and the BEKK, whereas the two types of approach include the standard and non-standard approaches. Empirical results show that, regarding the accuracy tests, the $\mathrm{VaR}$ forecast performance of stock portfolios varies with the variance-covariance specifications and the approaches of parameters estimate, whereas it does not vary with the weight combinations of portfolios. Conversely, the VaR forecast performance of currency-stock portfolios is almost the same for all models and still does not vary with the weight combinations of portfolios. Regarding the efficiency test via market risk capital, the NS-BEKK model is the most suitable model to be used in the stock and currency-stock portfolios for bank risk managers irrespective of the weight combination of portfolios.
\end{abstract}

Keywords: value-at-risk; accuracy test; efficiency test; constant conditional correlation; dynamic conditional correlation; stock market

\section{Introduction}

In recent years, volatility and value-at-risk (VaR) forecasts have been a key topic in the financial field because they can be used to measure the risk of assets, especially for the VaR. However, why is the VaR more popular than volatility when we measure the assets' risk? The reason is that it can react to the skewed and leptokurtic characteristics appearing at the return distribution of most financial assets when the long and short positions of assets are considered. Owing to this merit, VaR has been widely used in financial fields such as risk management, financial control, financial reporting, and computing capital requirement. For example, the capital requirement is the amount of capital a bank or another financial institution has to hold as required by its financial regulator. However, the capital requirements for general market risk are based on the output of a bank's internal value-at-risk model and are calibrated to a common supervisory standard. In other words, a value-at-risk model produces an estimate of the maximum amount that the bank can lose on a particular portfolio over a given holding period and with a given degree of statistical confidence. Notably, if the bank's internal value-at-risk model overestimates the actual VaR, then the bank may lose the opportunity cost, whereas when this 
model underestimates the actual VaR, then the bank cannot recover the loss as the crisis happens. Furthermore, there are a variety of empirical approaches to calculating value at risk. Hence, it is important to select an appropriate empirical approach or model to precisely predict the risk.

Studies in the VaR literature have almost always focused on VaR forecasts and performance comparison among several models (Bams et al. 2017; Bayer 2018; Laporta et al. 2018; Lee and Su 2012; Su 2014a, 2014b, 2014c, 2015; Su et al. 2014; Yu et al. 2018). In contrast to previous studies, we wish to apply the findings of this study to the real world. Hence, except for performing a VaR forecasts performance comparison, this study combines an efficiency test with market risk capital (MRC) under the 1996 Market Risk Amendment (MRA) of the Basel Capital Accord to select a suitable model to manage a bank's risk via the two-stage selection procedure of Sarma et al. (2003). MRC is the amount of regulatory capital a bank must hold with respect to its market risk exposure. In addition, most past studies of VaR have concentrated on the risk measure of a single asset (Lee and Su 2012; Su and Hung 2011; Su 2014a, 2014b, 2015; Su et al. 2014). Actually, investors cannot just hold a single asset during a real investment process. Hence, the risk measure of a portfolio has become a significant topic today. This trend has led to the popularity of the multivariate GARCH models in recent research. However, as the number of component assets of a portfolio increases, the difficulty of parameter estimates of the multivariate GARCH models is rapidly enlarged. Hence, investors must consider not only the accuracy of the model forecast but also the ease of use of the model when they choose an appropriate empirical approach or model to predict the VaR. In the literature on empirical models, studies have almost always used the CCC, DCC, or BEKK types of multivariate GARCH models to explore empirical issues (Caporale et al. 2014; Li 2012; Moore and Wang 2014; Tamakoshi and Hamori 2014; Wang et al. 2010; Wang and Wang 2010; Weber 2013; Yaya et al. 2016). In contrast to the literature, this study also considers the two-step asymmetric dynamic conditional correlation (ADCC) model of Cappiello et al. (2006) (hereafter, NS-ADCC) because the ADCC model is the more general form of the dynamic conditional correlation (DCC) model of Engle (2002). In other words, the DCC model is a special case of the ADCC model.

Regarding the above multivariate GARCH models, they can be classified as the following two categories when the interrelationship between two assets is discussed. The first class uses the conditional variances and correlations to depict the correlative relationship between two assets such as the constant conditional correlation (CCC) model of Bollerslev (1990), the DCC model of Engle (2002), and the ADCC model of Cappiello et al. (2006) (Caporale et al. 2014; Moore and Wang 2014; Tamakoshi and Hamori 2014; Yaya et al. 2016). The second class uses the conditional variance-covariance matrix to explore the correlative relationship between two assets, such as the BEKK model (Baldi et al. 2016; Chang et al. 2013; Lin and Li 2015; Liu et al. 2017). The first class of model (CCC and DCC models) are also divided into two sub-categories depending on whether the parameters are estimated by only one step or two successive steps. That is, the first sub-category is called the standard approach, and it includes the standard CCC and DCC models (hereafter, S-CCC and S-DCC), for which the parameters are estimated by one step only. In contrast, the second sub-category is called the non-standard approach, and it contains the non-standard CCC, DCC, and ADCC models (hereafter, NS-CCC, NS-DCC, and NS-ADCC), for which the parameters are estimated by two successive steps. The difference between the two sub-categories is that the non-standard, or two-step model, is easy to be estimated, and it is easy to be extended to the more flexible models. The second class of model, the BEKK model, is also divided into two sub-categories depending on whether the parameters of the model are simplified or not. That is, in the standard BEKK model (hereafter, S-BEKK), the parameters are not simplified. Conversely, in the non-standard BEKK model (hereafter, NS-BEKK) derived by $\mathrm{Su}$ (2014c), the parameters are simplified by adopting the suggestion of Moschini and Myers (2002). Hence, the non-standard BEKK model has the same merits that the non-standard CCC and DCC models own. That is, the non-standard BEKK model is easy to be estimated, and it is also easy to extend to the more flexible models. Owing to the two-step model's being easy to be estimated and extended to 
the more flexible models, the two-step or non-standard DCC ${ }^{1}$ is very useful for determining optimal hedging strategies, volatility spillovers, and causality in volatility among financial commodities. For example, Moore and Wang (2014) used the two-step bivariate DCC-GARCH model to investigate the sources of the dynamic relationship between real exchange rates and stock return differentials in relation to the US market for the developed and emerging Asian markets. Tamakoshi and Hamori (2014) adopted a two-step bivariate asymmetric DCC-GARCH model (hereafter, ADCC-GARCH) to examine the interdependence of US dollar exchange rates expressed in euros, British pounds, and Swiss francs and to further explore the effect of Europe's recent financial turmoil on these dynamic correlations. Turhan et al. (2014) examined the dynamic relationship between crude oil and major asset classes consisting of stock, bond, foreign exchange rate, and gold markets via the two-step bivariate DCC-GARCH model with a mixed data sampling methodology. Ozkan and Erden (2015) applied the two-step multivariate DCC-GARCH model to obtain the time-varying exchange rate pass-through (ERPT) measure, then used a panel regression model to investigate the macroeconomic determinants of the degree of ERPT. The ERPT denotes the transmission of the movements in exchange rates to import prices and domestic prices.

Subsequently, this study mainly uses the two-stage selection procedure of Sarma et al. (2003) to select a suitable model to manage the risk of the institution. The first stage is to perform the accuracy tests via using three types of back-testing-Kupiec (1995) unconditional coverage test, Christoffersen (1998) conditional coverage test, and Engle and Manganelli (2004) dynamic quantile test- to evaluate the out-of-sample VaR forecast performance of the seven bivariate GARCH models: the S-CCC, NS-CCC, S-DCC, NS-DCC, S-BEKK, NS-BEKK, and NS-ADCC. The samples include the 21 stock portfolios and seven currency-stock portfolios with three weight combinations. The results are used to investigate which bivariate variance-covariance specification and which parameter estimate approach has a better VaR forecast performance, and whether the asymmetric DCC model has a better forecast performance than its corresponding symmetric one. In addition, this study also explores whether the different weight combinations and component combinations of portfolios will affect the results. The second stage is to execute an efficiency test via market risk capital to select a suitable model to manage the risk of the bank. This is performed by the superior predictive ability (SPA) test of Hansen (2005). Empirical results show that, regarding the accuracy tests, the VaR forecast performance of stock portfolios varies with the variance-covariance specifications and the approaches of parameters estimate. For example, the standard (respectively, non-standard) approach has better VaR forecast performance for the DCC and BEKK (respectively, CCC) types of bivariate variance-covariance specification. In particular, the DCC type of bivariate variance-covariance specification with the standard approach achieves the best VaR forecast performance among the seven bivariate GARCH models with no exception, indicating that this result is one of the most significant findings in this study. Notably, the above findings do not change even if the weight combinations of the portfolios vary. On the contrary, the VaR forecast performance of currency-stock portfolios is almost the same for all models, and still does not vary with the weight combinations of the portfolios. Hence, the above VaR forecast performance comparison results vary with the component combination of the portfolio but do not vary with the weight combinations of portfolios for the accuracy tests. Regarding the efficiency test via market risk capital, the NS-BEKK model is the most suitable model to be used in both the stock and currency-stock portfolios for the bank risk manager, irrespective of the weight combination of the portfolios, implying that the result is another one of the most significant findings in this study.

The remainder of this paper is organized as follows. Section 2 describes the empirical models utilized in this study: the three correlation types of the bivariate GARCH model (CCC, DCC, ADCC) and the variance-covariance type of the bivariate GARCH model (BEKK). Section 3 discusses the

1 Owing to the wide application of the DCC model, McAleer (2018) derived the stationarity and invertibility conditions of the DCC model in order to provide a solid statistical foundation for the estimates of the DCC parameters. 
theory of three types of back-testing, market risk capital, and the superior predictive ability test that are used to evaluate the VaR forecast performance for alternative VaR models. Section 4 states the basic statistical features for the return series of both United States dollar index and seven stock indices in American and Europe. Section 5 analyzes the empirical results of alternative bivariate GARCH models and further explores the issues addressed in this study via the performance assessments of VaR forecasts. Finally, the conclusion is drawn in the last section.

\section{Methodology}

As shown in the section of the introduction, the seven bivariate GARCH models are composed of four bivariate variance-covariance specifications (i.e., the CCC, DCC, ADCC, and BEKK) with the standard and non-standard approaches. Notably, only the non-standard approach is considered for the ADCC specification (i.e., the NS-ADCC model). The four bivariate variance-covariance specifications can roughly be classified into the following two categories. The first category uses the conditional variances and correlations to depict the correlative relationship between two assets such as the CCC, $\mathrm{DCC}$, and the ADCC. The second category uses the conditional variance-covariance matrix to explore the correlative relationship between two assets such as the BEKK model. Subsequently, the theory of the above two categories of models is depicted at the following two subsections.

\subsection{The Variance-Correlation Type of Bivariate GARCH Models}

In this subsection, the CCC and DCC models are selected as the representative of the variance-correlation type of bivariate GARCH models. The bivariate DCC-GARCH(1,1) model is composed of a mean equation and a variance-covariance equation. Hence, the mean equation in the vector form can be defined as follows.

$$
\mathbf{r}_{\mathbf{t}}=\boldsymbol{\mu}+\mathbf{e}_{\mathbf{t}}, \mathbf{e}_{\mathbf{t}} \mid \Omega_{\mathrm{t}-1}=\mathbf{H}_{\mathbf{t}}^{1 / 2} \cdot \mathbf{z}_{\mathbf{t}} \sim \mathrm{N}\left(\mathbf{0}, \mathbf{H}_{\mathbf{t}}\right), \mathbf{z}_{\mathbf{t}} \sim \mathrm{N}(\mathbf{0}, \mathbf{I})
$$

where $\mathbf{r}_{\mathbf{t}}=\left(\mathrm{r}_{1, \mathrm{t}}, \mathrm{r}_{2, \mathrm{t}}\right)^{\prime}$ is a column vector of $\log$ returns, that is, $\mathrm{r}_{\mathrm{i}, \mathrm{t}}=\left(\ln \mathrm{P}_{\mathrm{i}, \mathrm{t}}-\ln \mathrm{P}_{\mathrm{i}, \mathrm{t}-1}\right) \times 100, \mathrm{P}_{\mathrm{i}, \mathrm{t}}$ denotes the close price of the ith stock index at time $t ; \mu=\left(\mu_{1}, \mu_{2}\right)^{\prime}$ denotes a column vector of the above mean returns; $\mathbf{e}_{\mathbf{t}}=\left(\mathrm{e}_{1, \mathrm{t}}, \mathrm{e}_{2, \mathrm{t}}\right)^{\prime}$ is a column vector of the error terms; and $\mathbf{z}_{\mathbf{t}}$ follows a bivariate Gaussian distribution with a mean zero and its variance-covariance matrix equals the identity matrix, I. Conversely, the variance-covariance equation is expressed in the form of DCC-GARCH(1,1), and its vector form is represented as follows.

$$
H_{t}=D_{t} \cdot R_{t} \cdot D_{t}
$$

where $\mathbf{H}_{\mathbf{t}}$ denotes the variance-covariance matrix; $\mathbf{D}_{\mathbf{t}}=\operatorname{diag}\left(\mathrm{h}_{11, \mathrm{t}}^{0.5}, \mathrm{~h}_{22, \mathrm{t}}^{0.5}\right)$ is a diagonal matrix; $\mathbf{R}_{\mathbf{t}}=\operatorname{diag}\left(\mathrm{q}_{11, \mathrm{t}}^{-0.5}, \mathrm{q}_{22, \mathrm{t}}^{-0.5}\right) \cdot \mathbf{Q}_{\mathbf{t}} \cdot \operatorname{diag}\left(\mathrm{q}_{11, \mathrm{t}}^{-0.5}, \mathrm{q}_{22, \mathrm{t}}^{-0.5}\right)$ is the correlation matrix, $\mathbf{Q}_{\mathbf{t}}=\left(\mathrm{q}_{\mathrm{ij}, \mathrm{t}}\right)$ denotes a $2 \times 2$ symmetric positive definite matrix, and can be expressed as $\mathbf{Q}_{\mathbf{t}}=\left(1-\mathrm{a}^{\prime}-\mathrm{b}^{\prime}\right) \overline{\mathbf{Q}}+\mathrm{a}^{\prime} \mathbf{u}_{\mathbf{t}-1} \cdot \mathbf{u}_{\mathbf{t}-1}^{\prime}+$ $\mathrm{b}^{\prime} \mathbf{Q}_{\mathbf{t}-1}, \mathbf{u}_{\mathbf{t}}=\left(\mathrm{u}_{1, \mathrm{t}}, \mathrm{u}_{2, \mathrm{t}}\right)^{\prime}$ is a column vector with $\mathrm{u}_{\mathrm{i}, \mathrm{t}}=\mathrm{e}_{\mathrm{i}, \mathrm{t}} / \sqrt{\mathrm{h}_{\mathrm{ii}, \mathrm{t}},}, \overline{\mathbf{Q}}$ is the $2 \times 2$ unconditional variance matrix of $\mathbf{u}_{t}$, and $\mathrm{a}^{\prime}$ and $\mathrm{b}^{\prime}$ are the non-negative scalar parameters satisfying the condition of $\mathrm{a}^{\prime}+\mathrm{b}^{\prime}<1$. $^{2}$ Except for the DCC-GARCH $(1,1)$ model, we also follow Tamakoshi and Hamori (2014) to use the asymmetric DCC-GARCH $(1,1)$ (hereafter, ADCC) model. The ADCC model is a special case of the asymmetric generalized DCC (hereafter, AGDCC) proposed by Cappiello et al. (2006). This model considers the asymmetry in the correlation and can better capture the heterogeneity present in the data. In the AGDCC model, $\mathbf{Q}_{\mathbf{t}}=\left(\mathrm{q}_{\mathrm{ij}, \mathrm{t}}\right)$ is expressed as follows.

$$
\mathbf{Q}_{\mathbf{t}}=\left(\overline{\mathbf{Q}}-\mathbf{A}^{\prime} \overline{\mathbf{Q}} \mathbf{A}-\mathbf{B}^{\prime} \overline{\mathbf{Q}} \mathbf{B}-\mathbf{G}^{\prime} \overline{\mathbf{N}} \mathbf{G}\right)+\mathbf{A}^{\prime} \mathbf{u}_{\mathbf{t}-1} \cdot \mathbf{u}_{\mathbf{t}-1}^{\prime} \mathbf{A}+\mathbf{G}^{\prime} \mathbf{n}_{\mathbf{t}-1} \cdot \mathbf{n}_{\mathbf{t}-1}^{\prime} \mathbf{G}+\mathbf{B}^{\prime} \mathbf{Q}_{\mathbf{t}-1} \mathbf{B}
$$

\footnotetext{
2 For more details about these two types of models, please see Bauwens et al. (2006) and Silvennoinen and Teräsvirta (2009).
} 
where $\mathbf{A}, \mathbf{B}$, and $\mathbf{G}$ are the $2 \times 2$ parameter matrices; $\overline{\mathbf{Q}}$ and $\overline{\mathbf{N}}$ are the unconditional correlation matrices of $\mathbf{u}_{\mathbf{t}}$ and $\mathbf{n}_{\mathbf{t}} ;$ and $\mathbf{n}_{\mathbf{t}}=\mathbf{I}\left[\mathbf{u}_{\mathbf{t}}<0\right] \circ \mathbf{u}_{\mathbf{t}}, \mathbf{I}[\cdot]$ is a $2 \times 1$ indicator function that takes on the value of 1 if the argument is true and 0 otherwise; ' $\mathrm{o}^{\prime}$ denotes a Hadamard product; and $\overline{\mathbf{Q}}=\mathrm{E}\left[\mathbf{u}_{\mathbf{t}} \mathbf{u}_{\mathbf{t}}^{\prime}\right]$, and $\overline{\mathbf{N}}=\mathrm{E}\left[\mathbf{n}_{\mathbf{t}} \mathbf{n}_{\mathbf{t}}^{\prime}\right]$. Notably, the $\overline{\mathbf{Q}}$ and $\overline{\mathbf{N}}$ can be replaced with the sample analogues, $\mathrm{T}^{-1} \sum_{\mathrm{t}=1}^{\mathrm{T}} \mathbf{u}_{\mathbf{t}} \cdot \mathbf{u}_{\mathbf{t}}^{\prime}$ and $\mathrm{T}^{-1} \sum_{\mathrm{t}=1}^{\mathrm{T}} \mathbf{n}_{\mathbf{t}} \cdot \mathbf{n}_{\mathbf{t}}^{\prime}$ ' respectively. $T$ denotes the sample size of the estimation period. If $\mathbf{A}, \mathbf{B}$, and $\mathbf{G}$ are respectively replaced by scalars $\bar{a}, \bar{b}$, and $\bar{g}$, then the AGDCC model degenerates into the ADCC model. Hence, the ADCC model can be expressed as the following form.

$$
\mathbf{Q}_{\mathbf{t}}=\left(\overline{\mathbf{Q}}-\mathrm{a}^{\prime} \overline{\mathbf{Q}}-\mathrm{b}^{\prime} \overline{\mathbf{Q}}-\mathrm{g}^{\prime} \overline{\mathbf{N}}\right)+\mathrm{a}^{\prime} \mathbf{u}_{\mathbf{t}-1} \cdot \mathbf{u}_{\mathbf{t}-1}^{\prime}+\mathrm{g}^{\prime} \mathbf{n}_{\mathbf{t}-1} \cdot \mathbf{n}_{\mathbf{t}-1}^{\prime}+\mathrm{b}^{\prime} \mathbf{Q}_{\mathbf{t}-1}
$$

where $\mathrm{a}^{\prime}=\overline{\mathrm{a}}^{2}, \mathrm{~b}^{\prime}=\overline{\mathrm{b}}^{2}$, and $\mathrm{g}^{\prime}=\overline{\mathrm{g}}^{2}$. In this case, parameters $\overline{\mathrm{a}}, \overline{\mathrm{b}}$, and $\overline{\mathrm{g}}$ are not restricted as positive values. If $\mathrm{g}^{\prime}=0$, then the ADCC model degenerates into the DCC model created by Engle (2002). The correlation matrix $\mathbf{R}_{\mathbf{t}}$ can be expressed as follows.

$$
\begin{aligned}
\mathbf{R}_{\mathbf{t}} & =\operatorname{diag}\left(\mathrm{q}_{11, \mathrm{q}}^{-0.5}, \mathrm{q}_{22, \mathrm{q}}^{-0.5}\right) \cdot \mathbf{Q}_{\mathbf{t}} \cdot \operatorname{diag}\left(\mathrm{q}_{11, \mathrm{q}}^{-0.5}, \mathrm{q}_{22, \mathrm{q}}^{-0.5}\right) \\
& =\left[\begin{array}{c}
\mathrm{q}_{11, \mathrm{q}}^{-0.5} \\
0 \mathrm{q}_{22, \mathrm{q}}^{-0.5}
\end{array}\right]\left[\begin{array}{l}
\mathrm{q}_{11, \mathrm{q}} \mathrm{q}_{12, \mathrm{q}} \\
\mathrm{q}_{12, \mathrm{q}} \mathrm{q}_{22, \mathrm{q}}
\end{array}\right]\left[\begin{array}{c}
\mathrm{q}_{11,5}^{-0.5} \mathrm{q} \\
0 \mathrm{q}_{22, \mathrm{q}}^{-0.5}
\end{array}\right] \\
& =\left[\begin{array}{cc}
1 & \mathrm{q}_{12, \mathrm{t}} \cdot\left(\mathrm{q}_{11, \mathrm{t}} \cdot \mathrm{q}_{22, \mathrm{t}}\right)^{-0.5} \\
\mathrm{q}_{12, \mathrm{t}} \cdot\left(\mathrm{q}_{11, \mathrm{t}} \cdot \mathrm{q}_{22, \mathrm{t}}\right)^{-0.5} & 1
\end{array}\right]
\end{aligned}
$$

Hence, $\mathbf{R}_{\mathbf{t}}$ is also a symmetric positive definite matrix including the time varying conditional correlations $\rho_{12, t}=q_{12, t} / \sqrt{q_{11, t} \cdot q_{22, t}}$ and $\rho_{i i, t}=1$ for $i=1,2$. Owing to $\mathbf{H}_{\mathbf{t}}=\mathbf{D}_{\mathbf{t}} \cdot \mathbf{R}_{\mathbf{t}} \cdot \mathbf{D}_{\mathbf{t}}$, the variance-covariance specification of bivariate DCC-GARCH $(1,1)$ or bivariate ADCC-GARCH $(1,1)$ model is also expressed as the following matrix form.

$$
\begin{aligned}
{\left[\begin{array}{ll}
\mathrm{h}_{11, \mathrm{t}} & \mathrm{h}_{12, \mathrm{t}} \\
\mathrm{h}_{21, \mathrm{t}} & \mathrm{h}_{22, \mathrm{t}}
\end{array}\right] } & =\left[\begin{array}{ll}
\mathrm{h}_{11, \mathrm{t}}^{0.5} & 0 \\
0 & \mathrm{~h}_{22, \mathrm{t}}^{0.5}
\end{array}\right]\left[\begin{array}{cr}
1 & \rho_{12, \mathrm{t}} \\
\rho_{12, \mathrm{t}} & 1
\end{array}\right]\left[\begin{array}{cc}
\mathrm{h}_{11, \mathrm{t}}^{0.5} & 0 \\
0 & \mathrm{~h}_{22, \mathrm{t}}^{0.5}
\end{array}\right] \\
& =\left[\begin{array}{lr}
\mathrm{h}_{11, \mathrm{t}} & \rho_{12, \mathrm{t}}\left(\mathrm{h}_{11, \mathrm{t}} \cdot \mathrm{h}_{22, \mathrm{t}}\right)^{0.5} \\
\rho_{12, \mathrm{t}}\left(\mathrm{h}_{11, \mathrm{t}} \cdot \mathrm{h}_{22, \mathrm{t}}\right)^{0.5} & \mathrm{~h}_{22, \mathrm{t}}
\end{array}\right]
\end{aligned}
$$

Therefore, $\mathrm{h}_{12, \mathrm{t}}=\mathrm{h}_{21, \mathrm{t}}=\rho_{12, \mathrm{t}} \sqrt{\mathrm{h}_{11, \mathrm{t}} \cdot \mathrm{h}_{22, \mathrm{t}}}$ and $\mathrm{h}_{\mathrm{ii}, \mathrm{t}}$ can be defined as any type of univariate GARCH(1,1) model such as $h_{i i, t}=\omega_{i}+\alpha_{i} e_{i, t-1}^{2}+\beta_{i} h_{i i, t-1}$ for $\mathrm{i}=1$, 2. Notably, the above bivariate DCC-GARCH $(1,1)$ model degenerates into the bivariate CCC-GARCH $(1,1)$ model when the parameters $\mathrm{a}^{\prime}$ and $\mathrm{b}^{\prime}$ are set as zero. Therefore, the log-likelihood function of the bivariate DCC-GARCH $(1,1)$, CCC-GARCH(1,1), and ADCC-GARCH(1,1) models can be written as follows:

$$
\begin{aligned}
\mathrm{L}(\mathbf{\Psi}) & =\sum_{\mathrm{t}=1}^{\mathrm{T}} \ln \left\{\mathrm{f}\left(\mathbf{r}_{\mathbf{t}} \mid \Omega_{\mathrm{t}-1} ; \mathbf{\Psi}\right)\right\} \\
& =-\frac{\mathrm{T}}{2} \ln (2 \pi)-\frac{1}{2} \sum_{\mathrm{t}=1}^{\mathrm{T}}\left(\ln \left|\mathbf{H}_{\mathbf{t}}\right|+\mathbf{e}_{\mathbf{t}}^{\prime} \cdot \mathbf{H}_{\mathbf{t}}^{-1} \cdot \mathbf{e}_{\mathbf{t}}\right)
\end{aligned}
$$

where $\boldsymbol{\Psi}=\left[\mu_{1}, \mu_{2}, \omega_{1}, \alpha_{1}, \beta_{1}, \omega_{2}, \alpha_{2}, \beta_{2}, \rho_{12}\right]$ and $\left[\mu_{1}, \mu_{2}, \omega_{1}, \alpha_{1}, \beta_{1}, \omega_{2}, \alpha_{2}, \beta_{2}, a^{\prime}, b^{\prime}\right]$, respectively, are the vector of parameters to be estimated for the bivariate CCC-GARCH $(1,1)$ and bivariate DCC-GARCH(1,1) models whereas $\Psi=\left[\mu_{1}, \mu_{2}, \omega_{1}, \alpha_{1}, \beta_{1}, \omega_{2}, \alpha_{2}, \beta_{2}, \bar{a}, \bar{b}, \bar{g}\right]$ is the vector of parameters to be estimated for the bivariate ADCC-GARCH $(1,1)$ model. T denotes the sample size of the estimate period, $\mathrm{f}(\cdot)$ denotes the bivariate normal density, $\Omega_{\mathrm{t}-1}$ denotes the information set of all observed returns up to time $\mathbf{t}-1$ whereas $\mathbf{r}_{\mathbf{t}}, \mathbf{e}_{\mathbf{t}}$, and $\mathbf{H}_{\mathbf{t}}$ are defined in Equations (1) and (2).

In addition, both the bivariate CCC-GARCH $(1,1)$ model and the bivariate DCC-GARCH $(1,1)$ model can be classified into two sub-categories based on the procedure of the parameters estimate. If all the parameters of these models are estimated via only one step, then the bivariate CCC-GARCH $(1,1)$ model and the bivariate DCC-GARCH $(1,1)$ model are respectively named as the standard CCC 
(hereafter, S-CCC) model and the standard DCC (hereafter, S-DCC) model. ${ }^{3}$ On the contrary, when the parameters of these models are estimated via two successive steps, the bivariate CCC-GARCH $(1,1)$ model and the bivariate DCC-GARCH $(1,1)$ model are respectively named as the non-standard CCC (hereafter, NS-CCC) model and the non-standard DCC (hereafter, NS-DCC) model. In this section, we select the NS-ADCC model as an example to illustrate the estimating procedure of the non-standard or two-step approach. The parameters of the bivariate ADCC-GARCH $(1,1)$ model are estimated via two successive steps only, hence, this model is named as the non-standard ADCC (hereafter, NS-ADCC) model. The detailed estimate procedure of NS-ADCC model is listed as follows. First, two univariate GARCH(1,1) models are fit for each of the two component assets' return series (i.e., $r_{i, t}$ for $i=1,2$ ), and then the estimates of variance series $h_{i i, t}$ and residue series $e_{i, t}$ for $i=1,2$ are obtained. Hence, the $\log$-likelihood value $\mathrm{LL}_{\mathrm{i}}$ and the values of parameters $\mu_{\mathrm{i}}, \omega_{\mathrm{i}}, \alpha_{\mathrm{i}}$, and $\beta_{\mathrm{i}}$ are obtained from the estimation of the ith univariate $\operatorname{GARCH}(1,1)$ model corresponding to the ith component asset for $\mathrm{i}=1,2$ during this step of estimation. Second, two standardized residual return series $\left(u_{i, t}\right.$ for $\left.i=1,2\right)$ are obtained by the residual return series $\left(e_{i, t}\right)$ divided by their estimated standard deviations series $\left(\sqrt{h_{i i, t}}\right)$ (i.e., $\mathrm{u}_{\mathrm{i}, \mathrm{t}}=\mathrm{e}_{\mathrm{i}, \mathrm{t}} / \sqrt{\mathrm{h}_{\mathrm{i} i, t}}$ for $\mathrm{i}=1,2$ ). In addition, the above two corresponding negative component residual return series $\left(n_{i, t}\right.$ for $\left.i=1,2\right)$ are obtained by the relation: $n_{i, t}=I\left[u_{i, t}<0\right] \cdot u_{i, t}$ where $I[\cdot]$ is an indicator function that takes on the value of 1 if the argument is true and 0 otherwise. Subsequently, the above two standardized residual return series $\left(u_{i, t}\right.$ for $\left.i=1,2\right)$ and their corresponding negative component residual return series $\left(n_{i, t}\right.$ for $\left.i=1,2\right)$ are used to estimate the intercept parameters of the conditional correlation $(\bar{a}, \bar{b}$, and $\bar{g})$. During this step of estimation, the log-likelihood value $\mathrm{LL}_{3}$ and the values of parameters $\bar{a}, \bar{b}$, and $\bar{g}$ are obtained from the estimation of the correlation matrix equation: $\mathbf{Q}_{\mathbf{t}}=\left(\overline{\mathbf{Q}}-\mathrm{a}^{\prime} \overline{\mathbf{Q}}-\mathrm{b}^{\prime} \overline{\mathbf{Q}}-\mathrm{g}^{\prime} \overline{\mathbf{N}}\right)+\mathrm{a}^{\prime} \mathbf{u}_{\mathbf{t}-1} \mathbf{u}_{\mathrm{t}-1}^{\prime}+\mathrm{g}^{\prime} \mathbf{n}_{\mathbf{t}-1} \mathbf{n}_{\mathbf{t}-1}^{\prime}+\mathrm{b}^{\prime} \mathbf{Q}_{\mathbf{t}-1}$ where $\mathrm{a}^{\prime}=\overline{\mathrm{a}}^{2}, \mathrm{~b}^{\prime}=\overline{\mathrm{b}}^{2}$, and $\mathrm{g}^{\prime}=\overline{\mathrm{g}}^{2}$. Notably, the two-step parameters estimate approach can be employed when the dimension of the multivariate GARCH model is greater than two.

Under the framework of the parametric techniques (Jorion 2000), the one-day-ahead long position VaR of a portfolio ${ }^{4}$ based on the bivariate CCC-GARCH(1,1), DCC-GARCH(1,1), and ADCC-GARCH $(1,1)$ models can be calculated as follows.

$$
\begin{gathered}
\operatorname{LVaR}_{P, t}=\mu_{P}+z_{\alpha} \cdot \sqrt{\hat{h}_{P, t+1 \mid t}} \\
=\sum_{i=1}^{2} w_{i} \cdot \mu_{i}+z_{\alpha} \sqrt{\sum_{i=1}^{2} \sum_{j=1}^{2} w_{i} w_{j} \hat{h}_{i j, t+1 \mid t}}
\end{gathered}
$$

where $\mu_{\mathrm{P}}$ is the conditional mean of return for a portfolio; $\mathrm{w}_{\mathrm{i}}$ is the weight of component asset $\mathrm{i}$ (i.e., the share of asset $i$ in a portfolio); $\mu_{i}$ is the conditional mean of return for component asset $i$, and $\mathrm{z}_{\alpha}$ denotes the left-tailed percentile at $\alpha \%$ for the standardized normal distribution; $\hat{\mathrm{h}}_{\mathrm{ij}, \mathrm{t}+1 \mid \mathrm{t}}$ is the one-step-ahead variance (respectively, covariance) forecast when $i=j$ (respectively, $i \neq j$ ) conditional on all information upon time $t$, and it can be obtained from Equation (6).

3 The parameters of the standard CCC and DCC models are estimated by the GARCH instruction provided by the Rats 6.0 program. The parameters of these models are estimated only by one step compared with the two steps' CCC and DCC models.

4 In a real case, if an institution wants to evaluate the operation performance of several fund managers that respectively have different values of assets measured with different currencies, indicating that it is hard to evaluate their operation performance when 'the VaR expressed in actual monetary value' is used. However, it is easy to evaluate their performance as 'the VaR expressed in return' is utilized since the return is dimensionless. Notably, we can convert the above expression via the following equation. 'The VaR expressed in actual monetary value' = 'the VaR expressed in return' * the value of asset's position. Taking an example to illustrate it, if the value of an asset is USD 1000, and its VaR expressed in return is $1.4091 \%$, then 'the VaR expressed in actual monetary value' is equal to USD $14.091\left(=1.4091 \%{ }^{*}\right.$ USD1000). 


\subsection{The Variance-Covariance Type of Bivariate GARCH Models}

In this subsection, the BEKK ${ }^{5}$ model is chosen as the representative of the variance-covariance type of bivariate GARCH models. The bivariate BEKK-GARCH $(1,1)$ model can be classified into the following two sub-categories based on the number of parameters to estimate in a model. The first sub-category: the standard BEKK-GARCH $(1,1)$ model (hereafter, S-BEKK) ${ }^{6}$ has eleven parameters. The second sub-category: the non-standard BEKK-GARCH(1,1) model derived by Su (2014c) (hereafter, NS-BEKK) has only nine parameters. The BEKK-GARCH model proposed by Engle and Kroner (1995) is a restricted version of the $\mathrm{VEC}$ model $^{7}$ and it has the attractive property of the conditional covariance matrix being definitely positive owing to its matrix's construction. Hence, the standard BEKK model has the following form.

$$
\mathbf{H}_{\mathbf{t}}=\mathbf{C}_{0}^{\prime} \mathbf{C}_{0}+\sum_{\mathbf{k}=1}^{\mathrm{K}} \sum_{\mathrm{i}=1}^{\mathrm{p}} \mathbf{A}_{\mathbf{i k}}^{\prime} \mathbf{e}_{\mathbf{t}-\mathbf{i}} \mathbf{e}_{\mathbf{t}-\mathbf{i}}^{\prime} \mathbf{A}_{\mathbf{i k}}+\sum_{\mathbf{k}=1}^{\mathrm{K}} \sum_{\mathbf{j}=1}^{\mathrm{q}} \mathbf{G}_{\mathbf{j} \mathbf{k}}^{\prime} \mathbf{H}_{\mathbf{t}-\mathbf{j}} \mathbf{G}_{\mathbf{j k}}
$$

where $\mathbf{A}_{\mathbf{i k}}$ and $\mathbf{G}_{\mathbf{j k}}$ are $\mathrm{n} \times \mathrm{n}$ dimensional matrices, and $\mathbf{C}_{0}$ is an upper triangular matrix. $\mathbf{e}_{\mathbf{t}-\mathbf{i}}$ is an $\mathrm{n} \times 1$ column vector of error terms, and $\mathbf{H}_{\mathbf{t}}$ denotes the $n \times n$ dimensional variance-covariance matrix. The decomposition of the constant term into a product of two triangular matrices is to ensure the positive definiteness of $\mathbf{H}_{\mathbf{t}}$ and the summation limit From the property of DMC, it holds that determines the generality of the process. It should be clear that Equation (9) will be definitely positive under very weak conditions. Furthermore, this representation is sufficiently general since it includes all positive definite diagonal representations and nearly all positive definite VEC representations. To clearly illustrate the BEKK-GARCH model, this study considers the bivariate BEKK-GARCH $(1,1)$ model with the restriction condition of ' $\mathrm{K}=\mathrm{p}=\mathrm{q}=1^{\prime}$ and ' $\mathrm{K}=2$, and $\mathrm{p}=\mathrm{q}=1^{\prime}$ for the standard and non-standard BEKK-GARCH models, respectively. The above standard and non-standard BEKK-GARCH models are respectively named as the S-BEKK and NS-BEKK models. Hence, when the restrictions ' $K=p=q=1$ and $n=2^{\prime}$ are substituted into Equation (9), the S-BEKK model can be obtained as follows.

$$
\mathrm{H}_{\mathrm{t}}=\mathrm{C}_{0}^{\prime} \mathrm{C}_{\mathbf{0}}+\mathrm{A}_{\mathbf{1 1}}^{\prime} \mathbf{e}_{\mathrm{t}-\mathbf{1}} \mathbf{e}_{\mathrm{t}-\mathbf{1}}^{\prime} \mathrm{A}_{\mathbf{1 1}}+\mathrm{G}_{\mathbf{1 1}}^{\prime} \mathrm{H}_{\mathrm{t}-\mathbf{1}} \mathrm{G}_{11}
$$

where the parameters $\mathbf{A}_{\mathbf{1 1}}$ and $\mathbf{G}_{\mathbf{1 1}}$ are $2 \times 2$ dimensional matrices and $\mathbf{C}_{\mathbf{0}}$ is an upper triangular matrix. They are defined as follows:

$$
\mathbf{H}_{\mathbf{t}}=\left[\begin{array}{ll}
h_{11, t} & h_{12, t} \\
h_{21, t} & h_{22, t}
\end{array}\right], \mathbf{e}_{t-1}=\left[\begin{array}{l}
e_{1, t-1} \\
e_{2, t-1}
\end{array}\right], \mathbf{C}_{\mathbf{0}}=\left[\begin{array}{cc}
c_{11} & c_{12} \\
0 & c_{22}
\end{array}\right], \mathbf{A}_{11}=\left[\begin{array}{ll}
a_{11} & a_{12} \\
a_{21} & a_{22}
\end{array}\right], \mathbf{G}_{11}=\left[\begin{array}{ll}
g_{11} & g_{12} \\
g_{21} & g_{22}
\end{array}\right] .
$$

Hence, the S-BEKK model can also be expressed as follows. When the above matrix expression is manipulated, we obtain that, first, the variance-covariance matrix $\mathbf{H}_{\mathbf{t}}$ is a symmetric matrix (i.e., $\mathrm{h}_{12, \mathrm{t}}=$ $\mathrm{h}_{21, \mathrm{t}}$ ). Second, the model in Equation (10) includes eleven parameters (i.e., the elements in matrices $\mathbf{C}_{0}$,

5 The BEKK model is named after Baba et al. (1990).

6 The parameters of the standard BEKK model are estimated by the GARCH instruction provided by the Rats 6.0 program. The parameters of these models are estimated only by one step. This approach is the same as the standard CCC and DCC models mentioned above.

7 According to Bauwens et al. (2006), there are three non-mutually exclusive approaches to construct multivariate GARCH models: (i) direct generalizations of the univariate GARCH model of Bollerslev (1986); (ii) linear combinations of univariate GARCH models; and (iii) nonlinear combinations of univariate GARCH models. Notably, both the VEC and BEKK models belong to the above first approach. In the general VEC model, each element of the conditional variance matrix $\left(\mathbf{H}_{\mathrm{t}}\right)$ is a linear function of the lagged squared errors and cross-products of errors and lagged values of the elements of $\mathbf{H}_{\mathrm{t}}$. The $\mathrm{BEKK}$ model is a special case of the VEC model. Hence, the number of parameters in the BEKK model is less than that in the VEC model. For example, the numbers of parameters in the $\operatorname{VEC}(1,1)$ and $\operatorname{BEKK}(1,1,1)$ models are $n(n+1)[n(n+1)+1] / 2$ and $\mathrm{n}(5 \mathrm{n}+1) / 2$, respectively. The $\operatorname{BEKK}(1,1,1)$ model is expressed as Equation $(10)$ in this study. 
$\mathbf{A}_{11}$, and $\mathbf{G}_{11}$ ). Third, the elements of this variance-covariance matrix $\mathbf{H}_{\mathbf{t}}$ is a function of $\mathrm{e}_{1, t-1}^{2}, \mathrm{e}_{2, t-1}^{2}$, $\mathrm{e}_{1, t-1} \mathrm{e}_{2, \mathrm{t}-1}, \mathrm{~h}_{11, \mathrm{t}-1}, \mathrm{~h}_{22, \mathrm{t}-1}$ and $\mathrm{h}_{12, \mathrm{t}-1}$ and is expressed as follows.

$$
\begin{aligned}
\mathrm{h}_{11, \mathrm{t}}=\mathrm{c}_{11}^{2}+\mathrm{a}_{11}^{2} \mathrm{e}_{1, \mathrm{t}-1}^{2}+2 \mathrm{a}_{11} \mathrm{a}_{21} \mathrm{e}_{1, \mathrm{t}-1} \mathrm{e}_{2, \mathrm{t}-1}+\mathrm{a}_{21}^{2} \mathrm{e}_{2, \mathrm{t}-1}^{2} \\
+\mathrm{g}_{11}^{2} \mathrm{~h}_{11, \mathrm{t}-1}+2 \mathrm{~g}_{11} \mathrm{~g}_{21} \mathrm{~h}_{12, \mathrm{t}-1}+\mathrm{g}_{21}^{2} \mathrm{~h}_{22, \mathrm{t}-1} \\
\mathrm{~h}_{12, \mathrm{t}}=\mathrm{c}_{12} \mathrm{c}_{11}+\mathrm{a}_{11} \mathrm{a}_{12} \mathrm{e}_{1, \mathrm{t}-1}^{2}+\left(\mathrm{a}_{21} \mathrm{a}_{12}+\mathrm{a}_{11} \mathrm{a}_{22}\right) \mathrm{e}_{1, \mathrm{t}-1} \mathrm{e}_{2, \mathrm{t}-1}+\mathrm{a}_{21} \mathrm{a}_{22} \mathrm{e}_{2, \mathrm{t}-1}^{2} \\
+\mathrm{g}_{11} \mathrm{~g}_{12} \mathrm{~h}_{11, \mathrm{t}-1}+\left(\mathrm{g}_{21} \mathrm{~g}_{12}+\mathrm{g}_{11} \mathrm{~g}_{22}\right) \mathrm{h}_{12, \mathrm{t}-1}+\mathrm{g}_{21} \mathrm{~g}_{22} \mathrm{~h}_{22, \mathrm{t}-1} \\
\mathrm{~h}_{22, \mathrm{t}}=\mathrm{c}_{22}^{2}+\mathrm{c}_{12}^{2}+\mathrm{a}_{12}^{2} \mathrm{e}_{1, \mathrm{t}-1}^{2}+2 \mathrm{a}_{12} \mathrm{a}_{22} \mathrm{e}_{1, \mathrm{t}-1} \mathrm{e}_{2, \mathrm{t}-1}+\mathrm{a}_{22}^{2} \mathrm{e}_{2, \mathrm{t}-1}^{2} \\
+\mathrm{g}_{12}^{2} \mathrm{~h}_{11, \mathrm{t}-1}+2 \mathrm{~g}_{12} \mathrm{~g}_{22} \mathrm{~h}_{12, \mathrm{t}-1}+\mathrm{g}_{22}^{2} \mathrm{~h}_{22, \mathrm{t}-1}
\end{aligned}
$$

where parameters $\mathrm{a}_{11}, \mathrm{~g}_{11}, \mathrm{c}_{11}$, and $\mathrm{c}_{22}$ are restricted to be positive in order to avoid 'the BEKK model with $\mathrm{K}=1^{\prime}$ being observationally equivalent structures ${ }^{8}$. Conversely, when the restrictions ' $\mathrm{K}=2$, $\mathrm{p}=\mathrm{q}=1$, and $\mathrm{n}=2^{\prime}$ are substituted into Equation (9), the NS-BEKK model can be obtained as follows.

$$
H_{t}=C_{0}^{\prime} C_{0}+A_{11}^{\prime} e_{t-1} e_{t-1}^{\prime} A_{11}+A_{12}^{\prime} e_{t-1} e_{t-1}^{\prime} A_{12}+G_{11}^{\prime} H_{t-1} G_{11}+G_{12}^{\prime} H_{t-1} G_{12}
$$

where the matrices $\mathbf{H}_{\mathbf{t}}, \mathbf{C}_{0}$ and the vector $\mathbf{e}_{\mathbf{t}-\mathbf{1}}$ are defined as the same as in Equation (10) and the parameters $\mathbf{A}_{\mathbf{1 1}}, \mathbf{A}_{\mathbf{1 2}}, \mathbf{G}_{\mathbf{1 1}}$ and $\mathbf{G}_{\mathbf{1 2}}$ are $2 \times 2$ dimensional matrices, defined as follows.

$$
\mathbf{A}_{\mathbf{1 1}}=\left[\begin{array}{cc}
\mathrm{a}_{11,1} & 0 \\
0 & \mathrm{a}_{22,1}
\end{array}\right], \mathbf{A}_{\mathbf{1 2}}=\left[\begin{array}{cc}
0 & 0 \\
0 & \mathrm{a}_{22,2}
\end{array}\right], \mathbf{G}_{\mathbf{1 1}}=\left[\begin{array}{cc}
\mathrm{g}_{11,1} & 0 \\
0 & \mathrm{~g}_{22,1}
\end{array}\right], \mathbf{G}_{\mathbf{1 2}}=\left[\begin{array}{cc}
0 & 0 \\
0 & \mathrm{~g}_{22,2}
\end{array}\right]
$$

Subsequently, substitute these matrices into Equation (12), we first obtain that the variance-covariance matrix $\mathbf{H}_{\mathbf{t}}$ is a symmetric matrix (i.e., $\mathrm{h}_{21, \mathrm{t}}=\mathrm{h}_{12, \mathrm{t}}$ ). Second, the number of parameters of the model in Equation (12) will decrease to nine (i.e., the elements in matrices $\mathbf{C}_{\mathbf{0}}, \mathbf{A}_{\mathbf{1 1}}$, $\mathbf{A}_{12}, \mathbf{G}_{11}$ and $\mathbf{G}_{12}$ ). Third, the elements of this variance-covariance matrix $\mathbf{H}_{\mathbf{t}}$ are expressed as the similar form of univariate $\operatorname{GARCH}(1,1)$, and are represented as follows.

$$
\begin{gathered}
\mathrm{h}_{11, \mathrm{t}}=\omega_{1}+\alpha_{1} \mathrm{e}_{1, \mathrm{t}-1}^{2}+\beta_{1} \mathrm{~h}_{11, \mathrm{t}-1} \\
\mathrm{~h}_{12, \mathrm{t}}=\omega_{12}+\alpha_{12} \mathrm{e}_{1, \mathrm{t}-1} \mathrm{e}_{2, \mathrm{t}-1}+\beta_{12} \mathrm{~h}_{12, \mathrm{t}-1} \\
\mathrm{~h}_{22, \mathrm{t}}=\omega_{2}+\alpha_{2} \mathrm{e}_{2, \mathrm{t}-1}^{2}+\beta_{2} \mathrm{~h}_{22, \mathrm{t}-1}
\end{gathered}
$$

where $\omega_{1}=c_{11}^{2}, \alpha_{1}=a_{11,1}^{2}, \beta_{1}=g_{11,1}^{2}, \omega_{12}=c_{12} c_{11}, \alpha_{12}=a_{11,1} a_{22,1}, \beta_{12}=g_{11,1} g_{22,1}, \omega_{2}=c_{22}^{2}+c_{12}^{2}$, $\alpha_{2}=\mathrm{a}_{22,1}^{2}+\mathrm{a}_{22,2}^{2}, \beta_{2}=\mathrm{g}_{22,1}^{2}+\mathrm{g}_{22,2}^{2}$. Hence, the bivariate BEKK GARCH model with the restrictions $' \mathrm{~K}=2$, and $\mathrm{p}=\mathrm{q}=1^{\prime}$ can be represented by a bivariate diagonal model in vech form.

$$
\operatorname{vech}\left(\mathbf{H}_{\mathbf{t}}\right)=\left[\begin{array}{c}
\mathrm{h}_{11, \mathrm{t}} \\
\mathrm{h}_{12, \mathrm{t}} \\
\mathrm{h}_{22, \mathrm{t}}
\end{array}\right]=\left[\begin{array}{c}
\omega_{1} \\
\omega_{12} \\
\omega_{2}
\end{array}\right]+\left[\begin{array}{ccc}
\alpha_{1} & 0 & 0 \\
0 & \alpha_{12} & 0 \\
0 & 0 & \alpha_{2}
\end{array}\right]\left[\begin{array}{c}
\mathrm{e}_{1, \mathrm{t}-1}^{2} \\
\mathrm{e}_{1, \mathrm{t}-1} \mathrm{e}_{2, \mathrm{t}-1} \\
\mathrm{e}_{2, \mathrm{t}-1}^{2}
\end{array}\right]+\left[\begin{array}{ccc}
\beta_{1} & 0 & 0 \\
0 & \beta_{12} & 0 \\
0 & 0 & \beta_{2}
\end{array}\right]\left[\begin{array}{c}
\mathrm{h}_{11, t-1} \\
\mathrm{~h}_{12, t-1} \\
\mathrm{~h}_{22, t-1}
\end{array}\right]
$$

where the vech operator takes the 'lower triangular' portion of a symmetric matrix and stacks each element into a vector with a single column. This bivariate diagonal type of BEKK model uses only 9 parameters. Thus it is more parsimonious as compared to the 11 parameters for the S-BEKK model under the condition of positive definite being fulfilled. Moreover, the parameters of the bivariate S-BEKK and NS-BEKK models are also estimated by the maximum likelihood (ML) optimizing

8 Please see the Proposition 2.1 of Engle and Kroner (1995) for more details. 
numerically the Gaussian log-likelihood function. Hence, the log-likelihood function of these two models can be written as follows:

$$
\begin{gathered}
\mathrm{L}(\mathbf{\Psi})=\sum_{\mathrm{t}=1}^{\mathrm{T}} \ln \left\{\mathrm{f}\left(\mathbf{r}_{\mathbf{t}} \mid \Omega_{\mathrm{t}-1} ; \mathbf{\Psi}\right)\right\} \\
=-\frac{\mathrm{T}}{2} \ln (2 \pi)-\frac{1}{2} \sum_{\mathrm{t}=1}^{\mathrm{T}}\left(\ln \left|\mathbf{H}_{\mathbf{t}}\right|+\mathbf{e}_{\mathbf{t}}^{\prime} \cdot \mathbf{H}_{\mathbf{t}}^{-1} \cdot \mathbf{e}_{\mathbf{t}}\right)
\end{gathered}
$$

where $\Psi=\left[\mu_{1}, \mu_{2}, c_{11}, c_{12}, c_{22}, a_{11}, a_{12}, a_{21}, a_{22}, g_{11}, g_{12}, g_{21}, g_{22}\right]$ and $\left[\mu_{1}, \mu_{2}, \omega_{1}, \alpha_{1}, \beta_{1}, \omega_{12}, \alpha_{12}, \beta_{12}\right.$, $\omega_{2}, \alpha_{2}, \beta_{2}$ ] respectively are the vector of parameters to be estimated for the bivariate S-BEKK and NS-BEKK models, $T$ denotes the sample size of estimate period, $f(\cdot)$ denotes the bivariate normal density and $\Omega_{\mathrm{t}-1}$ denotes the information set of all observed returns up to time $t-1$. Notably, the mean equation of these two models is also expressed in Equation (1).

Under the framework of the parametric techniques (Jorion 2000), the one-day-ahead long position VaR of a portfolio based on the bivariate S-BEKK and NS-BEKK models can be calculated as:

$$
\begin{gathered}
\operatorname{LVaR}_{P, t}=\mu_{P}+z_{\alpha} \cdot \sqrt{\hat{\mathrm{h}}_{\mathrm{P}, \mathrm{t}+1 \mid \mathrm{t}}} \\
=\sum_{\mathrm{i}=1}^{2} \mathrm{w}_{\mathrm{i}} \cdot \mu_{\mathrm{i}}+\mathrm{z}_{\alpha} \sqrt{\sum_{\mathrm{i}=1}^{2} \sum_{\mathrm{j}=1}^{2} \mathrm{w}_{\mathrm{i}} \mathrm{w}_{\mathrm{j}} \hat{\mathrm{h}}_{\mathrm{ij}, \mathrm{t}+1 \mid \mathrm{t}}}
\end{gathered}
$$

where $\mu_{\mathrm{P}}, \mathrm{w}_{\mathrm{i}}, \mu_{\mathrm{i}}$, and $\mathrm{z}_{\alpha}$ are defined as the same in Equation $(8) ; \hat{\mathrm{h}}_{\mathrm{ij}, \mathrm{t}+1 \mid \mathrm{t}}$ is one-step-ahead variance (respectively, covariance) forecast when $\mathrm{i}=\mathrm{j}$ (respectively, $\mathrm{i} \neq \mathrm{j}$ ) conditional on all information upon time t. $\hat{\mathrm{h}}_{\mathrm{ij}, \mathrm{t}+1 \mid \mathrm{t}}$ can be obtained from Equation (11) for the S-BEKK model and Equation (13) for the NS-BEKK model.

\section{Assessment Methods of Alternative VaR Models}

In the previous section, the seven bivariate GARCH models (S-CCC, NS-CCC, S-DCC, NS-DCC, S-BEKK, NS-BEKK, and NS-ADCC) were used to calculate the parametric approach VaR for 21 bi-component stock portfolios ${ }^{9}$ and seven bi-component currency-stock portfolios. The stock portfolios comprise of alternative two stock indices among seven stock markets in the US and Europe, whereas the seven currency-stock portfolios comprise the US dollar index with alternative one stock index among the seven stock markets. Moreover, many financial institutions are required to hold capital against their market risk exposure. The MRC requirements are calculated based on VaR estimates generated by the financial institutions' own risk management models. Hence, the accuracy of these VaR estimates is of concern to both financial institutions and their regulators. Thus, in this study, three accuracy measure tests-Kupiec (1995) unconditional coverage test, Christoffersen (1998) conditional coverage test, and Engle and Manganelli (2004) dynamic quantile test-are mainly used to perform the back-testing of the VaR model, and the empirical results are used to compare the VaR forecasting ability of the seven abovementioned models. Except for performing a VaR forecasts performance comparison, this study combines an efficiency test with MRC to select a suitable model to manage the risk to a bank via using the two-stage selection procedure of Sarma et al. (2003). Thus the theory of MRC and the superior predictive ability (SPA) test of Hansen (2005) are also described in this section.

\subsection{The Failure Rate and Unconditional Coverage Test}

If the predicted VaR is not able to cover the realized loss, this is termed as a violation. A binary loss function (BLF) is merely the reflection of the likelihood ratio test of the unconditional coverage

9 Regarding the seven stock indices, the total number of bi-component portfolios can be calculated by $C_{2}^{7}=21$. 
test $\left(\mathrm{LR}_{\mathrm{uc}}\right)$ and gives a penalty of one to each exception of the VaR. Hence, the BLF of a long position is a Bernoulli random variable and it can be defined as follows.

$$
\mathrm{BL}_{\mathrm{t}+1}=\left\{\begin{array}{l}
1 \text { if } \mathrm{r}_{\mathrm{P}, \mathrm{t}+1}<\mathrm{LVaR}_{\mathrm{P}, \mathrm{t}+1 \mid \mathrm{t}} \\
0 \text { if } \mathrm{r}_{\mathrm{P}, \mathrm{t}+1} \geq \operatorname{LVaR}_{\mathrm{P}, \mathrm{t}+1 \mid \mathrm{t}}
\end{array}\right.
$$

where $\mathrm{BL}_{\mathrm{t}+1}$ denotes the one-day-ahead BLF of long position, and $\mathrm{r}_{\mathrm{P}, \mathrm{t}}=\mathrm{w}_{1} \mathrm{r}_{1, \mathrm{t}}+\mathrm{w}_{2} \mathrm{r}_{2, \mathrm{t}}$, and $\mathrm{w}_{1}=$ $\mathrm{w}_{2}=0.5$ denote the component weights of an equal weight bi-component portfolio. However, in this study, there are other two component weights' combinations: $\mathrm{w}_{1}=0.25, \mathrm{w}_{2}=0.75$ and $\mathrm{w}_{1}=0.75, \mathrm{w}_{2}=0.25$. If a VaR model truly provides the level of coverage defined by its confidence level, then the average binary loss function (ABLF) or the failure rate over the full sample will equal $c$ for the $(1-c)$ th percentile VaR.

Kupiec (1995) proposed the unconditional coverage test $\left(\mathrm{LR}_{\mathrm{uc}}\right)$ which is a likelihood ratio test for testing the model accuracy. The null hypothesis of this test is that the probability of failure for each trial $(\hat{\pi})$ equals the specified model probability $(\mathrm{p})$. The likelihood ratio test statistic is given by

$$
\mathrm{LR}_{\mathrm{uc}}=-2 \ln \left[\frac{\mathrm{p}^{\mathrm{n}_{1}}(1-\mathrm{p})^{\mathrm{n}_{0}}}{\hat{\pi}^{\mathrm{n}_{1}}(1-\hat{\pi})^{\mathrm{n}_{0}}}\right] \sim \chi^{2}(1)
$$

where $\hat{\pi}=n_{1} /\left(n_{0}+n_{1}\right)$ is the maximum likelihood estimate of $p, n_{1}$ represents the total number of VaR violations and $n_{0}+n_{1}$ represents the full sample size. The $L_{\mathrm{uc}}$ test can be employed to test whether the sample point estimate is statistically consistent with the VaR model's prescribed confidence level.

\subsection{Conditional Coverage Test}

Even if the $\mathrm{LR}_{\mathrm{uc}}$ test can reject a model that either overestimates or underestimates the true but unobservable VaR, it cannot inspect whether the exceptions are randomly distributed. In a risk management framework, it is significant that the VaR exceptions must be uncorrelated over time, which hints that both the independence and unconditional coverage tests based on the evaluation of interval forecasts must be simultaneously considered when the competition of a group of VaR models is performing. Christoffersen (1998) thus proposed a conditional coverage test $\left(\mathrm{LR}_{\mathrm{cc}}\right)$ to jointly test the correct unconditional coverage and serial independence. The $\mathrm{LR}_{\mathrm{cc}}$ test is a joint test of these two properties and the corresponding test statistics are $\mathrm{LR}_{\mathrm{cc}}=\mathrm{LR}_{\mathrm{uc}}+\mathrm{LR}_{\mathrm{ind}}$ when we condition on the first observation. The $\mathrm{LR}_{\text {ind }}$ test denotes the likelihood ratio statistic that tests whether exceptions are independent, and the $\mathrm{LR}_{\mathrm{uc}}$ is defined in the previous subsection. Therefore, under the null hypothesis of the expected proportion of exceptions equals $\mathrm{p}$ and the failure process is independent, the appropriate likelihood ratio test statistic is expressed as follows:

$$
\mathrm{LR}_{\mathrm{cc}}=\mathrm{LR}_{\mathrm{uc}}+\mathrm{LR}_{\text {ind }}=-2 \ln \left[\frac{\mathrm{p}^{\mathrm{n}}(1-\mathrm{p})^{\mathrm{T}-\mathrm{n}}}{\hat{\pi}_{01}^{\mathrm{n}_{01}}\left(1-\hat{\pi}_{01}\right)^{\mathrm{n}_{00}} \hat{\pi}_{11}^{\mathrm{n}_{11}}\left(1-\hat{\pi}_{11}\right)^{\mathrm{n}_{10}}}\right] \sim \chi^{2}(2)
$$

where $n_{i j}$ denotes the number of observations with value i followed by value $j(i, j=0,1), \pi_{i j}=$ $\mathrm{P}\left\{\mathrm{I}_{\mathrm{t}}=\mathrm{j} \mid \mathrm{I}_{\mathrm{t}-1}=\mathrm{i}\right\}(\mathrm{i}, \mathrm{j}=0,1), \hat{\pi}_{01}=\mathrm{n}_{01} /\left(\mathrm{n}_{00}+\mathrm{n}_{01}\right), \hat{\pi}_{11}=\mathrm{n}_{11} /\left(\mathrm{n}_{10}+\mathrm{n}_{11}\right)$.

\subsection{Dynamic Quantile Test}

Engle and Manganelli (2004) proposed the dynamic quantile (DQ) test to remedy the inefficiency in the conditional coverage test by Christoffersen (1998). We define a sequence of indicator variables for testing the VaR of the long position as follows.

$$
\mathrm{Hit}_{\mathrm{L}, \mathrm{t}}=\mathrm{I}\left(\mathrm{r}_{\mathrm{P}, \mathrm{t}+1}<\mathrm{LVaR}_{\mathrm{P}, \mathrm{t}+1 \mid \mathrm{t}}\right)-\mathrm{c}
$$


where $\mathrm{Hit}_{\mathrm{L}, \mathrm{t}}$ is an indicator function of the long position. Engle and Manganelli (2004) suggested to jointly test that: (1) $\mathrm{E}\left(\mathrm{Hit}_{\mathrm{L}, \mathrm{t}}\right)=0$; (2) $\mathrm{Hit}_{\mathrm{L}, \mathrm{t}}$ is uncorrelated with variables included in the information set. These two tests can be done by using an artificial regression, $\mathrm{Hit}_{\mathrm{L}, \mathrm{t}}=\mathbf{X B}+\varepsilon_{\mathrm{t}}$, where $\mathbf{X}$ is an $\mathbf{N} \times \mathbf{k}$ matrix whose first column is a column of ones, and the remaining columns are additional explanatory variables such as five lags of $\mathrm{Hit}_{\mathrm{L}, \mathrm{t}}$ and the current $\mathrm{VaR}$, hence, $\mathrm{k}$ equals seven. Engle and Manganelli (2004) showed that under the null hypothesis, the dynamic quantile test statistic is represented as $\mathrm{DQ}=\widehat{\mathbf{B}}^{\prime} \mathbf{X}^{\prime} \mathbf{X} \widehat{\mathbf{B}} / \mathrm{c}(1-\mathrm{c})$, where $\widehat{\mathbf{B}}$ is the ordinary least squares estimate of $\mathbf{B}$, and $\mathbf{X}^{\prime}$ and $\widehat{\mathbf{B}}^{\prime}$ respectively denotes the transpose of matrix $\mathbf{X}$ and vector $\widehat{\mathbf{B}}$. The DQ test statistic has an asymptotic Chi-square distribution with seven degrees of freedom, $\chi^{2}(7)$.

\subsection{Market Risk Capital and the Superior Predictive Ability Test}

According to the 1996 Market Risk Amendment (MRA) to the Basel Capital Accord, the regulatory capital for the trading positions of commercial banks is determined by the banks' own internal $\mathrm{VaR}$ estimates and then the market risk capital (MRC) loss function for a long position is expressed as follows.

$$
\operatorname{MRC}_{\mathrm{t}}=\max \left[\operatorname{VaR}_{\mathrm{t}}(10,0.99), \frac{\mathrm{k}_{\mathrm{t}}}{60} \sum_{\mathrm{i}=0}^{59} \operatorname{VaR}_{\mathrm{t}-\mathrm{i}}(10,0.99)\right]
$$

where $\operatorname{VaR}_{t}(10,0.99)$ denotes the VaR estimate generated on day $t$ under the conditions of a $99 \%$ confidence level and a 10-day holding period, and it is expressed in return; $k_{t}$ is the MRA's multiplication factor that equals 3 to 4 depending on the number of exceptions over the past 250 days. For example, the multiplier value is 3 when the exceptions are between 0 and 4 ; the multiplier values are $3.4,3.5,3.65,3.75$, and 3.85 for the five through nine exceptions, respectively; and the multiplier value is 4 as the exceptions are above 10. In other words, $M R C_{t}$ is the amount of regulatory capital a bank must hold with respect to its market risk exposure. The MRA capital loss function has several elements that reflect the bank regulators' concerns. Given its actual use by market participants, the regulatory loss function implied in the MRA is a natural way to evaluate the relative performance of VaR estimates within an economic framework. For more details, please see Lopez (1999).

Subsequently, we will introduce the theory of the superior predictive ability (SPA) test by Hansen (2005). The SPA test is used to explore whether any of the competing models significantly outperform the benchmark. For the jth model, we generate a $T$ number of $V a R$ forecast: $V_{a k} R_{j, t}$ for $t=1,2, \ldots, T$. For every VaR forecast, we generate the loss function $\mathrm{L}_{\mathrm{j}, \mathrm{t}} \equiv \mathrm{MRC}_{\mathrm{j}, \mathrm{t}}$ that represents the function as defined in Equation (21). The performance of the jth model relative to the benchmark 0th model at time $t$ can be defined as:

$$
\mathrm{F}_{\mathrm{j}, \mathrm{t}}=\mathrm{L}_{0, \mathrm{t}}-\mathrm{L}_{\mathrm{j}, \mathrm{t}} \text { for } \mathrm{j}=1,2, \ldots, \mathrm{m} ; \mathrm{t}=1,2, \ldots, \mathrm{T}
$$

Assuming stability for $\mathrm{F}_{\mathrm{j}, \mathrm{t}}$, we can define the expected performance of the $\mathrm{jth}$ model relative to the benchmark as $\mu_{j}=E\left(F_{j, t}\right)$ for $j=1,2, \ldots, m$. If the $j$ th model outperforms the benchmark one, then the value of $\mu_{j}$ will be positive. Hence, we can analyze whether any of the competing models significantly outperform the benchmark via testing the null hypothesis that $\mu_{j} \leq 0$, for $\mathrm{j}=1,2, \ldots, \mathrm{m}$. Consequently, the null hypothesis that none of the models is better than the benchmark (i.e., no predictive superiority over the benchmark itself) can be formulated as $\mathrm{H}_{0}: \mu_{\max } \equiv \max \left(\mu_{\mathrm{j}} \leq 0, \mathrm{j}=1,2, \ldots, \mathrm{m}\right) \leq 0$. The associated test statistic proposed by Hansen (2005) is expressed as follows.

$$
\mathrm{T}^{\mathrm{SPA}}=\max \left(\frac{\sqrt{\mathrm{T}} \overline{\mathrm{F}}_{\mathrm{j}}}{\hat{\omega}_{\mathrm{jj}}}, \mathrm{j}=1,2, \ldots, \mathrm{m}\right)
$$

where $\hat{\omega}_{\mathrm{jj}}^{2}$ denotes a consistent estimate of $\omega_{\mathrm{jj}}^{2}=\lim _{\mathrm{T} \rightarrow \infty} \operatorname{var}\left(\sqrt{\mathrm{T}} \overline{\mathrm{F}}_{\mathrm{j}}\right)$, and $\overline{\mathrm{F}}_{\mathrm{j}}=\left(\sum_{\mathrm{t}=1}^{\mathrm{T}} \mathrm{F}_{\mathrm{j}, \mathrm{t}}\right) / \mathrm{T}$. A consistent estimator of $\omega_{\mathrm{jj}}$ and $p$-value of test statistic $\mathrm{T}^{\mathrm{SPA}}$ can be obtained by the stationary bootstrap procedure 
by Politis and Romano (1994). More details of this procedure are illustrated in Hansen (2005) and Hansen and Lunde (2005).

\section{Data and Descriptive Statistics}

The study data include the daily prices of the following seven stock indices (with abbreviations in parentheses): the US NYSE (Ny), S\&P500 (Sp), and Nasdaq (Na) in America; the France CAC40 (Ca), Germany DAX (Da), UK FTSE (Ft), and Swiss SMI (Sm) in Europe; and the one US dollar index (Udi). Subsequently, 21 alternative weight combinations' bi-component stock portfolios are constructed by choosing alternative two stock indices among the above seven stock indices, and they are the Ny-Sp, Ny-Na, Ny-Ca, Ny-Da, Ny-Ft, Ny-Sm, Sp-Na, Sp-Ca, Sp-Da, Sp-Ft, Sp-Sm, Na-Ca, Na-Da, $\mathrm{Na}-\mathrm{Ft}, \mathrm{Na}-\mathrm{Sm}, \mathrm{Ca}-\mathrm{Da}, \mathrm{Ca}-\mathrm{Ft}, \mathrm{Ca}-\mathrm{Sm}, \mathrm{Da}-\mathrm{Ft}, \mathrm{Da}-\mathrm{Sm}$, and $\mathrm{Ft}-\mathrm{Sm}^{10}$. In addition, seven alternative weight combinations' bi-component currency-stock portfolios are constructed by the US dollar index with an alternative one-stock index among the above seven stock indices: Udi-Ny, Udi-Sp, Udi-Na, Udi-Ca, Udi-Da, Udi-Ft, and Udi-Sm. These 21 stock portfolios and seven currency-stock portfolios are used as the data to evaluate the $\mathrm{VaR}$ of seven bivariate GARCH models. For example, the Ny-Sp pair of data of an equal weight bi-component's portfolio is constructed by NYSE and the S\&P500 stock indices with the same weights. The daily closing spot prices of the seven stock indices cover the period from 24 August 2000 (respectively, 3 February 2014) to 31 January 2014 (respectively, 7 March 2016) for the estimation (respectively, forecast) period, totaling 3300 (respectively, 500) observations ${ }^{11}$. These trade data for alternative stock indices were downloaded from http:/ / finance.yahoo.com/. The trade data of the US dollar index were downloaded from https:/ / research.stlouisfed.org. Returns are defined as the difference in the logarithms of two successive daily prices of stock index multiplied by 100 .

Table 1 lists the basic statistical characteristics of the US dollar index and the seven stock indices' return series for the overall sample periods. The average daily returns are positive for NYSE, S\&P500, Nasdaq, and DAX and negative for the other indices. However, they are very small compared to their corresponding standard deviations except for the UDI, implying that the seven stock indices are volatile in terms of price level except for UDI. Regarding the coefficient of skewness, most of these return series are significantly left-skewed except for Nasdaq, CAC40, and DAX. As indicated by the excess kurtosis, all the values significantly exceed zero at the $1 \%$ level, thereby inferring that the distribution of returns has a larger and thicker tail than the normal distribution, and implying a leptokurtic characteristic. Moreover, the J-B normality test statistic proposed by Jarque and Bera (1987) are all significant at the $1 \%$ level and thus reject the hypothesis of normality, confirming that none of the return series is normally distributed. The Ljung-Box $Q^{2}(24)$ statistics for the squared returns are all significant at the $1 \%$ level and thus indicate that the return series exhibit serial dependence and strong ARCH effects. Thus, the above preliminary data analysis suggests that the GARCH family models can be used to seize the fat tails and time-varying volatility found in the above eight indices' return series.

10 For each pair of data, they are retained for the same trade date and are deleted otherwise. Taking the Ny-Da pair of data as an example, both NYSE and DAX are traded on 31 January 2002, thus the close prices of both data are retained on this date. Conversely, if only NYSE is traded on 25 May 2003, whereas DAX is not traded on this date, then the close price of NYSE on this date must be deleted, and vice versa.

11 When we conduct a hypothesis test there are two kinds of errors: type I and type II errors. Briefly, type I errors happen when we reject a true null hypothesis whereas type II errors happen when we fail to reject a false null hypothesis. Although the errors cannot be completely eliminated, we can minimize one type of error. However, when we try to decrease the probability of one type of error, the probability for the other type increases. The only way to decrease these two types of errors is to increase the sample size. Thus, in this study, we set the sample size of the estimation (respectively, forecast) period as 3300 (respectively, 500). They are large enough in order to decrease type I and type II errors as much as we can. 
Table 1. The descriptive statistics of daily return for the overall period.

\begin{tabular}{ccccccccc}
\hline & Mean & Std. Dev. & Max. & Min. & Skewness & Kurtosis & J-B & $\mathbf{Q}^{\mathbf{2}}(\mathbf{2 4 )}$ \\
\hline NYSE & 0.0089 & 1.2783 & 11.5257 & -10.232 & $-0.2954^{\mathrm{c}}$ & $9.169^{\mathrm{c}}$ & $13,370.5^{\mathrm{c}}$ & $7455.9^{\mathrm{c}}$ \\
S\&P500 & 0.0074 & 1.2701 & 10.9571 & -9.4695 & $-0.1789^{\mathrm{c}}$ & $8.1254^{\mathrm{c}}$ & $10,476.6^{\mathrm{c}}$ & $6366.9^{\mathrm{c}}$ \\
Nasdaq & 0.0042 & 1.5947 & 11.1594 & -9.5876 & 0.0327 & $4.6001^{\mathrm{c}}$ & $3352.0^{\mathrm{c}}$ & $5291.3^{\mathrm{c}}$ \\
CAC40 & -0.0100 & 1.5396 & 10.5945 & -9.4715 & 0.0105 & $4.6143^{\mathrm{c}}$ & $3372.2^{\mathrm{c}}$ & $3455.4^{\mathrm{c}}$ \\
DAX & 0.0079 & 1.5817 & 10.7974 & -9.5756 & -0.0399 & $4.4070^{\mathrm{c}}$ & $3076.9^{\mathrm{c}}$ & $3645.6^{\mathrm{c}}$ \\
FTSE & -0.0015 & 1.2463 & 9.3842 & -9.2645 & $-0.0890^{\mathrm{b}}$ & $5.9661^{\mathrm{c}}$ & $5642.3^{\mathrm{c}}$ & $4986.8^{\mathrm{c}}$ \\
SMI & -0.0011 & 1.2668 & 10.7876 & -10.518 & $-0.1255^{\mathrm{c}}$ & $8.2662^{\mathrm{c}}$ & $10,831.7^{\mathrm{c}}$ & $2591.4^{\mathrm{c}}$ \\
UDI & -0.0028 & 0.4755 & 2.1552 & -4.1066 & $-0.2346^{\mathrm{c}}$ & $3.3553^{\mathrm{c}}$ & $1817.9^{\mathrm{c}}$ & $1062.7^{\mathrm{c}}$ \\
\hline
\end{tabular}

Notes: (1) The superscripts b and c at each statistic denote that the values of that statistic are significant at the $5 \%$ and $1 \%$ levels, respectively. (2) Kurtosis denotes the excess kurtosis. (3) J-B statistics are based on Jarque and Bera (1987), and they are asymptotically chi-squared-distributed with 2 degrees of freedom. (4) $\mathrm{Q}^{2}(24)$ statistics are asymptotically chi-squared-distributed with 24 degrees of freedom.

\section{Empirical Results and Analyses}

In this study, the seven bivariate GARCH models: the S-CCC, NS-CCC, S-DCC, NS-DCC, S-BEKK, NS-BEKK, and NS-ADCC models are utilized to estimate the VaR of 21 bi-component stock portfolios, and seven bi-component currency-stock portfolios, and the further three accuracy measures: the LRuc, LRcc, and DQ tests and one efficiency test are used to evaluate the out-of-sample VaR forecast performance of the above seven bivariate GARCH models ${ }^{12}$. Before the performance competition of VaR forecast for the above seven bivariate GARCH models is executed, the fitting ability of the above seven models is explored via the empirical results of the parameters for the alternative models.

\subsection{Estimation Results for Alternative Bivariate GARCH Models}

In this subsection, only the empirical results of the non-standard or the two-step ADCC type of the bivariate GARCH model (i.e., the NS-ADCC model) for the overall period are illustrated. Table 2 lists the empirical result of the NS-ADCC model for the six NYSE-based bi-component portfolios ${ }^{13}$. Notably, via the example of Ny-Sp portfolio in this table, this two-step estimate procedure is performed as follows. First, the parameters of the NS-ADCC model for two stock indices are estimated by using the two independent univariate GARCH $(1,1)$ models. Thus, the coefficients $\mu_{1}(0.0505), \omega_{1}(0.0178)$, $\alpha_{1}(0.0886), \beta_{1}(0.8986)$ and one log-likelihood value $\mathrm{LL}_{1}(-4800.17)$ for the first univariate $\operatorname{GARCH}(1,1)$ model corresponding to the first component stock index are produced, and they are listed in the column 'Ny-Sp' in panel A of Table 2. Similarly, the coefficients $\mu_{2}(0.0491), \omega_{2}(0.0168), \alpha_{2}(0.0880), \beta_{2}(0.9000)$ and one value of the log-likelihood $\mathrm{LL}_{2}(-4803.92)$ for the second univariate $\mathrm{GARCH}(1,1)$ model corresponding to the second component stock index are produced and they are listed in the column 'Ny-Sp' in panel B of Table 2. In addition, the two variance series (i.e., $\mathrm{h}_{11, \mathrm{t}}$, and $\mathrm{h}_{22, \mathrm{t}}$ ) and two residue series (i.e., $\mathrm{e}_{1, \mathrm{t}}$ and $\mathrm{e}_{2, \mathrm{t}}$ ) are also obtained in this step. Second, the above two standardized residual return series $\left(u_{i, t}\right.$ for $\left.i=1,2\right)$ and their corresponding negative component residual return series $\left(n_{i, t}\right.$ for $\left.i=1,2\right)$ are used to estimate the intercept parameters of the conditional correlation matrix equation listed in Equation (4). During this step of estimation, the values of parameters $\overline{\mathrm{a}}(0.2041)$, $\overline{\mathrm{b}}(0.9738)$, and $\overline{\mathrm{g}}\left(-2 \times 10^{-5}\right)$ and one log-likelihood value $\mathrm{LL}_{3}(-4386.75)$ are obtained, and they are listed in panel $C$ of Table 2. As shown in Table 2, the $\omega_{i}, \alpha_{i}$, and $\beta_{i}$ coefficients where $i=1,2$

12 The out-of-sample VaR forecast is executed via a rolling window approach. That is, the seven bivariate GARCH models are estimated for each of 28 pair-wise data series, with a sample of 3300 daily returns, and then a one-day-ahead VaR forecast of the bi-component portfolio for the next period is obtained. Subsequently, the estimation period is then rolled forward by adding one new day and dropping the most distant day. Via repeating this procedure, the out-of-sample VaR forecasts are computed for the next 500 days.

13 Due to the limited space, the empirical results of the other 22 bi-component portfolios for the NS-ADCC model, and the empirical results for the other six bivariate GARCH models (i.e. the S-CCC, NS-CSS, S-DCC, NS-DCC, S-BEKK, and NS-BEKK models) are all omitted here and are available upon request. 
are positive and significant at the $1 \%$ level for all six NYSE-based portfolios. Notably, the values of $\omega_{1}, \alpha_{1}$, and $\beta_{1}$ coefficients are all equal for all NYSE-based portfolios owing to having the same first component asset within the two-step estimate procedure. Moreover, the values of parameters $\overline{\mathrm{a}}$ and $\overline{\mathrm{b}}$ are all significantly positive, whereas the values of parameter $\bar{g}$ are very small and are not significant for most cases, indicating that the asymmetric property of correlation seems not to exist in the stock-based portfolios. Notably, the values of $\bar{a}^{2}+\bar{b}^{2}+\bar{g}^{2}$ for the six NYSE-based portfolios are less than 1 , indicating that the correlation matrix $\mathbf{Q}_{\mathbf{t}}$ is positive definite. In addition, the mean conditional correlation for the overall period is between $0.4944(\mathrm{Ny}-\mathrm{Sm})$ and $0.9746(\mathrm{Ny}-\mathrm{Sp})$ for all NYSE-based portfolios. Finally, the values of $Q_{1}^{2}(24)$ and $Q_{2}^{2}(24)$ test statistics are significant for most of the six pairs of data. However, the values of the above statistics are significantly lower than those appearing in Table 1 . These results indicate that the serial correlation has been significantly reduced in standard residuals, confirming that the NS-ADCC model addressed in this study is sufficient to correct the serial correlation that exists in the conditional variance equation of these six pairs of returns series.

Table 2. The empirical results of NS-ADCC model.

\begin{tabular}{|c|c|c|c|c|c|c|}
\hline & $\mathrm{Ny}-\mathrm{Sp}$ & $\mathrm{Ny}-\mathrm{Na}$ & $\mathrm{Ny}-\mathrm{Ca}$ & Ny-Da & Ny-Ft & Ny-Sm \\
\hline \multicolumn{7}{|c|}{ Panel A. The univariate GARCH $(1,1)$ model for the first component stock index } \\
\hline \multirow[b]{2}{*}{$\mu_{1}$} & 0.0505 & 0.0505 & 0.0505 & 0.0505 & 0.0505 & 0.0505 \\
\hline & $(0.015)^{\mathrm{c}}$ & $(0.015)^{\mathrm{c}}$ & $(0.015)^{\mathrm{c}}$ & $(0.015)^{\mathrm{c}}$ & $(0.015)^{\mathrm{c}}$ & $(0.015)^{\mathrm{c}}$ \\
\hline \multirow[b]{2}{*}{$\omega_{1}$} & 0.0178 & 0.0178 & 0.0178 & 0.0178 & 0.0178 & 0.0178 \\
\hline & $(0.003)^{c}$ & $(0.003)^{\mathrm{c}}$ & $(0.003)^{c}$ & $(0.003)^{\mathrm{c}}$ & $(0.003)^{\mathrm{c}}$ & $(0.003)^{\mathrm{c}}$ \\
\hline \multirow[b]{2}{*}{$\alpha_{1}$} & 0.0886 & 0.0886 & 0.0886 & 0.0886 & 0.0886 & 0.0886 \\
\hline & $(0.003)^{c}$ & $(0.003)^{c}$ & $(0.003)^{c}$ & $(0.003)^{c}$ & $(0.003)^{\mathrm{c}}$ & $(0.003)^{c}$ \\
\hline \multirow{2}{*}{$\beta_{1}$} & 0.8986 & 0.8986 & 0.8986 & 0.8986 & 0.8986 & 0.8986 \\
\hline & $(0.006)^{c}$ & $(0.006)^{\mathrm{c}}$ & $(0.006)^{\mathrm{c}}$ & $(0.006)^{\mathrm{c}}$ & $(0.006)^{c}$ & $(0.006)^{c}$ \\
\hline \multirow{2}{*}{$\begin{array}{c}\mathrm{Q}_{1}^{2}(24) \\
\mathrm{LL}_{1}\end{array}$} & $39.228^{b}$ & $39.228^{b}$ & $39.228^{b}$ & $39.228^{b}$ & $39.228^{b}$ & $39.228^{b}$ \\
\hline & -4800.17 & -4800.17 & -4800.17 & -4800.17 & -4800.17 & -4800.17 \\
\hline \multicolumn{7}{|c|}{ Panel B. The univariate GARCH $(1,1)$ model for the second component stock index } \\
\hline \multirow{3}{*}{$\mu_{2}$} & 0.0491 & 0.0656 & 0.0503 & 0.0811 & 0.0407 & 0.0512 \\
\hline & $(0.015)^{\mathrm{c}}$ & $(0.018)^{\mathrm{c}}$ & $(0.018)^{\mathrm{c}}$ & $(0.018)^{\mathrm{c}}$ & $(0.014)^{\mathrm{c}}$ & $(0.016)^{\mathrm{c}}$ \\
\hline & 0.0168 & 0.0174 & 0.0220 & 0.0239 & 0.0132 & 0.0387 \\
\hline$\omega_{2}$ & $(0.001)^{\mathrm{c}}$ & $(0.001)^{\mathrm{c}}$ & $(0.001)^{\mathrm{c}}$ & $(0.002)^{c}$ & $(0.001)^{\mathrm{c}}$ & $(0.001)^{\mathrm{c}}$ \\
\hline \multirow{2}{*}{$\alpha_{2}$} & 0.0880 & 0.0758 & 0.0872 & 0.0926 & 0.0945 & 0.1242 \\
\hline & $(0.002)^{c}$ & $(0.001)^{\mathrm{c}}$ & $(0.002)^{c}$ & $(0.002)^{c}$ & $(0.002)^{c}$ & $(0.002)^{\mathrm{c}}$ \\
\hline \multirow{2}{*}{$\beta_{2}$} & 0.9000 & 0.9163 & 0.9040 & 0.8982 & 0.8972 & 0.8511 \\
\hline & $(0.001)^{\mathrm{c}}$ & $(0.001)^{\mathrm{c}}$ & $(0.001)^{\mathrm{c}}$ & $(0.001)^{\mathrm{c}}$ & $(0.002)^{c}$ & $(0.001)^{\mathrm{c}}$ \\
\hline \multirow{2}{*}{$\begin{array}{c}\mathrm{Q}_{2}^{2}(24) \\
\mathrm{LL}_{2}\end{array}$} & $38.818^{b}$ & $44.580^{\mathrm{c}}$ & 30.213 & 26.734 & 30.074 & 8.831 \\
\hline & -4803.92 & -5598.51 & -5557.72 & -5588.51 & -4751.05 & -4833.02 \\
\hline \multicolumn{7}{|c|}{ Panel C. The conditional correlation matrix equation } \\
\hline \multirow{2}{*}{$\overline{\mathrm{a}}$} & 0.2041 & 0.1925 & 0.1000 & 0.0715 & 0.1451 & -0.101 \\
\hline & $(0.009)^{\mathrm{c}}$ & $(0.019)^{\mathrm{c}}$ & $(0.011)^{\mathrm{c}}$ & $\left(4 \times 10^{-8}\right)^{\mathrm{c}}$ & $(0.000)^{\mathrm{c}}$ & $\left(5 \times 10^{-10}\right)^{c}$ \\
\hline \multirow{2}{*}{$\overline{\mathrm{b}}$} & 0.9738 & 0.9782 & 0.9939 & 0.9934 & 0.9619 & 0.6633 \\
\hline & $(0.002)^{c}$ & $(0.003)^{c}$ & $(0.001)^{\mathrm{c}}$ & $\left(3 \times 10^{-8}\right)^{c}$ & $\left(1 \times 10^{-10}\right)^{c}$ & $\left(1 \times 10^{-9}\right)^{\mathrm{c}}$ \\
\hline \multirow{2}{*}{$\overline{\mathrm{g}}$} & $-2 \times 10^{-5}$ & 0.0701 & $-9 \times 10^{-6}$ & 0.1044 & $-1 \times 10^{-5}$ & $-1.3 \times 10^{-4}$ \\
\hline & $\left(3 \times 10^{-5}\right)$ & $(0.064)$ & $(0.035)$ & $\left(2 \times 10^{-11}\right)^{c}$ & $(0.000)^{\mathrm{c}}$ & $(0.0)^{\mathrm{c}}$ \\
\hline
\end{tabular}


Table 2. Cont.

\begin{tabular}{|c|c|c|c|c|c|c|}
\hline & Ny-Sp & $\mathrm{Ny}-\mathrm{Na}$ & $\mathrm{Ny}-\mathrm{Ca}$ & Ny-Da & Ny-Ft & Ny-Sm \\
\hline \multicolumn{7}{|c|}{ Panel C. The conditional correlation matrix equation } \\
\hline & 0.9746 & 0.8748 & 0.6219 & 0.6326 & 0.5769 & 0.4944 \\
\hline$\rho_{12}$ & $(0.014)$ & $(0.059)$ & $(0.093)$ & $(0.090)$ & $(0.051)$ & $(0.011)$ \\
\hline $\mathrm{LL}_{3}$ & -4386.75 & -7768.51 & -9449.89 & -9428.01 & -8758.57 & -9078.06 \\
\hline
\end{tabular}

Note: (1) The symbols $\mathrm{Ny}, \mathrm{Sp}, \mathrm{Na}, \mathrm{Ca}, \mathrm{Da}, \mathrm{Ft}$, and Sm denote the USNYSE, S\&P500, and Nasdaq; France CAC40; Germany DAX; United Kingdom FTSE; and Swiss SMI stock indices, respectively. (2) The superscripts b and c at each coefficient estimate denote the value of that coefficient being significant at the $5 \%$ and $1 \%$ levels, respectively. (3) Numbers in parentheses are standard errors. (4) $L L_{1}$ and $L L_{2}$ respectively indicate the log-likelihood value for two independent univariate GARCH equations whereas $\mathrm{LL}_{3}$ denotes the log-likelihood value for the bivariate ADCC equation. (5) $Q_{1}^{2}(24)$ and $Q_{2}^{2}(24)$ respectively denote the Ljung-Box $Q$ test for the 24th order serial correlation of the squared returns for the first and second component stock indices of an equal weight bi-component portfolio. (6) $\rho_{12}$ is the mean correlation between two component stock indices of an equal weight bi-component portfolio during the first estimate period.

\subsection{The Performance Assessments of VaR Forecasts}

In this study, according to the procedure of the parameters estimate or the number of parameter estimate of model (i.e., the approach of parameters estimate), the seven bivariate GARCH models: the S-CCC, NS-CCC, S-DCC, NS-DCC, NS-ADCC, S-BEKK, and NS-BEKK models can be classified into the following two categories: the standard CCC, DCC, and BEKK models (i.e., the S-CCC, S-DCC, and S-BEKK models); and the non-standard CCC, DCC, ADCC, and BEKK models (i.e., the NS-CCC, NS-DCC, NS-ADCC, and NS-BEKK models). Or, according to the specification depicting the correlative relationship between two assets, they can be divided as the following four categories: the CCC model by Bollerslev (1990) (i.e., the S-CCC and NS-CCC models), the DCC model by Engle (2002) (i.e., the S-DCC and NS-DCC models), the ADCC model by Cappiello et al. (2006) (i.e., the NS-ADCC model), and the BEKK model defined in Engle and Kroner (1995) (i.e., the S-BEKK and NS-BEKK models). Subsequently, the above seven bivariate GARCH models are utilized to estimate the VaR of the 21 bi-component stock portfolios and seven bi-component currency-stock portfolios, and then the three accuracy measures and one efficiency test are used to evaluate the out-of-sample VaR forecast performance of the above seven bivariate GARCH models. Further, regarding the results of accuracy tests, this study explores which bivariate variance-covariance specification, which parameter estimate approach has a better VaR forecast performance, and whether the asymmetric DCC model has t better forecast performance than its corresponding symmetric one. In addition, this study also explores whether the different weight combinations and the different component combinations of portfolios affect the above comparison results. Regarding the results of the efficiency test, which determines which model is the most suitable to manage the risk of a bank via combing the MRC. The above efficiency test is performed by the superior predictive ability (SPA) test by Hansen (2005).

\subsubsection{Preliminary Analysis of Average VaR Performance}

In this subsection, the failure rate and the mean $\mathrm{VaR}^{14}$ during the out-of-sample period are first used to evaluate the forecast performance of the above seven bivariate GARCH models: the S-CCC, NS-CCC, S-DCC, NS-DCC, NS-ADCC, S-BEKK, and NS-BEKK models ${ }^{15}$. Basically, the greater (respectively, smaller) the mean VaR of a model in the absolute value, the lower (respectively, higher)

14 The mean VaR is the average of all the VaR values over the out-of-sample period, and can be calculated by the following equation: Mean $\operatorname{VaR}=\left(\sum_{t=1}^{500} \mathrm{LVaR}_{\mathrm{p}, \mathrm{t}}\right) / 500$, where $\mathrm{LVaR}_{\mathrm{p}, \mathrm{t}}$ denotes the value of the portfolio's VaR at time $\mathrm{t}$, and can be calculated by Equation (8) or Equation (16). The sample size of the out-of-sample period is equal to 500 in this study.

15 Actually, it is very hard to compete against the models' forecasting performance via the failure rate since it cannot provide the significance level for the obtained conclusion. Owing to the above reason, the forecasting performance comparison of alternative models based on the failure rate is listed in the section of 'Preliminary analysis of average VaR performance'. 
the failure rate of the model. If, as reported in the empirical results, all the failure rates are almost higher (respectively, lower) than the prescribed level, indicating that all models underestimate (respectively, overestimate) the true VaR and if a model produces only lower (respectively, higher) failure rates or the greater (respectively, smaller) mean VaR, then this model will have a better performance.

Regarding the bi-component stock portfolios with an equal weight, Table 3 (respectively, Table 4) reports the failure rates (respectively, mean $\mathrm{VaR}$ ) of long position for each of the seven bivariate GARCH models under a $95 \%$ confidence level over the entire out-of-sample period ${ }^{16}$. Before the implementation of more VaR evaluation tests, the failure rates and mean VaR can be considered as the preliminary analysis of average VaR performance during the forecasting period. To easily explore the issues addressed in this study, the corresponding comparison results of failure rates (respectively, mean VaR) are summarized in panel A (respectively, panel B) of Table 5. Subsequently, we will illustrate how to execute the several groups of model performance competition regarding the issues addressed, and then depict how to summarize the comparison results in Table 5. As shown in Table 3, except for a few cases such as the Na-Sm and Ca-Sm of S-DCC, all failure rates are almost higher than the prescribed level, indicating that all models underestimate the true VaR. This result implies which kind of VaR models can bear a better performance because they produce lower failure rates. According to the issues addressed in this study, four categories of the model performance competitions will be executed in this section. The first category of the model performance competition is the performance competition between the standard approach and its corresponding non-standard approach based on the same bivariate variance-covariance specification and it includes three groups of the model performance competitions-the S-CCC vs. NS-CCC, the S-DCC vs. NS-DCC, and the S-BEKK vs. NS-BEKK. The first category of the model performance competition is used to inspect which approach of parameters estimate, the standard or non-standard approach, has a better VaR forecast performance, and it is accomplished by finding the total number of portfolios with a lower value of the failure rate between the standard approach and its corresponding non-standard approach that a specified bivariate GARCH model has based on the same variance-covariance specification, and then these results are summarized in column S1 in Table 3. For instance, regarding the first panel of Table 3, the S-CCC (respectively, NS-CCC) model has the lower value of failure rate between the S-CCC and NS-CCC models only for the Ny-Sp and Sp-Na portfolios (respectively, $\mathrm{Ny}$-Da and $\mathrm{Ny}$-Ft portfolios). Hence, the numbers in column S1 corresponding to the S-CCC and NS-CCC models of the first panel in Table 3 are 2 and 2, respectively. Conversely, the S-DCC (respectively, NS-DCC) model has the lower value of failure rate between the S-DCC and NS-DCC models for all seven portfolios (respectively, none of the portfolios). Hence, the numbers in column S1 corresponding to the S-DCC and NS-DCC models of the first panel in Table 3 are 7 and 0, respectively. Concerning the last group of the model performance competition, the S-BEKK vs. NS-BEKK, and the other two panels, the results are summarized in column S1 of Table 3 corresponding to the specified model and the specified panel with the same inference process. Finally, regarding the 95\% level, the results in column S1 corresponding to the three panels of Table 3 are also respectively summarized at the three columns underneath the $95 \%$ level that are also underneath $\mathrm{S} 1$ in Panel A of Table 5.

16 Notably, the failure rate and mean VaR is regarded as the preliminary analysis of the average VaR performance. They cannot provide precise results. Moreover, due to the limited space, the detailed results of the VaR forecasting performance at the $99 \%$ level based on failure rate are omitted here and are available upon request. However, the summary results of this level are also listed in Table 5. 
Table 3. The out-of-sample Value-at-risk (VaR) forecasts performance based on the failure rates.

\begin{tabular}{|c|c|c|c|c|c|c|c|c|c|c|c|}
\hline & Ny-Sp & $\mathrm{Ny}-\mathrm{Na}$ & Ny-Ca & Ny-Da & $\mathrm{Ny}-\mathrm{Ft}$ & Ny-Sm & $\mathrm{Sp}-\mathrm{Na}$ & S1 & $\mathrm{S} 2$ & S3 & S4 \\
\hline S-CCC & 0.056 & 0.072 & 0.078 & 0.086 & 0.082 & 0.068 & 0.072 & 2 & 0 & 0 & - \\
\hline NS-CCC & $\underline{0.064}$ & 0.072 & 0.078 & $\underline{0.084}$ & 0.080 & $\underline{0.068}$ & 0.074 & 2 & 3 & 0 & - \\
\hline S-DCC & $\underline{0.050}$ & $\underline{0.058}$ & $\underline{0.066}$ & $\underline{0.060}$ & $\underline{0.060}$ & $\underline{0.050}$ & $\underline{0.058}$ & 7 & 7 & 7 & - \\
\hline NS-DCC & 0.064 & 0.072 & 0.074 & 0.084 & 0.074 & 0.072 & 0.074 & 0 & 4 & 0 & 2 \\
\hline S-BEKK & $\overline{0.064}$ & 0.072 & $\overline{0.080}$ & $\overline{0.074}$ & $\overline{0.082}$ & 0.072 & 0.078 & 2 & 0 & 0 & - \\
\hline NS-BEKK & 0.066 & 0.072 & 0.078 & 0.086 & 0.078 & 0.072 & 0.072 & 3 & 1 & 0 & - \\
\hline \multirow[t]{2}{*}{ NS-ADCC } & 0.064 & 0.072 & 0.076 & 0.084 & 0.076 & 0.068 & 0.074 & - & - & - & 1 \\
\hline & Sp-Ca & Sp-Da & Sp-Ft & Sp-Sm & $\mathrm{Na}-\mathrm{Ca}$ & Na-Da & Na-Ft & & & & \\
\hline S-CCC & 0.092 & 0.078 & 0.090 & 0.074 & 0.080 & 0.074 & 0.088 & 0 & 0 & 0 & - \\
\hline NS-CCC & 0.080 & 0.076 & 0.084 & $\underline{0.070}$ & 0.080 & $\underline{0.072}$ & 0.088 & 5 & 2 & 0 & - \\
\hline S-DCC & $\underline{0.060}$ & $\underline{0.058}$ & $\underline{0.074}$ & 0.058 & $\underline{0.058}$ & 0.070 & $\underline{0.064}$ & 7 & 6 & 6 & - \\
\hline NS-DCC & $\underline{0.078}$ & $\underline{0.074}$ & 0.082 & 0.070 & 0.076 & $\underline{0.072}$ & 0.086 & 0 & 5 & 0 & 1 \\
\hline S-BEKK & 0.076 & 0.068 & 0.090 & 0.074 & 0.078 & $\underline{0.068}$ & 0.082 & 3 & 1 & 1 & - \\
\hline NS-BEKK & 0.080 & 0.078 & $\underline{0.080}$ & 0.072 & $\underline{0.076}$ & 0.076 & $\underline{0.080}$ & 4 & 3 & 0 & - \\
\hline \multirow[t]{2}{*}{ NS-ADCC } & 0.080 & 0.074 & $\overline{0.082}$ & 0.070 & 0.076 & 0.070 & $\overline{0.082}$ & - & - & - & 2 \\
\hline & $\mathrm{Na}-\mathrm{Sm}$ & Ca-Da & Ca-Ft & Ca-Sm & Da-Ft & Da-Sm & Ft-Sm & & & & \\
\hline S-CCC & 0.072 & 0.074 & 0.068 & 0.060 & 0.072 & $\underline{0.066}$ & 0.072 & 2 & 1 & 1 & - \\
\hline NS-CCC & 0.072 & 0.066 & 0.062 & 0.064 & $\underline{0.070}$ & $\overline{0.068}$ & $\underline{0.066}$ & 4 & 2 & 0 & - \\
\hline S-DCC & $\underline{0.042 *}$ & $\underline{0.060}$ & 0.062 & $0.046 *$ & 0.058 & 0.068 & 0.052 & 5 & 5 & 5 & - \\
\hline NS-DCC & 0.072 & $\underline{0.064}$ & 0.062 & $\underline{0.060}$ & 0.072 & 0.068 & 0.068 & 0 & 2 & 0 & 1 \\
\hline S-BEKK & 0.074 & 0.070 & $\underline{0.058}$ & 0.062 & 0.064 & $\underline{0.066}$ & 0.064 & 4 & 2 & 2 & - \\
\hline NS-BEKK & $\underline{0.068}$ & $\underline{0.064}$ & 0.062 & $\underline{0.060}$ & 0.074 & 0.068 & $\underline{0.066}$ & 3 & 4 & 0 & - \\
\hline NS-ADCC & $\overline{0.074}$ & $\overline{0.064}$ & 0.062 & $\overline{0.060}$ & 0.072 & 0.068 & $\overline{0.068}$ & - & - & - & 0 \\
\hline
\end{tabular}

Note: (1) Ny, Sp, Na, Ca, Da, Ft and Sm denote the USNYSE, S\&P500, and Nasdaq; France CAC40, Germany DAX United Kingdom FTSE; and Swiss SMI stock indices, respectively. (2) S-CCC and NS-CCC respectively denote the standard and non-standard (i.e., the two-step) constant conditional correlation models; S-DCC and NS-DCC respectively denote the standard and non-standard (i.e., the two-step) dynamic conditional correlation models; S-BEKK denotes the standard BEKK model whereas NS-BEKK denotes the non-standard (i.e., the simplified) BEKK model derived by Su (2014a); NS-ADCC denotes the non-standard (i.e., the two-step) asymmetric type of the dynamic conditional correlation models. (3) The symbol '-' in column S1, S2, S3, and S4 denotes that no comparison result exists in this case. (4) The number in this table denotes the failure rate at the $95 \%$ level for equal weight bi-component stock portfolios. (5) The superscript * represents that the empirical failure rate is lower than the theoretical failure rate. (6) The bold font denotes the lower value of the failure rate when the predictive accuracies of the two bivariate GARCH models are compared with each other based on the same bivariate models but with different types of estimate approaches. (i.e., the S-CCC vs. NS-CCC; the S-DCC vs. NS-DCC; and the S-BEKK vs. NS-BEKK) (7) The underlined font denotes the lowest value of failure rate when the predictive accuracies of the three bivariate GARCH models are compared with each other based on the same estimated approaches but with different types of bivariate models (i.e., the S-CCC, S-DCC, and S-BEKK; the NS-CCC, NS-DCC, and NS-BEKK). (8) The shaded font denotes the lowest value of the failure rate when the predictive accuracies of all bivariate GARCH models except the NS-ADCC are compared with each other. (9) The italic font denotes the lower value of failure rate when the predictive accuracies of the non-standard symmetric and asymmetric DCC bivariate GARCH models are compared with each other (i.e., the NS-DCC vs. NS-ADCC). (10) The numbers in column S1 denote the total number of portfolios that have the lower failure rate when the S-CCC, S-DCC, and S-BEKK models are compared with the NS-CCC, NS-DCC, and NS-BEKK models, respectively. (11) The numbers in column S2 denote the total number of portfolios that have the lowest failure rate when three bivariate GARCH models (i.e., the S-CCC, S-DCC, and S-BEKK) or the other three bivariate GARCH models (i.e., the NS-CCC, NS-DCC, and NS-BEKK) are compared with each other. (12) The numbers in column S3 denote the total number of portfolios that have the lowest failure rate when all bivariate GARCH models except the NS-ADCC are compared with each other. (13) The numbers in column S4 denote the total number of portfolios that have the lower failure rate when the NS-DCC and NS-ADCC models are compared with each other. 
Table 4. The out-of-sample VaR forecasts performance based on the mean VaR.

\begin{tabular}{|c|c|c|c|c|c|c|c|c|c|c|c|}
\hline & Ny-Sp & $\mathrm{Ny}-\mathrm{Na}$ & $\mathrm{Ny}-\mathrm{Ca}$ & Ny-Da & $\mathrm{Ny}-\mathrm{Ft}$ & Ny-Sm & $\mathrm{Sp}-\mathrm{Na}$ & S1 & S2 & S3 & S4 \\
\hline S-CCC & -1.4091 & -1.4483 & -1.5124 & -1.5304 & -1.2833 & -1.3269 & -1.4743 & 0 & 0 & 0 & - \\
\hline NS-CCC & -1.4098 & -1.4657 & -1.5443 & -1.5693 & -1.3090 & -1.3493 & -1.4983 & 7 & 1 & 0 & - \\
\hline S-DCC & -1.5538 & -1.5421 & -1.6369 & -1.7554 & -1.3867 & -1.4296 & -1.5800 & 7 & 7 & 7 & - \\
\hline NS-DCC & -1.4102 & -1.4910 & -1.5578 & -1.5693 & -1.3243 & -1.3507 & -1.5198 & 0 & 7 & 0 & 4 \\
\hline S-BEKK & $\overline{-1.3908}$ & $\overline{-1.4551}$ & $\overline{-1.5733}$ & $\overline{-1.5852}$ & $\overline{-1.3034}$ & $\overline{-1.3448}$ & $\overline{-1.4913}$ & 4 & 0 & 0 & - \\
\hline NS-BEKK & -1.3820 & -1.4664 & -1.5387 & -1.5411 & -1.3126 & -1.3253 & -1.4967 & 3 & 0 & 0 & - \\
\hline \multirow[t]{2}{*}{ NS-ADCC } & -1.4102 & -1.4909 & -1.5551 & -1.5693 & -1.3234 & -1.3479 & -1.5198 & - & - & - & 0 \\
\hline & $\mathrm{Sp}-\mathrm{Ca}$ & Sp-Da & $\mathrm{Sp}-\mathrm{Ft}$ & Sp-Sm & $\mathrm{Na}-\mathrm{Ca}$ & $\mathrm{Na}-\mathrm{Da}$ & Na-Ft & & & & \\
\hline S-CCC & -1.4932 & -1.5176 & -1.2668 & -1.3117 & -1.5738 & -1.6023 & -1.3522 & 0 & 0 & 0 & - \\
\hline NS-CCC & -1.5298 & -1.5596 & -1.2943 & -1.3374 & -1.6024 & -1.6381 & -1.3720 & 7 & 1 & 0 & - \\
\hline S-DCC & -1.5915 & -1.6840 & -1.3337 & -1.4311 & -1.7643 & -1.7069 & -1.4406 & 7 & 7 & 7 & - \\
\hline NS-DCC & -1.5432 & -1.5586 & -1.3081 & -1.3427 & -1.6171 & -1.6402 & -1.3913 & 0 & 6 & 0 & 4 \\
\hline S-BEKK & $\overline{-1.5550}$ & -1.5769 & $\overline{-1.2827}$ & $\overline{-1.3176}$ & $\overline{-1.6229}$ & $\overline{-1.6598}$ & $\overline{-1.3950}$ & 6 & 0 & 0 & - \\
\hline NS-BEKK & -1.5219 & -1.5321 & -1.2919 & -1.3174 & -1.6058 & -1.6177 & -1.3758 & 1 & 0 & 0 & - \\
\hline \multirow[t]{2}{*}{ NS-ADCC } & -1.5415 & -1.5611 & -1.3061 & -1.3380 & -1.6178 & -1.6425 & -1.3865 & - & - & - & 3 \\
\hline & Na-Sm & Ca-Da & Ca-Ft & Ca-Sm & Da-Ft & Da-Sm & Ft-Sm & & & & \\
\hline S-CCC & -1.3946 & -1.9465 & -1.6814 & -1.7286 & -1.6709 & -1.7457 & -1.4840 & 0 & 0 & 0 & - \\
\hline NS-CCC & -1.4078 & -2.0114 & -1.7267 & -1.7713 & -1.7241 & -1.7910 & -1.5147 & 7 & 0 & 0 & - \\
\hline S-DCC & -1.6290 & -2.0847 & -1.7812 & -2.0290 & -1.9297 & -1.7918 & -1.6887 & 6 & 7 & 6 & - \\
\hline NS-DCC & -1.4211 & -2.0574 & -1.7398 & -1.7773 & -1.7435 & -1.7951 & -1.5154 & 1 & 7 & 1 & 2 \\
\hline S-BEKK & -1.3816 & $\overline{-2.0203}$ & $\overline{-1.7504}$ & $\overline{-1.7624}$ & $\overline{-1.7478}$ & -1.7912 & $\overline{-1.5184}$ & 6 & 0 & 0 & - \\
\hline NS-BEKK & -1.4024 & -2.0156 & -1.7250 & -1.7125 & -1.7332 & -1.7133 & -1.4849 & 1 & 0 & 0 & - \\
\hline NS-ADCC & -1.4111 & -2.0557 & -1.7398 & -1.7773 & -1.7435 & -1.7951 & -1.5154 & - & - & - & 0 \\
\hline
\end{tabular}

Note: (1) Refer to notes 1-3 of Table 3. (2) The numbers in this table denote the mean VaR at the $95 \%$ level for equal weight bi-component stock portfolios. (3) The bold font denotes the greater value of mean VaR in absolute value when the predictive accuracies of two bivariate GARCH models are compared with each other based on the same bivariate models but using different types of estimate approaches (i.e., S-CCC vs. NS-CCC; S-DCC vs. NS-DCC; and S-BEKK vs. NS-BEKK). (4) The underlined font denotes the greatest value of mean VaR in absolute value when the predictive accuracies of three bivariate GARCH models are compared with each other based on the same estimated approaches but using different types of bivariate models (i.e., the S-CCC, S-DCC, and S-BEKK; the NS-CCC, NS-DCC, and NS-BEKK). (5) The shaded font denotes the greatest value of mean VaR in absolute value when the predictive accuracies of all bivariate GARCH models except the NS-ADCC are compared with each other. (6) The italic font denotes the greater value of mean VaR in absolute value when the predictive accuracies of the non-standard symmetric and asymmetric DCC bivariate GARCH models are compared with each other (i.e., the NS-DCC vs. NS-ADCC). (7) The numbers in column S1 denote the total number of portfolios that have a greater value of mean VaR in absolute value when the S-CCC, S-DCC, and S-BEKK models are compared with NS-CCC, NS-DCC, and NS-BEKK models, respectively. (8) The numbers in column S2 denote the total number of portfolios that have the greatest value of mean VaR in absolute value when three bivariate GARCH models (i.e., S-CCC, S-DCC, and S-BEKK) or the other three bivariate GARCH models (i.e., NS-CCC, NS-DCC, and NS-BEKK) are compared with each other. (9) The numbers in column S3 denote the total number of portfolios that have the greatest value of mean VaR in absolute value when all bivariate GARCH models except the NS-ADCC are compared with each other. (10) The numbers in column S4 denote the total number of portfolios that have the greater value of mean VaR in absolute value when the NS-DCC and NS-ADCC models are compared with each other. 
Table 5. The summary results for the out-of-sample VaR forecasts performance of equal-weight stock portfolios based on the mean VaR and failure rate.

\begin{tabular}{|c|c|c|c|c|c|c|c|c|c|c|c|c|c|c|c|c|c|c|c|c|c|c|c|c|c|c|c|c|c|c|c|c|c|}
\hline \multicolumn{34}{|c|}{ Panel A. Failure Rate } \\
\hline & \multicolumn{9}{|c|}{ S1 } & \multicolumn{8}{|c|}{ S2 } & \multicolumn{7}{|c|}{ S3 } & \multicolumn{9}{|c|}{ S4 } \\
\hline & \multicolumn{3}{|c|}{ 95\% Level } & \multirow{2}{*}{$\frac{S_{1,95}}{4}$} & \multicolumn{3}{|c|}{ 99\% Level } & \multirow{2}{*}{$\frac{S_{1,99}}{2}$} & \multirow{2}{*}{$\begin{array}{l}\text { SS1 } \\
6\end{array}$} & \multicolumn{2}{|c|}{ 95\% Level } & \multirow{2}{*}{$\begin{array}{c}\mathrm{S}_{2,95} \\
1\end{array}$} & \multicolumn{3}{|c|}{ 99\% Level } & \multirow{2}{*}{$\frac{\mathbf{S}_{2,99}}{0}$} & \multirow{2}{*}{$\begin{array}{c}\text { SS2 } \\
1\end{array}$} & \multicolumn{2}{|c|}{ 95\% Level } & \multirow{2}{*}{$\begin{array}{c}S_{3,95} \\
1\end{array}$} & \multicolumn{2}{|c|}{ 99\% Level } & \multirow{2}{*}{$\begin{array}{c}\mathrm{S}_{3,99} \\
0\end{array}$} & \multirow{2}{*}{\begin{tabular}{|c|} 
SS3 \\
1
\end{tabular}} & \multicolumn{3}{|c|}{ 95\% Level } & \multirow{2}{*}{$\mathrm{S}_{4,95}$} & & \% Leve & & $\mathrm{S}_{4,99}$ & SS4 \\
\hline S-CCC & 2 & 0 & 2 & & 1 & 1 & 0 & & & 0 & 0 & & 0 & 0 & 0 & & & 0 & 0 & & 0 & 0 & & & - & - & - & & - & - & - & - & - \\
\hline NS-CCC & 2 & 5 & 4 & 11 & 1 & 2 & 5 & 8 & 19 & 3 & 2 & 7 & 2 & 2 & 4 & 8 & 15 & 0 & 0 & 0 & 1 & 0 & 1 & 1 & - & - & - & - & - & - & - & - & - \\
\hline S-DCC & 7 & 7 & 5 & 19 & 5 & 7 & 5 & 17 & 36 & 7 & 6 & 18 & 5 & 6 & 5 & 16 & 34 & 7 & 6 & 18 & 5 & 6 & 16 & 34 & - & - & - & - & - & - & - & - & - \\
\hline NS-DCC & 0 & 0 & 0 & 0 & 1 & 0 & 0 & 1 & 1 & 4 & 5 & 11 & 2 & 1 & 2 & 5 & 16 & 0 & 0 & 0 & 1 & 0 & 1 & 1 & 2 & 1 & 1 & 4 & 1 & 0 & 1 & 2 & 6 \\
\hline S-BEKK & 2 & 3 & 4 & 9 & 2 & 4 & 5 & 11 & 20 & 0 & 1 & 3 & 4 & 1 & 3 & 8 & 11 & 0 & 1 & 3 & 4 & 1 & 8 & 11 & - & - & - & - & - & - & - & - & - \\
\hline NS-BEKK & 3 & 4 & 3 & 10 & 1 & 2 & 2 & 5 & 15 & 1 & 3 & 8 & 3 & 3 & 2 & 8 & 16 & 0 & 0 & 0 & 3 & 2 & 5 & 5 & - & - & - & - & - & - & - & - & - \\
\hline NS-ADCC & - & - & - & - & - & - & - & - & - & - & - & - & - & - & - & - & - & - & - & - & - & - & - & - & 1 & 2 & 0 & 3 & 0 & 0 & 0 & 0 & 3 \\
\hline Panel B. M & $\ln V$ & & & & & & & & & & & & & & & & & & & & & & & & & & & & & & & & \\
\hline & & & & & S1 & & & & & & & & S2 & & & & & & & & S3 & & & & & & & & S4 & & & & \\
\hline & & o Le & & $S_{1,95}$ & & 6 Lev & & $S_{1,99}$ & SS1 & & \% Level & $S_{2,95}$ & & 6 Lev & & $S_{2,99}$ & SS2 & & o Level & $S_{3,95}$ & & 6 Level & $S_{3,99}$ & SS3 & & 6 Leve & & $S_{4,95}$ & & $\%$ Leve & & $S_{4,99}$ & SS4 \\
\hline S-CCC & 0 & 0 & 0 & 0 & 1 & 0 & 0 & 1 & 1 & 0 & $\begin{array}{ll}0 & 0\end{array}$ & 0 & 0 & 0 & 0 & 0 & 0 & 0 & 0 & 0 & 0 & $\begin{array}{ll}0 & 0\end{array}$ & 0 & 0 & - & - & - & - & - & - & - & - & - \\
\hline NS-CCC & 7 & 7 & 7 & 21 & 6 & 7 & 7 & 20 & 41 & 1 & 1 & 2 & 1 & 1 & 0 & 2 & 4 & 0 & 0 & 0 & 0 & 0 & 0 & 0 & - & - & - & - & - & - & - & - & - \\
\hline S-DCC & 7 & 7 & 6 & 20 & 7 & 7 & 6 & 20 & 40 & 7 & 7 & 21 & 7 & 7 & 6 & 20 & 41 & 7 & 7 & 20 & 7 & 7 & 20 & 40 & - & - & - & - & - & - & - & - & - \\
\hline NS-DCC & 0 & 0 & 1 & 1 & 0 & 0 & 1 & 1 & 2 & 7 & 6 & 20 & 7 & 6 & 7 & 20 & 40 & 0 & 0 & 1 & 0 & 0 & 1 & 2 & 4 & 4 & 2 & 10 & 4 & 4 & 2 & 10 & 20 \\
\hline S-BEKK & 4 & 6 & 6 & 16 & 4 & 5 & 6 & 15 & 31 & 0 & 0 & 0 & 0 & 0 & 1 & 1 & 1 & 0 & 0 & 0 & 0 & 0 & 0 & 0 & - & - & - & - & - & - & - & - & - \\
\hline NS-BEKK & 3 & 1 & 1 & 5 & 3 & 2 & 1 & 6 & 11 & 0 & 0 & 0 & 0 & 0 & 0 & 0 & 0 & 0 & 0 & 0 & 0 & 0 & 0 & 0 & - & - & - & - & - & - & - & - & - \\
\hline NS-ADCC & - & - & - & - & - & - & - & - & - & - & - & - & - & - & - & - & - & - & - & - & - & - & - & - & 0 & 3 & 0 & 3 & 2 & 3 & 0 & 5 & 8 \\
\hline
\end{tabular}

Note: (1) Refer to notes 2-3 of Table 3. (2) The numbers in the columns $95 \%$ underneath S1 and S2 at panel A (respectively, panel B), respectively, are summarized from the numbers in the column S1 and S2 of Table 3 (respectively, Table 4) corresponding to the 95\% level. (3) The numbers in the columns 95\% underneath S3 and S4 at panel A (respectively, panel B), respectively, are summarized from the numbers in column S3 and S4 of Table 3 (respectively, Table 4) corresponding to the $95 \%$ level. (4) The numbers in the columns $\mathrm{S}_{1,95}$ and $\mathrm{S}_{1,99}$ underneath S1 at panel A (respectively, panel B), respectively, denote the total sum of three corresponding numbers in the columns $95 \%$ and $99 \%$ underneath S1 at panel A (respectively, panel B) and the numbers in the column SS1 underneath S1 at panel A (respectively, panel B) denote the total sum of two corresponding numbers in the columns $\mathrm{S}_{1,95}$ and $\mathrm{S}_{1,99}$ underneath S1 at panel A (respectively, panel B). (5) In the same inference process, the numbers in the column SS2 underneath S2 at panel A (respectively, panel B) denote the total sum of two corresponding numbers in the columns $\mathrm{S}_{2,95}$ and $\mathrm{S}_{2,99}$ underneath S2 at panel A (respectively, panel B) whereas the numbers in the column SS3 underneath S3 at panel A (respectively, panel B) denote the total sum of two corresponding numbers in the columns $\mathrm{S}_{3,95}$ and $\mathrm{S}_{3,99}$ underneath S3 at panel A (respectively, panel B). In addition, the numbers in the column SS4 underneath S4 at panel A (respectively, panel B) denote the total sum of two corresponding numbers in the columns $\mathrm{S}_{4,95}$ and $\mathrm{S}_{4,99}$ underneath S4 at panel A (respectively, panel B). (6) The bold font in all columns under S1 denotes the greater number when two numbers corresponding to two models are compared with each other and these two models have the same bivariate variance-covariance specification but with different approaches of parameter estimates (i.e., the S-CCC vs. NS-CCC; the S-DCC vs. NS-DCC; and the S-BEKK vs. NS-BEKK). (7) The bold font in all columns under S2 denotes the greatest number when three numbers corresponding to three models are compared with each other and these three models have the same approach of parameter estimates but with different bivariate variance-covariance specification (i.e., the S-CCC, S-DCC, and S-BEKK; the NS-CCC, NS-DCC, and NS-BEKK). (8) The bold font in all columns under S3 denotes the greatest number when six numbers corresponding to the six models are compared with each other, and these six models are the S-CCC, NS-CCC, S-DCC, NS-DCC, S-BEKK, and NS-BEKK. (9) The bold font in all columns under 44 denotes the greater number when two numbers corresponding to two models are compared with each other. The two models are the NS-DCC and NS_ADCC. 
The second category of the model performance competition is the performance competition among the three types of bivariate variance-covariance specifications (i.e., the CCC, DCC, and BEKK) based on the same approach of parameters estimate and it includes two groups of the model performance competition-the S-CCC, S-DCC, and S-BEKK; and the NS-CCC, NS-DCC, and NS-BEKK. The second category of the model performance competition is used to inspect which type of bivariate variance-covariance specification has the best VaR forecast performance and it is achieved by finding the total number of portfolios with the lowest value of the failure rate among three types of bivariate variance-covariance specifications (i.e., the CCC, DCC, and BEKK) that a specified bivariate GARCH model has based on the same approach of parameters estimate, and then these results are summarized in column S2 in Table 3. For instance, regarding the first panel of Table 3, the S-DCC (respectively, the S-CCC and S-BEKK) model has the lowest value of failure rate among the S-CCC, S-DC,C and S-BEKK models for all seven portfolios (respectively, none of the portfolio). Hence, the numbers in column S2 corresponding to the S-CCC, S-DCC, and S-BEKK models of the first panel in Table 3 are 0 , 7, and 0, respectively. Similarity, the NS-CCC (respectively, NS-DCC) model has the lowest value of failure rate among the NS-CCC, NS-DCC, and NS-BEKK models for the Ny-Sp, Ny-Da and Ny-Sm portfolios (respectively, $\mathrm{Ny}-\mathrm{Sp}, \mathrm{Ny}-\mathrm{Ca}, \mathrm{Ny}-\mathrm{Da}$, and $\mathrm{Ny}-\mathrm{Ft}$ portfolios) whereas the NS-BEKK has the lowest value of failure rate only for Sp-Na. Hence, the numbers in column S2 corresponding to the NS-CCC, NS-DCC, and NS-BEKK models of the first panel in Table 3 are 3, 4, and 1, respectively. Concerning the other two panels, the results are summarized in column S2 of Table 3 corresponding to the specified model and the specified panel with the same inference process. Finally, regarding the 95\% level, the results in column S2 corresponding to three panels of Table 3 are also respectively summarized at the three columns underneath 95\% level that are also underneath S2 in Panel A of Table 5. The third category of the model performance competition is the performance competition among all the bivariate GARCH models except the NS-ADCC model in order to inspect which model has the best VaR forecast performance, and it is achieved by finding the total number of portfolios with the lowest value of the failure rate among all the above six bivariate GARCH models that a specified bivariate GARCH model has, and then these results are summarized in column S3 in Table 3. For instance, regarding the first panel of Table 3, the S-DCC model has the lowest failure rate value among all the bivariate GARCH models except the NS-ADCC model for all seven portfolios. Hence, the number in column S3 corresponding to the S-DCC model of the first panel in Table 3 is 7 whereas those corresponding to the other five models are all zero except the NS-ADCC model. Concerning the other two panels, the results are summarized in column S3 of Table 3 corresponding to the specified model and the specified panel with the same inference process. Finally, regarding the $95 \%$ level, the results in column S3 corresponding to three panels of Table 3 are also respectively summarized at the three columns underneath the 95\% level that are also underneath S3 in Panel A of Table 5. The last category of the model performance competition is the performance competition between the NS-DCC and NS-ADCC models and is used to inspect whether the asymmetric DCC model has a better forecast performance than its corresponding symmetric one. It is accomplished by finding the total number of portfolios with a lower value of the failure rate between the NS-DCC and NS-ADCC models, and then these results are summarized in column S4 in Table 3. For instance, regarding the first panel of Table 3, the NS-DCC (respectively, NS-ADCC) model has the lower value of failure rate between the NS-DCC and NS-ADCC models only for Ny-Ca and Ny-Ft portfolios (respectively, the Ny-Sm portfolio). Hence, the numbers in column S4 corresponding to the NS-DCC and NS-ADCC models of the first panel in Table 3 are 2 and 1, respectively. Concerning the other two panels, the results are summarized in column S4 of Table 3 corresponding to the specified model and the specified panel with the same inference process. Finally, regarding the $95 \%$ level, the results in column S4 corresponding to three panels of Table 3 are also respectively summarized at the three columns underneath the $95 \%$ level that are also underneath 54 in Panel A of Table 5.

Regarding the seven bivariate GARCH models, panel A of Table 5 summarizes the results of the out-of-sample VaR forecasts' performance of the equal weight bi-component stock portfolios based on 
failure rate for both $95 \%$ and $99 \%$ levels. Subsequently, in order to easily execute the competition of predictive performances for the seven bivariate GARCH models, we sum the total number of portfolios owning the lower or the lowest value of failure rate that a specified bivariate GARCH model has based on two levels (i.e., the $95 \%$ and $99 \%$ levels) for each of the four categories of the model performance competition, and list them in column SS1 underneath S1, column SS2 underneath S2, column SS3 underneath S3, and column SS4 underneath S4 for the first, second, third, and last categories of the model performance competition, respectively. For instance, regarding the first category of the model performance competition and regarding the $95 \%$ level, the total number of portfolios with the lower value of the failure rate that the S-CCC model has is 4 , that is, the summation of three numbers 2 , 0 , and 2. This number, 4 , is listed in the entry corresponding to S-CCC model of the column $\mathrm{S}_{1,95}$ underneath S1. In the same inference, regarding the $99 \%$ level, the total number of portfolios with the lower value of failure rate that the S-CCC model has is 2 , that is, the summation of three numbers 1,1 , and 0 . This number, 2 , is listed in the entry corresponding to S-CCC model of the column $S_{1,99}$ underneath S1. Finally, we sum the above two numbers, 4 and 2, and record this number, 6 at the entry corresponding to the row S-CCC and column SS1 underneath S1. As shown in column SS1 underneath S1 in panel A of Table 5, we find that the NS-CCC model has a better VaR forecast performance for the CCC type of bivariate variance-covariance specification since this model has the larger number, 19 between the S-CCC (6) and NS-CCC (19) models, where the number in the brackets beside each model denotes the summation of the total number of portfolios having the lower value of failure rate for both $95 \%$ and $99 \%$ levels. In the same inference process, the S-DCC (respectively, S-BEKK) model has a better VaR forecast performance for the DCC (respectively, BEKK) type of bivariate variance-covariance specification. These results indicate that the standard approach has better VaR forecast performance for the DCC and BEKK types of bivariate variance-covariance specification whereas the non-standard or two-step approach has a better VaR forecast performance only for the CCC type of bivariate variance-covariance specification. As reported in column SS2 underneath S2 in panel A of Table 5, we find that the S-DCC model has the best VaR forecast performance since this model has the larger number, 34, among the S-CCC (1), S-DCC (34), and S-BEKK (11) models. On the contrary, the NS-CCC, NS-DCC, and NS-BEKK models seem to have the same VaR forecast performance since these three models have a nearly equal number among the NS-CCC (15), NS-DCC (16), and NS-BEKK (16) models. These results indicate that the DCC type of bivariate variance-covariance specification has the best $\mathrm{VaR}$ forecast performance for the standard approach, whereas the three types of bivariate variance-covariance specification seem to have the same VaR forecast performance for the non-standard approach. As listed in column SS3 underneath S3 in panel A of Table 5, we find that the S-DCC model has the best VaR forecast performance since this model has the largest number, 34 among all six bivariate GARCH models. These results indicate that the DCC type of bivariate variance-covariance specification with a standard approach has the best VaR forecast performance. Finally, as shown in column SS4 underneath S4 in panel A of Table 5, we find that the NS-DCC model has a better VaR forecast performance since this model has the larger number, 6 between the NS-DCC (6), and NS-ADCC (3) models. These results indicate that the asymmetric DCC model does not have a better forecast performance than its corresponding symmetric one.

Regarding the bi-component stock portfolios with an equal weight, Table 4 reports the mean VaR of long position for each of the seven bivariate GARCH models under a 95\% confidence level over the entire out-of-sample period ${ }^{17}$. The performance competition of four groups of models will be executed with the same inference process as that implemented by the failure rate of Table 3. From Table 4, we find that all the values of mean VaR are negative since only the long position is considered in this study. As reported in the empirical results of Table 3, all models almost underestimate the

17 Due to the limited space, the detailed results of the VaR forecasting performance at the $99 \%$ level based on mean VaR are omitted here and are available upon request. However, the summary results of this level are also listed in Table 5. 
true VaR since all failure rates are almost higher than the prescribed level. Moreover, the greater the mean VaR of a model in absolute value, the lower the failure rate of the model, indicating that the model with a greater value of mean VaR will bear better performance. Hence, regarding the $95 \%$ level, the first category of the model performance competition is accomplished by finding the total number of portfolios with a greater value of the mean VaR in absolute value between the standard approach and its corresponding non-standard approach that a specified bivariate GARCH model has, based on the same variance-covariance specification. Then these results are summarized in column S1 in Table 4. For instance, regarding the first panel of Table 4, the S-CCC (respectively, NS-CCC) model has a greater value of mean VaR in absolute value between the S-CCC and NS-CCC models for none of these portfolios (respectively, all of the portfolios). Hence, the numbers in column S1 corresponding to the S-CCC and NS-CCC models of the first panel in Table 4 are 0 and 7, respectively. Concerning the other two groups of the model performance competition (i.e., the S-DCC vs. NS-DCC; and the S-BEKK vs. NS-BEKK), and the other two panels in Table 4, the results are summarized in column S1 of Table 4 corresponding to the specified model and the specified panel with the same inference process. Finally, regarding the $95 \%$ level, the results in column S1 corresponding to three panels of Table 4 are also respectively summarized at the three columns underneath the $95 \%$ level that are also underneath S1 in Panel B of Table 5 .

In the same inference process, regarding the 95\% level, the second category of the model performance competition is achieved by finding the total number of portfolios with the greatest value of mean $\mathrm{VaR}$ in absolute value among the three types of bivariate variance-covariance specifications (i.e., CCC, DCC, and BEKK) that a specified bivariate GARCH model has, based on the same approach of parameters estimate. Then these results are summarized in column S2 in Table 4. Subsequently, regarding the 95\% level, the results in column S2 corresponding to three panels of Table 4 are also respectively summarized at the three columns underneath the 95\% level that are also underneath S2 in Panel B of Table 5. Concerning the 95\% level, the third category of the model performance competition is achieved by finding the total number of portfolios with the greatest value of mean VaR in absolute value among all bivariate GARCH models except the NS-ADCC model that a specified bivariate GARCH model has, and then these results are summarized in column S3 in Table 4. Subsequently, the results in column S3 corresponding to three panels of Table 4 are also respectively summarized at the three columns underneath the 95\% level that are also underneath S3 in Panel B of Table 5. Regarding the 95\% level, the last category of the model performance competition is accomplished by finding the total number of portfolios with a greater value of mean VaR in absolute value between the NS-DCC and NS-ADCC models, and then these results are summarized in column S4 in Table 4. Subsequently, the results in column S4 corresponding to the three panels of Table 4 are also respectively summarized at the three columns underneath the 95\% level that are also underneath S4 in Panel B of Table 5. Finally, we sum the total number of portfolios having a greater or the greatest value of mean VaR in absolute value that a specified bivariate GARCH model has based on two levels (i.e., $95 \%$ and $99 \%$ levels) for each of the four categories of the model performance competition and list them in column SS1 underneath S1, column SS2 underneath S2, column SS3 underneath S3, and column SS4 underneath S4 in Panel B of Table 5 for the first, second, third, and last categories of the model performance competition, respectively.

As shown in column SS1 underneath S1, column SS2 underneath S2, column SS3 underneath S3, and column SS4 underneath S4 in panel B of Table 5, we find that the results are almost the same as those found in the case of the failure rate. That is, regarding the first group of performance competition, the standard approach has a better VaR forecast performance for the DCC and BEKK types of bivariate variance-covariance specification whereas the non-standard or two-step approach has a better VaR forecast performance only for the CCC type of bivariate variance-covariance specification. Regarding the third group of the performance competition, the DCC type of bivariate variance-covariance specification with a standard approach has the best VaR forecast performance. With regard to the last group of performance competition, the NS-DCC model has better VaR forecast performance than 
the NS-ADCC model. From the above findings, these results of the first, third, and last groups of the performance competition are consistent with those found in the failure rate. Regarding the second group of the performance competition, the DCC type of bivariate variance-covariance specification has the best VaR forecast performance among all three types of bivariate variance-covariance specifications irrespective of the standard or non-standard approach. This result is slightly different from that found in the failure rate. Based on the failure rate, the DCC type of bivariate variance-covariance specification has the best VaR forecast performance only for the standard approach, whereas three types of bivariate variance-covariance specification seem to have the same VaR forecast performance for the non-standard approach.

\subsubsection{Summary Comparison Results Based on Alternative Accuracy Measures}

In this subsection, the 21 equal weight bi-component stock portfolios are used as a sample and three accuracy measures (i.e., $\mathrm{LR}_{\mathrm{uc}}, \mathrm{LR}_{\mathrm{cc}}$, and DQ) are utilized to perform the back-testing of each of the seven bivariate GARCH models: the S-CCC, NS-CCC, S-DCC, NS-DCC, S-BEKK, NS-BEKK, and the NS-ADCC models, and then the produced results are used to assess the VaR forecast performance for the above seven models according to the issues explored in this study. In principle, the model with the greater number that passes the above three back-testing bears a better performance than the model with the smaller that number.

Table 6 reports the $\mathrm{LR}_{\mathrm{uc}}, \mathrm{LR}_{\mathrm{cc}}$, and DQ test statistics of long position for each of the seven bivariate GARCH models under a $95 \%$ confidence level over the entire out-of-sample period ${ }^{18}$. Moreover, regarding a specified model, the total number of portfolios that pass the $\mathrm{LR}_{\mathrm{uc}}, \mathrm{LR}_{\mathrm{cc}}$, and $\mathrm{DQ}$ types of back-testing are counted and are respectively listed in column Sum of Panels A, B, and C in Table 6. For example, regarding the first subpanel of Panel A in Table 6, both the S-CCC and NS-CCC models pass the $\mathrm{LR}_{\mathrm{uc}}$ test only for the Ny-Sp and Ny-Sm portfolios. Hence, the numbers in column Sum corresponding to the rows S-CCC and NS-CCC models of the first subpanel of Panel A in Table 6 are 2 and 2, respectively. Concerning the other five models and the other two subpanels, the results are summarized in column Sum of Panel A in Table 6 corresponding to the specified model and the specified subpanel with the same inference process. Finally, the results in column Sum corresponding to three subpanels of Panel A in Table 6 are also respectively summarized at the three columns underneath $\mathrm{LR}_{\mathrm{uc}}$ that are also underneath $95 \%$ in the first panel of Table 7 . In the same inference, the results in column Sum corresponding to three subpanels of Panel B (respectively, C) in Table 6 are also respectively summarized at the three columns underneath $\mathrm{LR}_{\mathrm{cc}}$ (respectively, DQ) that are also underneath $95 \%$ in the first panel of Table 7.

Table 6. The out-of-sample VaR forecasts performance based on alternative accuracy tests.

\begin{tabular}{|c|c|c|c|c|c|c|c|c|}
\hline \multicolumn{9}{|c|}{ Panel A. The LR uc $_{\text {Test }}$} \\
\hline & Ny-Sp & $\mathrm{Ny}-\mathrm{Na}$ & $\mathrm{Ny}-\mathrm{Ca}$ & Ny-Da & Ny-Ft & Ny-Sm & Sp-Na & Sum \\
\hline \multirow{2}{*}{ S-CCC } & 0.3653 & 4.5110 & 7.1022 & 11.3307 & 9.1101 & 3.0805 & 4.5110 & \multirow{2}{*}{2} \\
\hline & [0.5455] & [0.0336] & {$[0.0076]$} & [0.0007] & [0.0025] & [0.0792] & {$[0.0336]$} & \\
\hline \multirow{2}{*}{ NS-CCC } & 1.9027 & 4.5110 & 7.1022 & 10.1944 & 8.0790 & 3.0805 & 5.3168 & \multirow{2}{*}{2} \\
\hline & [0.1677] & [0.0336] & {$[0.0076]$} & [0.0014] & [0.0044] & [0.0792] & [0.0211] & \\
\hline \multirow{2}{*}{ S-DCC } & 0.0000 & 0.6421 & 2.4591 & 0.9921 & 0.9921 & 0.0000 & 0.6421 & \multirow{2}{*}{7} \\
\hline & [1.0000] & [0.4229] & [0.1168] & [0.3192] & [0.3192] & {$[1.0000]$} & [0.4229] & \\
\hline \multirow{2}{*}{ NS-DCC } & 1.9027 & 4.5110 & 5.3168 & 10.1944 & 5.3168 & 4.5110 & 5.3168 & \multirow[b]{2}{*}{1} \\
\hline & [0.1677] & {$[0.0336]$} & {$[0.0211]$} & [0.0014] & {$[0.0211]$} & {$[0.0336]$} & {$[0.0211]$} & \\
\hline
\end{tabular}

18 Due to the limited space, the detailed results of the VaR forecasting performance at the other three levels $(90 \%$, $99 \%$, and $99.5 \%$ ) based on the $\mathrm{LR}_{\mathrm{uc}}, \mathrm{LR}_{\mathrm{cc}}$, $\mathrm{DQ}$ tests are omitted here and are available upon request. However, the summary results of these three levels are also listed in Table 7. 
Table 6. Cont.

\begin{tabular}{|c|c|c|c|c|c|c|c|c|}
\hline \multicolumn{9}{|c|}{ Panel A. The LR uc $_{\text {Test }}$} \\
\hline & Ny-Sp & $\mathrm{Ny}-\mathrm{Na}$ & $\mathrm{Ny}-\mathrm{Ca}$ & Ny-Da & Ny-Ft & $\mathrm{Ny}-\mathrm{Sm}$ & $\mathrm{Sp}-\mathrm{Na}$ & Sum \\
\hline \multirow[b]{2}{*}{ S-BEKK } & 1.9027 & 4.5110 & 8.0790 & 5.3168 & 9.1101 & 4.5110 & 7.1022 & \multirow[b]{2}{*}{1} \\
\hline & [0.1677] & {$[0.0336]$} & {$[0.0044]$} & {$[0.0211]$} & [0.0025] & {$[0.0336]$} & {$[0.0076]$} & \\
\hline \multirow{2}{*}{ NS-BEKK } & 2.4591 & 4.5110 & 7.1022 & 11.3307 & 7.1022 & 4.5110 & 4.5110 & \multirow[b]{2}{*}{1} \\
\hline & [0.1168] & {$[0.0336]$} & {$[0.0076]$} & [0.0007] & [0.0076] & [0.0336] & [0.0336] & \\
\hline \multirow{3}{*}{ NS-ADCC } & 1.9027 & 4.5110 & 6.1810 & 10.1944 & 6.1810 & 3.0805 & 5.3168 & \multirow[b]{2}{*}{2} \\
\hline & [0.1677] & [0.0336] & [0.0129] & [0.0014] & [0.0129] & [0.0792] & [0.0211] & \\
\hline & Sp-Ca & Sp-Da & $S p-F t$ & Sp-Sm & $\mathrm{Na}-\mathrm{Ca}$ & Na-Da & $\mathrm{Na}-\mathrm{Ft}$ & \\
\hline \multirow{2}{*}{ S-CCC } & 15.0408 & 7.1022 & 13.7549 & 5.3168 & 8.0790 & 5.3168 & 12.5179 & \multirow{2}{*}{0} \\
\hline & [0.0001] & [0.0076] & [0.0002] & [0.0211] & [0.0044] & [0.0211] & {$[0.0004]$} & \\
\hline \multirow{2}{*}{ NS-CCC } & 8.0790 & 6.1810 & 10.1944 & 3.7650 & 8.0790 & 4.5110 & 12.5179 & \multirow[b]{2}{*}{1} \\
\hline & [0.0044] & [0.0129] & {$[0.0014]$} & [0.0523] & [0.0044] & [0.0336] & {$[0.0004]$} & \\
\hline \multirow{2}{*}{ S-DCC } & 0.9921 & 0.6421 & 5.3168 & 0.6421 & 0.6421 & 3.7650 & 1.9027 & \multirow{2}{*}{6} \\
\hline & [0.3192] & [0.4229] & [0.0211] & [0.4229] & [0.4229] & [0.0523] & [0.1677] & \\
\hline \multirow{2}{*}{ NS-DCC } & 7.1022 & 5.3168 & 9.1101 & 3.7650 & 6.1810 & 4.5110 & 11.3307 & \multirow[b]{2}{*}{1} \\
\hline & {$[0.0076]$} & {$[0.0211]$} & {$[0.0025]$} & [0.0523] & [0.0129] & [0.0336] & [0.0007] & \\
\hline \multirow{2}{*}{ S-BEKK } & 6.1810 & 3.0805 & 13.7549 & 5.3168 & 7.1022 & 3.0805 & 9.1101 & \multirow{2}{*}{2} \\
\hline & [0.0129] & [0.0792] & [0.0002] & [0.0211] & [0.0076] & [0.0792] & [0.0025] & \\
\hline \multirow{2}{*}{ NS-BEKK } & 8.0790 & 7.1022 & 8.0790 & 4.5110 & 6.1810 & 6.1810 & 8.0790 & \\
\hline & [0.0044] & [0.0076] & [0.0044] & [0.0336] & [0.0129] & [0.0129] & {$[0.0044]$} & 0 \\
\hline & 8.0790 & 5.3168 & 9.1101 & 3.7650 & 6.1810 & 3.7650 & 9.1101 & \\
\hline NS-ADCC & [0.0044] & [0.0211] & [0.0025] & [0.0523] & [0.0129] & [0.0523] & [0.0025] & 2 \\
\hline & Na-Sm & Ca-Da & Ca-Ft & Ca-Sm & Da-Ft & Da-Sm & Ft-Sm & \\
\hline & 4.5110 & 5.3168 & 3.0805 & 0.9921 & 4.5110 & 2.4591 & 4.5110 & \\
\hline S-CCC & [0.0336] & [0.0211] & [0.0792] & [0.3192] & [0.0336] & [0.1168] & [0.0336] & 3 \\
\hline & 4.5110 & 2.4591 & 1.4130 & 1.9027 & 3.7650 & 3.0805 & 2.4591 & \\
\hline $\mathrm{NS}-\mathrm{CCC}$ & [0.0336] & [0.1168] & [0.2345] & [0.1677] & [0.0523] & [0.0792] & [0.1168] & 6 \\
\hline & 0.7107 & 0.9921 & 1.4130 & 0.1728 & 0.6421 & 3.0805 & 0.0415 & \\
\hline S-DCC & [0.3991] & [0.3192] & [0.2345] & [0.6775] & [0.4229] & [0.0792] & [0.8384] & 7 \\
\hline & 4.5110 & 1.9027 & 1.4130 & 0.9921 & 4.5110 & 3.0805 & 3.0805 & \\
\hline NS-DCC & [0.0336] & [0.1677] & [0.2345] & [0.3192] & [0.0336] & [0.0792] & [0.0792] & 5 \\
\hline & 5.3168 & 3.7650 & 0.6421 & 1.4130 & 1.9027 & 2.4591 & 1.9027 & \\
\hline S-BEKK & {$[0.0211]$} & [0.0523] & [0.4229] & {$[0.2345]$} & [0.1677] & [0.1168] & [0.1677] & 6 \\
\hline NS_BEKK & 3.0805 & 1.9027 & 1.4130 & 0.9921 & 5.3168 & 3.0805 & 2.4591 & \\
\hline NS-BEKK & [0.0792] & [0.1677] & [0.2345] & [0.3192] & [0.0211] & [0.0792] & [0.1168] & 6 \\
\hline & 5.3168 & 1.9027 & 1.4130 & 0.9921 & 4.5110 & 3.0805 & 3.0805 & \\
\hline NS-ADCC & [0.0211] & [0.1677] & [0.2345] & [0.3192] & [0.0336] & [0.0792] & [0.0792] & 5 \\
\hline Panel B. Th & LR $_{\mathrm{cc}}$ Test & & & & & & & \\
\hline & Ny-Sp & $\mathrm{Ny}-\mathrm{Na}$ & $\mathrm{Ny}-\mathrm{Ca}$ & Ny-Da & Ny-Ft & Ny-Sm & Sp-Na & Sum \\
\hline & 0.4874 & 4.5806 & 8.3725 & 14.2417 & 11.1676 & 5.8915 & 4.5806 & \\
\hline S-CCC & {$[0.7836]$} & [0.1012] & [0.0152] & [0.0008] & [0.0037] & [0.0525] & [0.1012] & 4 \\
\hline & 2.3481 & 4.5806 & 8.3725 & 13.5015 & 10.4649 & 5.8915 & 5.3441 & \\
\hline $\mathrm{NS}-\mathrm{CCC}$ & [0.3091] & [0.1012] & [0.0152] & [0.0011] & [0.0053] & [0.0525] & [0.0691] & 4 \\
\hline & 0.4258 & 0.7050 & 3.8973 & 8.3789 & 3.3337 & 4.4727 & 1.6051 & \\
\hline S-DCC & [0.8082] & [0.7029] & [0.1424] & [0.0151] & [0.1888] & [0.1068] & [0.4481] & 6 \\
\hline NS $D C C$ & 2.3481 & 4.5806 & 7.1218 & 13.5015 & 8.8586 & 6.6231 & 5.9173 & 3 \\
\hline NS-DCC & [0.3091] & [0.1012] & {$[0.0284]$} & {$[0.0011]$} & [0.0119] & {$[0.0364]$} & [0.0518] & 3 \\
\hline & 2.3481 & 4.5806 & 10.4649 & 8.8586 & 11.1676 & 8.4983 & 7.4256 & \\
\hline S-BEKK & [0.3091] & [0.1012] & [0.0053] & [0.0119] & [0.0037] & [0.0142] & {$[0.0244]$} & 2 \\
\hline & 2.7784 & 4.5806 & 8.3725 & 14.2417 & 9.8444 & 6.6231 & 4.5806 & \\
\hline NS-BEKK & [0.2492] & [0.1012] & [0.0152] & [0.0008] & [0.0072] & [0.0364] & [0.1012] & 3 \\
\hline & 2.3481 & 4.5806 & 7.7056 & 13.5015 & 9.3082 & 5.8915 & 5.9173 & \\
\hline NS-ADCC & [0.3091] & [0.1012] & {$[0.0212]$} & [0.0011] & [0.0095] & [0.0525] & {$[0.0518]$} & 4 \\
\hline
\end{tabular}


Table 6. Cont.

\begin{tabular}{|c|c|c|c|c|c|c|c|c|}
\hline \multicolumn{9}{|c|}{ Panel B. The LR $\mathrm{R}_{\mathrm{cc}}$ Test } \\
\hline & Sp-Ca & Sp-Da & Sp-Ft & Sp-Sm & $\mathrm{Na}-\mathrm{Ca}$ & $\mathrm{Na}-\mathrm{Da}$ & $\mathrm{Na}-\mathrm{Ft}$ & \\
\hline \multirow{2}{*}{ S-CCC } & 16.9305 & 8.3725 & 17.5529 & 7.1218 & 10.4649 & 11.0641 & 15.0612 & \multirow{2}{*}{0} \\
\hline & [0.0002] & [0.0152] & [0.0001] & [0.0284] & [0.0053] & [0.0039] & [0.0005] & \\
\hline \multirow{2}{*}{ NS-CCC } & 10.4649 & 9.3082 & 15.4585 & 4.7351 & 10.4649 & 8.4983 & 15.0612 & \multirow{2}{*}{1} \\
\hline & [0.0053] & [0.0095] & [0.0004] & [0.0937] & [0.0053] & [0.0142] & [0.0005] & \\
\hline \multirow{2}{*}{ S-DCC } & 1.7585 & 3.3432 & 5.9173 & 3.3432 & 1.6051 & 8.2299 & 5.5328 & \multirow{2}{*}{6} \\
\hline & [0.4150] & [0.1879] & [0.0518] & [0.1879] & [0.4481] & [0.0163] & [0.0628] & \\
\hline \multirow{2}{*}{ NS-DCC } & 8.3725 & 8.8586 & 12.8426 & 4.7351 & 7.7056 & 8.4983 & 14.2417 & \multirow{2}{*}{1} \\
\hline & [0.0152] & [0.0119] & [0.0016] & [0.0937] & [0.0212] & [0.0142] & [0.0008] & \\
\hline \multirow{2}{*}{ S-BEKK } & 9.3082 & 5.891 & 17.5529 & 11.0641 & 8.3725 & 5.8915 & 11.1676 & \multirow{2}{*}{2} \\
\hline & [0.0095] & $5[0.0525]$ & [0.0001] & [0.0039] & [0.0152] & [0.0525] & [0.0037] & \\
\hline \multirow{2}{*}{ NS-BEKK } & 9.1201 & 8.3725 & 12.2670 & 6.6231 & 7.7056 & 11.3752 & 12.2670 & \multirow{2}{*}{0} \\
\hline & [0.0104] & [0.0152] & {$[0.0021]$} & [0.0364] & [0.0212] & [0.0033] & {$[0.0021]$} & \\
\hline \multirow{3}{*}{ NS-ADCC } & 10.4649 & 8.8586 & 12.8426 & 4.7351 & 7.7056 & 8.2299 & 12.8426 & \multirow[b]{2}{*}{1} \\
\hline & [0.0053] & [0.0119] & [0.0016] & [0.0937] & [0.0212] & [0.0163] & [0.0016] & \\
\hline & Na-Sm & Ca-Da & Ca-Ft & Ca-Sm & Da-Ft & Da-Sm & Ft-Sm & \\
\hline \multirow{2}{*}{ S-CCC } & 8.4983 & 11.0641 & 5.8915 & 5.5726 & 8.4983 & 7.9810 & 6.6231 & \multirow{2}{*}{2} \\
\hline & [0.0142] & [0.0039] & [0.0525] & [0.0616] & [0.0142] & [0.0184] & {$[0.0364]$} & \\
\hline \multirow{2}{*}{ NS-CCC } & 8.4983 & 10.7855 & 3.4251 & 5.5328 & 6.2122 & 8.0564 & 2.7784 & \\
\hline & [0.0142] & [0.0045] & [0.1804] & [0.0628] & [0.0447] & [0.0178] & [0.2492] & 3 \\
\hline & 7.5978 & 1.7585 & 2.0071 & 5.7610 & 1.6051 & 5.8915 & 4.0175 & \\
\hline S-DCC & [0.0223] & [0.4150] & [0.3665] & {$[0.0561]$} & [0.4481] & [0.0525] & [0.1341] & 6 \\
\hline & 8.4983 & 10.9746 & 3.4251 & 3.3337 & 8.4983 & 8.0564 & 3.2955 & \\
\hline NS-DCC & [0.0142] & [0.0041] & [0.1804] & [0.1888] & [0.0142] & [0.0178] & [0.1924] & 3 \\
\hline & 11.0641 & 10.7251 & 3.3432 & 3.4251 & 3.6140 & 7.9810 & 2.3481 & \\
\hline S-BEKK & [0.0039] & [0.0046] & [0.1879] & [0.1804] & [0.1641] & [0.0184] & [0.3091] & 4 \\
\hline & 5.8915 & 10.9746 & 3.4251 & 5.5726 & 8.8586 & 8.0564 & 2.7784 & \\
\hline NS-BEKK & [0.0525] & [0.0041] & [0.1804] & [0.0616] & [0.0119] & [0.0178] & [0.2492] & 4 \\
\hline & 11.0641 & 10.9746 & 3.4251 & 3.3337 & 8.4983 & 8.0564 & 3.2955 & \\
\hline NS-ADCC & [0.0039] & [0.0041] & [0.1804] & [0.1888] & [0.0142] & [0.0178] & [0.1924] & 3 \\
\hline Panel C. Th & DQ Test & & & & & & & \\
\hline & $\mathrm{Ny}-\mathrm{Sp}$ & $\mathrm{Ny}-\mathrm{Na}$ & $\mathrm{Ny}-\mathrm{Ca}$ & Ny-Da & Ny-Ft & Ny-Sm & $\mathrm{Sp}-\mathrm{Na}$ & Sum \\
\hline & 10.3218 & 12.2181 & 12.0662 & 33.4966 & 26.8956 & 12.3289 & 10.0792 & \\
\hline $\mathrm{S}-\mathrm{CCC}$ & [0.1710] & [0.0936] & [0.0983] & {$[0.0000]$} & [0.0003] & [0.0902] & [0.1841] & 5 \\
\hline & 10.2944 & 12.0725 & 11.9839 & 28.8697 & 27.2485 & 12.5786 & 10.8587 & \\
\hline NS-CCC & [0.1724] & [0.0981] & [0.1010] & [0.0001] & [0.0003] & [0.0830] & [0.1448] & 5 \\
\hline & 3.7374 & 8.5843 & 7.3272 & 19.6552 & 18.7722 & 10.3007 & 13.4539 & \\
\hline S-DCC & [0.8094] & {$[0.2838]$} & [0.3956] & [0.0063] & [0.0089] & [0.1721] & [0.0617] & 5 \\
\hline & 10.3132 & 12.1512 & 11.2779 & 37.2880 & 22.0679 & 13.0092 & 12.2997 & \\
\hline NS-DCC & [0.1715] & [0.0956] & [0.1269] & [0.0000] & [0.0024] & [0.0718] & [0.0911] & 5 \\
\hline & 10.0575 & 12.2142 & 16.0366 & 19.1733 & 23.0047 & 20.5890 & 14.0009 & 2 \\
\hline S-BEKK & [0.1853] & [0.0937] & [0.0247] & [0.0076] & [0.0017] & [0.0044] & {$[0.0511]$} & 3 \\
\hline & 10.1730 & 12.5699 & 11.8918 & 34.6125 & 24.0851 & 11.2893 & 10.2065 & \\
\hline NS-BEKK & [0.1789] & [0.0833] & [0.1041] & [0.0000] & [0.0011] & [0.1264] & [0.1771] & 5 \\
\hline & 10.3132 & 12.1526 & 11.5718 & 33.5806 & 23.4834 & 12.5590 & 12.3032 & \\
\hline NS-ADCC & [0.1715] & [0.0956] & [0.1155] & [0.0000] & [0.0014] & [0.0836] & [0.0910] & 5 \\
\hline & $\mathrm{Sp}-\mathrm{Ca}$ & Sp-Da & Sp-Ft & Sp-Sm & $\mathrm{Na}-\mathrm{Ca}$ & Na-Da & $\mathrm{Na}-\mathrm{Ft}$ & \\
\hline & 30.3576 & 18.2263 & 37.9757 & 16.0300 & 15.2448 & 24.5045 & 31.0751 & \\
\hline S-CCC & {$[0.0000]$} & [0.0109] & {$[0.0000]$} & {$[0.0248]$} & [0.0329] & [0.0009] & {$[0.0000]$} & 0 \\
\hline & 20.2060 & 18.0954 & 37.3363 & 12.2757 & 15.3185 & 18.6607 & 31.1347 & 1 \\
\hline NS-CCC & [0.0051] & [0.0115] & {$[0.0000]$} & [0.0918] & {$[0.0321]$} & [0.0093] & {$[0.0000]$} & 1 \\
\hline & 4.3366 & 6.6243 & 13.7254 & 11.9702 & 3.6055 & 15.4307 & 12.6713 & \\
\hline S-DCC & [0.7402] & [0.4690] & {$[0.0562]$} & [0.1015] & [0.8239] & {$[0.0308]$} & {$[0.0805]$} & 6 \\
\hline
\end{tabular}


Table 6. Cont.

\begin{tabular}{|c|c|c|c|c|c|c|c|c|}
\hline \multicolumn{9}{|c|}{ Panel C. The DQ Test } \\
\hline & Sp-Ca & Sp-Da & $\mathrm{Sp}-\mathrm{Ft}$ & Sp-Sm & $\mathrm{Na}-\mathrm{Ca}$ & Na-Da & Na-Ft & \\
\hline \multirow{2}{*}{ NS-DCC } & 14.5434 & 18.7120 & 30.9949 & 12.2764 & 14.4964 & 18.6412 & 30.5141 & \multirow{2}{*}{1} \\
\hline & {$[0.0423]$} & [0.0091] & {$[0.0000]$} & {$[0.0918]$} & {$[0.0430]$} & {$[0.0093]$} & {$[0.0000]$} & \\
\hline \multirow{2}{*}{ S-BEKK } & 16.1927 & 13.1625 & 35.5377 & 20.6767 & 15.3437 & 13.9051 & 20.7264 & \multirow{2}{*}{2} \\
\hline & {$[0.0234]$} & [0.0682] & {$[0.0000]$} & [0.0042] & {$[0.0318]$} & {$[0.0528]$} & {$[0.0041]$} & \\
\hline \multirow{2}{*}{ NS-BEKK } & 12.8649 & 18.0528 & 39.2391 & 13.9991 & 13.9110 & 25.1249 & 29.5862 & \multirow{2}{*}{3} \\
\hline & {$[0.0754]$} & [0.0117] & {$[0.0000]$} & {$[0.0511]$} & {$[0.0527]$} & {$[0.0007]$} & {$[0.0001]$} & \\
\hline \multirow{3}{*}{ NS-ADCC } & 20.5613 & 18.7242 & 31.0229 & 12.2829 & 14.4518 & 18.1772 & 34.3521 & \multirow{2}{*}{1} \\
\hline & {$[0.0044]$} & {$[0.0090]$} & {$[0.0000]$} & {$[0.0916]$} & {$[0.0437]$} & {$[0.0111]$} & {$[0.0000]$} & \\
\hline & $\mathrm{Na}-\mathrm{Sm}$ & Ca-Da & Ca-Ft & Ca-Sm & Da-Ft & Da-Sm & Ft-Sm & \\
\hline \multirow{2}{*}{ S-CCC } & 25.8101 & 22.3909 & 10.9822 & 12.0453 & 17.3897 & 17.2360 & 26.4417 & \multirow{2}{*}{2} \\
\hline & [0.0005] & {$[0.0021]$} & [0.1393] & [0.0990] & [0.0150] & [0.0159] & [0.0004] & \\
\hline \multirow{2}{*}{ NS-CCC } & 25.8747 & 21.4803 & 7.6053 & 12.5239 & 13.7256 & 17.2310 & 7.1334 & \multirow{2}{*}{4} \\
\hline & [0.0005] & [0.0031] & [0.3686] & [0.0845] & [0.0562] & [0.0159] & [0.4151] & \\
\hline \multirow[b]{2}{*}{ S-DCC } & 13.3830 & 3.3975 & 4.8187 & 10.4288 & 13.2134 & 17.0012 & 10.4312 & \multirow[b]{2}{*}{6} \\
\hline & [0.0633] & [0.8459] & [0.6820] & [0.1655] & [0.0670] & [0.0173] & [0.1654] & \\
\hline \multirow{2}{*}{ NS-DCC } & 25.8073 & 21.9385 & 7.7121 & 7.7693 & 19.4782 & 16.9916 & 9.4860 & \multirow{2}{*}{3} \\
\hline & [0.0005] & {$[0.0026]$} & [0.3586] & [0.3533] & {$[0.0068]$} & {$[0.0174]$} & [0.2196] & \\
\hline \multirow{2}{*}{ S-BEKK } & 23.7673 & 21.6152 & 7.5296 & 9.2160 & 10.0008 & 17.0505 & 6.3742 & \multirow[b]{2}{*}{4} \\
\hline & [0.0012] & [0.0029] & [0.3758] & [0.2375] & [0.1885] & [0.0170] & [0.4967] & \\
\hline \multirow{2}{*}{ NS-BEKK } & 12.0903 & 21.9022 & 7.6893 & 11.8549 & 17.9357 & 16.7977 & 17.1000 & \multirow{2}{*}{3} \\
\hline & [0.0976] & [0.0026] & [0.3607] & [0.1054] & [0.0122] & [0.0187] & [0.0167] & \\
\hline \multirow{2}{*}{ NS-ADCC } & 31.0924 & 21.9193 & 7.7121 & 7.7693 & 19.4782 & 16.9965 & 9.4886 & \multirow[b]{2}{*}{3} \\
\hline & [0.0000] & [0.0026] & [0.3586] & [0.3533] & [0.0068] & [0.0174] & [0.2194] & \\
\hline
\end{tabular}

Note: (1) Refer to notes 1-2 of Table 3. (2) The numbers in this table denote the value of the three accuracy tests at the $95 \%$ level for equal weight bi-component stock portfolios. The number in the bracket underneath the preceding number denotes the corresponding $p$-value of that test statistic. (3) The bold font indicates that the null hypothesis of the specific test statistic is accepted at the $5 \%$ significance level. (4) The $L_{\mathrm{uc}}$ (respectively, $\mathrm{LR}_{\mathrm{cc}}$ ) test statistic is asymptotically $\chi^{2}(1)$ (respectively, $\chi^{2}(2)$ ) distributed and its corresponding critical values at the $5 \%$ significance level is 3.841 (respectively, 5.991 ). On the contrary, the DQ test statistic is asymptotically $\chi^{2}(7)$ distributed and its corresponding critical values at the $5 \%$ significance level is 14.067. (5) The numbers in column Sum denote the total number of portfolios passing the specific test at the $5 \%$ significance level.

Table 7 summarizes the results of the above three accuracy tests (i.e., $\mathrm{LR}_{\mathrm{uc}}, \mathrm{LR}_{\mathrm{cc}}$, and DQ) for four levels (i.e., $90 \%, 95 \%, 99 \%$, and $99.5 \%$ ) based on 21 equal weight bi-component stock portfolios as a sample. Subsequently, regarding all 21 equal weight bi-component stock portfolios, we sum the total number of portfolios that pass the three accuracy measures (i.e., $\mathrm{LR}_{\mathrm{uc}}, \mathrm{LR}_{\mathrm{cc}}$, and $\mathrm{DQ}$ ) under the $90 \%$ (respectively, 95\%) level for each of the seven bivariate GARCH models, and list them in column $\mathrm{S}_{90}$ (respectively, $\mathrm{S}_{95}$ ) underneath the 90\% (respectively, 95\%) level at the first panel in Table 7. In other words, the numbers in column $\mathrm{S}_{90}$ (respectively, $\mathrm{S}_{95}$ ) underneath the $90 \%$ (respectively, 95\%) level at the first panel of Table 7 denote the summation of three corresponding numbers in columns $S_{90, u c}, S_{90, \text { cc }}$ and $S_{90, d q}$ (respectively, $S_{95, u c}, S_{95, c c}$ and $S_{95, d q}$ ). Moreover, the numbers in column $S_{90, u c}$ (respectively, $S_{90, c c}$ ) underneath the $90 \%$ denote the summation of three corresponding numbers in column $\mathrm{LR}_{\mathrm{uc}}$ (respectively, $\mathrm{LR}_{\mathrm{cc}}$ ) underneath the $90 \%$ whereas those in column $\mathrm{S}_{90, \mathrm{dq}}$ underneath the $90 \%$ denote the summation of three corresponding numbers in column DQ underneath the $90 \%$. In the same inference process, we sum the total number of portfolios that pass the three accuracy measures (i.e., $\mathrm{LR}_{\mathrm{uc}}$, $\mathrm{LR}$ and $\mathrm{DQ}$ ) under a $99 \%$ (respectively, 99.5\%) level for each of the seven bivariate GARCH models and list them in column $\mathrm{S}_{99}$ (respectively, $\mathrm{S}_{995}$ ) underneath a $99 \%$ (respectively, $99.5 \%$ ) level at the second panel of Table 7 .

In the same inference process that is executed in the previous subsection, four categories of the model performance competition will be executed in this section according to the issues addressed in this study. The issues are respectively explored for the $90 \%, 95 \%, 99 \%$, and $99.5 \%$ levels via the numbers in column $\mathrm{S}_{90}$ underneath the $90 \%$ level, $\mathrm{S}_{95}$ underneath the $95 \%$ level, $\mathrm{S}_{99}$ underneath the $99 \%$ level, 
and $S_{995}$ underneath the $99.5 \%$ level in Table 7 . The first category of the model performance competition is used to inspect which approach of parameters estimate (i.e., the standard or non-standard approach) has a better VaR forecast performance based on the same bivariate variance-covariance specification. We find that the NS-CCC model has a better VaR forecast performance than the S-CCC model for the CCC type of bivariate variance-covariance specification for most of the four levels since the NS-CCC model has the larger total number of portfolios that pass three accuracy measures except the $99.5 \%$ level. For example, regarding the 90\% level, the NS-CCC model has the larger number, 38 between the S-CCC (33) and NS-CCC (38) models, where the number in the brackets beside each model denotes the summation of the total number of portfolios that pass three accuracy measures for the $90 \%$ level. In the same inference process, the S-DCC (respectively, S-BEKK) model has a better VaR forecast performance for the DCC (respectively, BEKK) type of bivariate variance-covariance specification for all levels. These results indicate that the standard approach has better VaR forecast performance for the DCC and BEKK types of bivariate variance-covariance specification whereas the non-standard approach has a better VaR forecast performance only for the CCC type of bivariate variance-covariance specification. These results are consistent with those found in the failure rate and mean VaR.

The second category of the model performance competition is used to inspect which type of bivariate variance-covariance specification will have the best VaR forecast performance based on the same approach of parameters estimate. We find that the S-DCC model has the best VaR forecast performance since this model has the largest total number of portfolios that pass the three accuracy measures among the S-CCC, S-DCC, and S-BEKK models for all four levels. On the contrary, the NS-CCC, NS-DCC, and NS-BEKK models seem to have the same VaR forecast performance since, for these three models, the corresponding total numbers of portfolios that pass the three accuracy measures are almost equal. For example, regarding the 90\% (respectively, 95\%) level, the above total numbers are 38 (respectively, 27), 42 (respectively, 23), 38 (respectively, 25) for the NS-CCC, NS-DCC, and NS-BEKK models, respectively. Conversely, regarding the 99\% (respectively, 99.5\%) level, the above total numbers are 6 (respectively, 2), 5 (respectively, 5), 9 (respectively, 3) for the NS-CCC, NS-DCC, and NS-BEKK models, respectively. The above results indicate that the DCC type of bivariate variance-covariance specification has the best VaR forecast performance only for the standard approach, whereas three types of bivariate variance-covariance specifications seem to have the same VaR forecast performance for the non-standard approach. In other words, the above results are completely consistent with those found in the failure rate, whereas they are slightly different from those found in the mean VaR. The third category of the model performance competition is used to inspect which model has the best VaR forecast performance among all the bivariate GARCH models except the NS-ADCC model. We find that the S-DCC model has the best VaR forecast performance since this model has the largest total number of portfolios that pass three accuracy measures among all bivariate GARCH models excluding or including the NS-ADCC model. These results indicate that the DCC type of bivariate variance-covariance specification with the standard approach has the best VaR forecast performance. These results are consistent with those found in the failure rate and mean VaR. Finally, the last or the fourth category of the model performance competition is used to explore whether the two-step asymmetric DCC model has a better performance than its corresponding symmetric one. We find that both the NS-ADCC and NS-DCC models almost have the same forecast performance since the NS-ADCC model has a larger total number of portfolios that pass three accuracy measures for the $95 \%$ and $99.5 \%$ levels whereas the NS-DCC model has the larger total number of portfolios that pass the three accuracy measures for the $90 \%$ and $99 \%$ levels. For example, regarding the $90 \%$ (respectively, 95\%) level, the above total numbers are 42 (respectively, 23) and 40 (respectively, 26) for the NS-DCC and NS-ADCC models, respectively. Conversely, regarding the 99\% (respectively, $99.5 \%$ ) level, the above total numbers are 5 (respectively, 5) and 0 (respectively, 7) for the NS-DCC and NS-ADCC models, respectively. 
Table 7. The summary results for the out-of-sample VaR forecasts performance of equal-weight stock portfolios based on alternative accuracy tests.

\begin{tabular}{|c|c|c|c|c|c|c|c|c|c|c|c|c|c|c|c|c|c|c|c|c|c|c|c|c|c|c|}
\hline & \multicolumn{13}{|c|}{$90 \%$ Level } & \multicolumn{13}{|c|}{ 95\% Level } \\
\hline & \multicolumn{3}{|c|}{$\mathbf{L R}_{\mathrm{uc}}$} & $\mathrm{S}_{90, \mathrm{uc}}$ & \multicolumn{3}{|c|}{$\mathbf{L R}_{\mathrm{cc}}$} & \multicolumn{2}{|l|}{$\mathrm{S}_{90, \mathrm{cc}}$} & \multicolumn{2}{|l|}{ DQ } & $S_{90, d q}$ & \multirow[t]{2}{*}{$\mathrm{S}_{90}$} & \multicolumn{3}{|c|}{$\mathbf{L R}_{\mathrm{uc}}$} & $\mathrm{S}_{95, \mathrm{uc}}$ & \multicolumn{3}{|c|}{$\mathbf{L R}_{\mathrm{cc}}$} & \multicolumn{2}{|l|}{$\mathrm{S}_{95, \mathrm{cc}}$} & \multicolumn{2}{|l|}{ DQ } & $S_{95, d q}$ & \multirow{2}{*}{$\begin{array}{c}\mathrm{S}_{\mathbf{9 5}} \\
18\end{array}$} \\
\hline S-CCC & 7 & 7 & 4 & 18 & 5 & 2 & 1 & 8 & 3 & 2 & 2 & 7 & & 2 & 0 & 3 & 5 & 4 & 0 & 2 & 6 & 5 & 0 & 2 & 7 & \\
\hline NS-CCC & 7 & 7 & 5 & 19 & 6 & 3 & 2 & 11 & 3 & 3 & 2 & 8 & 38 & 2 & 1 & 6 & 9 & 4 & 1 & 3 & 8 & 5 & 1 & 4 & 10 & $\underline{27}$ \\
\hline S-DCC & 7 & 7 & 7 & 21 & 7 & 7 & 4 & 18 & 6 & 4 & 3 & 13 & $\underline{52}$ & 7 & 6 & 7 & 20 & 6 & 6 & 6 & 18 & 5 & 6 & 6 & 17 & $\underline{55}$ \\
\hline NS-DCC & 7 & 7 & 6 & 20 & 6 & 5 & 3 & 14 & 3 & 3 & 2 & 8 & $\underline{42}$ & 1 & 1 & 5 & 7 & 3 & 1 & 3 & 7 & 5 & 1 & 3 & 9 & 23 \\
\hline S-BEKK & 7 & 7 & 7 & 21 & 5 & 5 & 4 & 14 & 3 & 2 & 3 & 8 & 43 & 1 & 2 & 6 & 9 & 2 & 2 & 4 & 8 & 3 & 2 & 4 & 9 & 26 \\
\hline NS-BEKK & 7 & 7 & 4 & 18 & 7 & 4 & 2 & 13 & 3 & 2 & 2 & 7 & 38 & 1 & 0 & 6 & 7 & 3 & 0 & 4 & 7 & 5 & 3 & 3 & 11 & 25 \\
\hline \multirow[t]{3}{*}{ NS-ADCC } & 7 & 7 & 6 & 20 & 6 & 4 & 3 & 13 & 3 & 2 & 2 & 7 & 40 & 2 & 2 & 5 & 9 & 4 & 1 & 3 & 8 & 5 & 1 & 3 & 9 & 26 \\
\hline & \multicolumn{13}{|c|}{ 99\% Level } & \multicolumn{13}{|c|}{ 99.5\% Level } \\
\hline & & $\mathbf{L R}_{\mathrm{uc}}$ & & $S_{99, u c}$ & & $\mathbf{L R}_{\mathrm{cc}}$ & & $\mathrm{S}_{99, \mathrm{cc}}$ & & DQ & & $S_{99, d q}$ & $S_{99}$ & & $\mathbf{L R}_{\mathrm{uc}}$ & & $\mathrm{S}_{995, \mathrm{uc}}$ & & $\mathbf{L R}_{\mathrm{cc}}$ & & $\mathrm{S}_{995, \mathrm{cc}}$ & & DQ & & $S_{995, d q}$ & $\mathrm{~S}_{995}$ \\
\hline S-CCC & 2 & 1 & 0 & 3 & 1 & 0 & 0 & 1 & 1 & 0 & 0 & 1 & 5 & 2 & 1 & 0 & 3 & 0 & 0 & 0 & 0 & 0 & 0 & 0 & 0 & 3 \\
\hline NS-CCC & 1 & 1 & 0 & 2 & 1 & 0 & 1 & 2 & 1 & 0 & 1 & 2 & 6 & 1 & 1 & 0 & 2 & 0 & 0 & 0 & 0 & 0 & 0 & 0 & 0 & 2 \\
\hline S-DCC & 4 & 5 & 4 & 13 & 3 & 2 & 2 & 7 & 2 & 2 & 2 & 6 & $\underline{26}$ & 5 & 5 & 5 & 15 & 1 & 0 & 0 & 1 & 1 & 0 & 3 & 4 & $\underline{20}$ \\
\hline NS-DCC & 1 & 0 & 0 & 1 & 1 & 0 & 1 & 2 & 1 & 0 & 1 & 2 & $\overline{5}$ & 2 & 3 & 0 & 5 & 0 & 0 & 0 & 0 & 0 & 0 & 0 & 0 & $\overline{5}$ \\
\hline S-BEKK & 2 & 3 & 0 & 5 & 2 & 2 & 0 & 4 & 1 & 1 & 1 & 3 & 12 & 2 & 4 & 1 & 7 & 0 & 0 & 1 & 1 & 1 & 0 & 2 & 2 & $\overline{10}$ \\
\hline NS-BEKK & 1 & 1 & 1 & 3 & 2 & 1 & 1 & 4 & 1 & 0 & 1 & 2 & $\underline{9}$ & 1 & 2 & 0 & 3 & 0 & 0 & 0 & 0 & 0 & 0 & 0 & 0 & 3 \\
\hline NS-ADCC & 0 & 0 & 0 & 0 & 0 & 0 & 0 & 0 & 0 & 0 & 0 & 0 & $\overline{0}$ & 2 & 4 & 0 & 6 & 0 & 0 & 0 & 0 & 0 & 0 & 1 & 1 & 7 \\
\hline
\end{tabular}

Note: (1) Refer to note 2 of Table 3. (2) The numbers in the columns $\mathrm{LR}_{\mathrm{uc}}, \mathrm{LR}_{\mathrm{cc}}$, and DQ underneath the $95 \%$ level at the first panel are respectively summarized from the numbers in

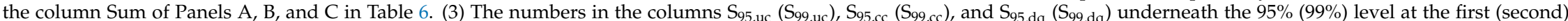
panel denote the total number of portfolios that pass the $\mathrm{LR}_{\mathrm{uc}} \mathrm{LR}_{\mathrm{cc}}$, and DQ tests at the specified model for all 21 bi-component stock portfolios, respectively. (4) The numbers in column $\mathrm{S}_{95}\left(\mathrm{~S}_{99}\right)$ underneath the $95 \%(99 \%)$ level at the first (second) panel denote the total sum of three corresponding numbers in columns $\mathrm{S}_{95}, \mathrm{uc}\left(\mathrm{S}_{99}, \mathrm{uc}\right)$, $\mathrm{S}_{95, \mathrm{cc}}\left(\mathrm{S}_{99, \mathrm{cc}}\right)$, and $\mathrm{S}_{95} \mathrm{dq}\left(\mathrm{S}_{99, \mathrm{dq}}\right)$ representing the total number of portfolios that pass the $\mathrm{LR}_{\mathrm{uc}}, \mathrm{LR}_{\mathrm{cc}}$, or DQ tests at the specified model for the $95 \%(99 \%)$ level. (5) In the same inference process, the numbers in column $\mathrm{S}_{90}\left(\mathrm{~S}_{995}\right)$ underneath the $90 \%(99.5 \%)$ level at the first (second) panel denote the total sum of three corresponding numbers in columns $\mathrm{S}_{90, \mathrm{uc}}\left(\mathrm{S}_{995, \mathrm{uc}}\right)$, $\mathrm{S}_{90, \mathrm{cc}}\left(\mathrm{S}_{995, \mathrm{cc}}\right)$, and $\mathrm{S}_{90, \mathrm{dq}}\left(\mathrm{S}_{995, \mathrm{dq}}\right)$. (6) The bold font in columns $\mathrm{S}_{90}, \mathrm{~S}_{95}, \mathrm{~S}_{99}$, and $\mathrm{S}_{995}$ denotes the greater number when two numbers corresponding to two models are compared with each other and these two models have the same bivariate variance-covariance specification but a different parameter estimate approach (i.e., the S-CCC vs. NS-CCC; the S-DCC vs. NS-DCC; and the S-BEKK vs. NS-BEKK). (7) The underlined font in columns $\mathrm{S}_{90}, \mathrm{~S}_{95}, \mathrm{~S}_{99}$, and $\mathrm{S}_{995}$ denotes the greatest number when three numbers corresponding to the three models are compared with each other and these three models have the same parameter estimate approach but a different bivariate variance-covariance specification (i.e., the S-CCC, S-DCC, and S-BEKK; the NS-CCC, NS-DCC, and NS-BEKK). (8) The shade font in columns $\mathrm{S}_{90}, \mathrm{~S}_{95}, \mathrm{~S}_{99}$, and $\mathrm{S}_{995}$ denotes the greatest number when six numbers corresponding to the six models are compared with each other and these six models are the S-CCC, NS-CCC, S-DCC, NS-DCC, S-BEKK, and NS-BEKK models. (9) The italic font in columns $\mathrm{S}_{90}$, $\mathrm{S}_{95}$, $\mathrm{S}_{99}$, and $\mathrm{S}_{995}$ denotes the greater number when two numbers corresponding to two models are compared with each other and these two models are the NS-DCC and NS-ADCC. 
To sum up, irrespective of the results from the preliminary analysis of the average VaR performance in the previous subsection or the results from the three types of back-testing in this subsection, we get the following conclusions: first, the standard approach has a better VaR forecast performance for the DCC and BEKK types of bivariate variance-covariance specification whereas the non-standard approach has a better VaR forecast performance only for the CCC type of bivariate variance-covariance specification; second, the DCC type of bivariate variance-covariance specification has the best VaR forecast performance for the standard approach whereas three types of bivariate variance-covariance specification seem to have the same VaR forecast performance for the non-standard approach; third, the DCC type of bivariate variance-covariance specification with the standard approach has the best VaR forecast performance among all the bivariate GARCH models including the NS-ADCC model; fourth, both the NS-ADCC and NS-DCC models almost have the same VaR forecast performance. Finally, we firmly believe that the DCC type of bivariate variance-covariance specification plays a significantly important role as the dynamic risk is measured.

\subsection{Robust Check for the Performance Assessments of VaR Forecasts}

To check whether a different portfolio (different components with different weights) has the same VaR forecast comparison results with the equal-weight bi-component portfolio described in the previous section, we add the following two additional sub-issues in this section. First we add two other weight combinations $\left(\mathrm{w}_{1}=25 \%, \mathrm{w}_{2}=75 \%\right.$; and $\mathrm{w}_{1}=75 \%, \mathrm{w}_{2}=25 \%$ ) for the original 21 stock-based bi-component portfolios to investigate whether the different weight combinations of portfolios will affect the VaR forecast comparison results. Second, this work also considers Udi as a new component asset to construct seven currency-stock-based bi-component portfolios to investigate whether the different component combinations of portfolios will affect the VaR forecast comparison results. In addition, besides the three accuracy tests, we also perform an efficiency test via the MRC to analyze whether any of the competing models significantly outperform the benchmark, and then select the most suitable model for the risk management of a bank.

\subsubsection{Can the Weight Combinations of Portfolios Affect the Performance of VaR Forecasts?}

Regarding the above first sub-issue, we summarize the results of Table 7 again to easily compare the results for the three weight combinations of stock-based portfolios. Taking an example of the $90 \%$ level, the numbers in column $S_{90, u c}$ (respectively, $S_{90, c c}$ ) of Table 7 are recorded in column $L_{\mathrm{uc}}$ (respectively, $\mathrm{LR}_{\mathrm{cc}}$ ) underneath the $90 \%$ level in panel A of Table 8 . Similarly, the numbers in column $\mathrm{S}_{90, \mathrm{dq}}$ (respectively, $\mathrm{S}_{90}$ ) of Table 7 are recorded in column DQ (respectively, Sum) underneath the $90 \%$ level in panel A of Table 8. Subsequently, via following the procedure in the case of equal-weight bi-component portfolios, we summarize the results of three accuracy tests for the weight combinations: $\mathrm{w}_{1}=25 \%$, and $\mathrm{w}_{2}=75 \%$ (respectively, $\mathrm{w}_{1}=75 \%$, and $\mathrm{w}_{2}=25 \%$ ) in panel B (respectively, C) of Table 8 . Table 8 lists all summary results of the out-of-sample VaR forecasts performance for the three weight combinations of stock-based portfolios. Then we execute four groups of the model performance comparisons as listed in Section 5.2.2. As reported in Table 8, regarding the three weight combinations, we find that, first, the NS-CCC model has a better VaR forecast performance than the S-CCC model for the CCC type of bivariate variance-covariance specification for most cases because the NS-CCC model has a larger total number of portfolios that pass the three accuracy measures except for the cases of the $99.5 \%$ level in panel A and both the $99 \%$ and $99.5 \%$ levels in panel C. Using the same inference process, the S-DCC model has a better VaR forecast performance than the NS-DCC model for all cases. Conversely, the S-BEKK model has a better VaR forecast performance than the NS-BEKK model except for the $90 \%, 95 \%$, and $99 \%$ levels in panel B. Second, the S-DCC model has the best VaR forecast performance because this model has the largest total number of portfolios that pass the three accuracy measures among the S-CCC, S-DCC, and S-BEKK models for all cases. In contrast, the NS-CCC, NS-DCC, and NS-BEKK models seem to have the same VaR forecast performance because, for these three models, the corresponding total numbers of portfolios that pass the three accuracy measures are 
almost equal. Third, the S-DCC model has the best VaR forecast performance because this model has the largest total number of portfolios that pass the three accuracy measures among all seven bivariate GARCH models for all cases. Fourth, both the NS-ADCC and NS-DCC models have almost the same VaR forecast performance because, for these two models, the corresponding total numbers of portfolios that pass the three accuracy measures are almost equal.

From this, we reach the following conclusions irrespective of weight combinations. First, the standard approach has a better VaR forecast performance for the DCC and BEKK types of bivariate variance-covariance specifications, whereas the non-standard approach has better VaR forecast performance only for the CCC type of bivariate variance-covariance specification. Second, the DCC type of bivariate variance-covariance specification has the best VaR forecast performance only for the standard approach, whereas three types of bivariate variance-covariance specifications seem to have the same VaR forecast performance for the non-standard approach. Third, the DCC type of bivariate variance-covariance specification with the standard approach shows the best VaR forecast performance among the seven bivariate GARCH models. Fourth, the NS-ADCC and NS-DCC models have almost the same VaR forecast performance. These findings can also be observed from the numbers in the column SUM of Table 8. Hence the different weight combinations of portfolios do not affect the VaR forecast comparison results for the stock-based portfolio. Notably, the finding that the DCC type of bivariate variance-covariance specification with the standard approach (i.e., the S-DCC model) shows that the best VaR forecast performance among the seven bivariate GARCH models is the most significant because there is no exception in this group in terms of the model performance comparisons for all four levels and for all three weight combinations.

\subsubsection{Can the Component Combinations of Portfolios Affect the Performance of VaR Forecasts?}

Regarding this second sub-issue, Table 9 reports the out-of-sample VaR forecasts performance of seven equal-weight currency-stock portfolios based on alternative accuracy tests for the $90 \%$ level. Subsequently, we summarize the results of Table 9 in Table 10 to easily compare the results for three weight combinations of currency-stock-based portfolios. For example, the numbers in column Sum in panel A (respectively, B) in Table 9 are recorded in column LR $_{\mathrm{uc}}$ (respectively, $\mathrm{LR}_{\mathrm{cc}}$ ) underneath the $90 \%$ level in panel A of Table 10. Conversely, the numbers in column Sum in panel C in Table 9 are recorded in column DQ underneath the $90 \%$ level in panel A of Table 10. Table 10 lists all the summary results of the out-of-sample VaR forecast performance for three weight combinations of currency-stock-based portfolios. Then we execute four groups of the model performance comparisons imitating the same process performed in Table 8 . Before we perform this analysis, we find a specific phenomenon existing in Table 10 compared to Table 8 . For example, the total numbers of portfolios that pass three accuracy measures are almost equal for most cases, such as all four levels of panel A; the $99 \%$ and $99.5 \%$ levels of panel B; the $90 \%$ and $95 \%$ levels of panel B except for the S-CCC model; and the $90 \%, 95 \%$; and $99.5 \%$ levels of panel C except for the S-CCC model. Taking an example of the $90 \%$ level of panel A, the total numbers of portfolios that pass the three accuracy measures are 17, 18, 20, 20, 19, 20, and 21 for the S-CCC, NS-CCC, S-DCC, NS-DCC, S-BEKK, NS-BEKK, and NS-ADCC models, respectively. This phenomenon indicates that all seven models seem to have the same VaR forecast performance because the seven numbers are almost the same.

Subsequently, we execute four groups of the model performance comparisons. As reported in Table 10, regarding the three weight combinations, we find that, first, both the S-CCC and NS-CCC models seem to have the same VaR forecast performance because, for these two models, the corresponding total numbers of portfolios that pass the three accuracy measures are almost equal except for the cases of the $90 \%$ and $95 \%$ levels of panel B and all levels of panel $C$. The phenomenon is more significant for both the S-DCC and NS-DCC models and for both the S-BEKK and NS-BEKK models because, regarding these two pairs of models, the total numbers of portfolios that pass the three accuracy measures are almost equal for all three panels and for all three levels. Second, the S-DCC (respectively, NS-DCC) model seems to have the best VaR forecast performance because this 
model has the largest total number of portfolios that pass the three accuracy measures among the S-CCC, S-DCC, and S-BEKK (respectively, NS-CCC, NS-DCC, and NS-BEKK) models for most cases. However, this result is not significant because the corresponding total numbers are almost equal for these three models. Third, the seven models seem to have the same VaR forecast performance because the models with the largest total number of portfolios that pass the three accuracy measures among the seven models are uniformly distributed in all seven models. Fourth, the NS-ADCC and NS-DCC models have almost the same VaR forecast performance because the corresponding total numbers of portfolios that pass the three accuracy measures are almost equal for these two models.

From this, we reach the following conclusions irrespective of weight combinations. All seven models seem to have the same VaR forecast performance. This result is consistent with that found at the preliminary analysis in the previous paragraph. These findings can also be roughly observed from the numbers in the column SUM of Table 10. Hence the different weight combinations of portfolios do not affect the comparison results for the currency-stock-based portfolio. To sum up, the weight combinations of portfolios do not affect the comparison results for both the currency-stock and stock-based portfolios. However, the different component combinations of portfolios will affect the comparison results.

\subsubsection{Efficiency Evaluation Test via Market Risk Capital}

Through performing the VaR forecasts' performance comparison among all seven models via three accuracy tests, we know which approach of parameters estimate (i.e., the standard or non-standard approach) has a better VaR forecast performance for a specific type of bivariate variance-covariance specification and which type of bivariate variance-covariance specification (i.e., the CCC, DCC, or BEKK) has a better VaR forecast performance for a specific approach of parameters estimate and, more strictly, which model has the best VaR forecast performance among all seven models. The question is how to use these findings in real cases such as the risk management of a bank. That is, which model is more suitable for banking risk management? Thus, via combining the MRC under the 1996 MRA to the Basel Capital Accord, this study utilizes the two-stage selection procedure of Sarma et al. (2003) to select a suitable model to manage the institutional risk. Regarding the above two-stage selection procedure, the first stage of the model selection involves several statistical accuracy tests (e.g., $\mathrm{LR}_{\mathrm{uc}}, \mathrm{LR}_{\mathrm{cc}}$, and $\mathrm{DQ}$ ) that were executed previously. On the other hand, the second stage includes an efficiency test based on specific loss functions such as the MRC loss function. To repeat, the MRC is the amount of regulatory capital a bank must hold with respect to its market risk exposure. Regarding the above efficiency test, we use the superior predictive ability (SPA) test by Hansen (2005). The null hypothesis of this test is that none of the models is better than the benchmark. If the $p$-value of this test statistic is greater than the $10 \%$ level, then the null hypothesis is accepted, or the benchmark model shows better performance than the other competing models. In the SPA test, each competing model has to take turns being the benchmark model. Hence, we perform this test seven times for the seven bivariate GARCH models.

As defined by the MRC in Equation (21), the values of MRC depend on the values of VaR at the $99 \%$ level. Hence, we only consider four models (S-DCC, NS-DCC, NS-BEKK, and NS-ADCC ${ }^{19}$ ) to perform the efficiency test. That is, we exclude the other three models (S-CCC, NS-CCC, and S-BEKK) because they have no portfolios passing the alternative accuracy test at the first stage. For example, the total number of tests passing the three accuracy tests is zero for the S-CCC model in panel B of Table 10 (i.e., $\mathrm{w}_{1}=25 \%$, and $\mathrm{w}_{2}=75 \%$ weight combination of currency-stock portfolio), the NS-CCC model in panel A of Table 10 (i.e., $\mathrm{w}_{1}=50 \%$, and $\mathrm{w}_{2}=50 \%$ weight combination of currency-stock

19 Even if the total number of passing three accuracy tests is zero for the NS-ADCC model at panel A of Table 8 (i.e., $\mathrm{w}_{1}=$ $50 \%$, and $\mathrm{w}_{2}=50 \%$ weight combination of stock portfolio), we considered this model since the NS-DCC model is the special case of NS-ADCC model. 
portfolio), and the S-BEKK model in panel B of Table 8 (i.e., $\mathrm{w}_{1}=25 \%$, and $\mathrm{w}_{2}=75 \%$ weight combination of stock portfolio). Table 11 lists the results of the efficiency evaluation test based on MRC for equal-weight bi-component stock and currency-stock portfolio ${ }^{20}$. Moreover, regarding a specified model, the total number of portfolios that pass the SPA test is counted and listed in column Sum of Table 11. For example, regarding the first subpanel of panel A of Table 11, no stock portfolio passes the SPA test for both the NS-DCC and NS-ADCC models; only the Ny-Ft portfolio passes this test for the S-DCC model and all seven stock portfolios pass this test for the NS-BEKK model. Hence, the numbers in column Sum corresponding to the rows S-DCC, NS-DCC, NS-BEKK, and NS-ADCC models of the first subpanel of panel A of Table 11 are 1, 0, 7, and 0, respectively. We also count the total number of portfolios that pass the SPA test for a specified model when taking 21 stock portfolios as a whole, and then record it in parentheses "( )" in column Sum in the third subpanel of panel A. As reported there, the total numbers of portfolios that pass the SPA test for the S-DCC, NS-DCC, NS-BEKK, and NS-ADCC models respectively are 8, 2, 21, and 2 when taking 21 stock portfolios as a whole. These results are also summarized in column " $\mathrm{w}_{1}=0.5, \mathrm{w}_{2}=0.5$ " underneath Stock portfolios in Table 12. With the same inference process, the total numbers of portfolios that pass the SPA test for the S-DCC, NS-DCC, NS-BEKK, and NS-ADCC models respectively are 5, 0, 7, and 1 when taking seven currency-stock portfolios as a whole. These results are recorded in the column Sum of panel B in Table 11 and also summarized in column " $\mathrm{w}_{1}=0.5, \mathrm{w}_{2}=0.5$ " underneath Currency-stock portfolios in Table 12. In Table 11, we also show that when a model passes the SPA test, the corresponding MRC is almost the smallest among all competing models' MRCs.

Table 12 lists the summary results of the efficiency evaluation test based on MRCs for three weight combinations of stock and currency-stock portfolios. As reported in Table 12, we find that the NS-BEKK model has the best efficiency, followed by the S-DCC model for all the cases of three weight combinations of both the stock and currency-stock portfolios because the NS-BEKK model has the largest total number of portfolios that pass the SPA test. For example, as shown in column " $\mathrm{w}_{1}=0.5, \mathrm{w}_{2}=0.5$ " underneath Stock portfolios in Table 12, the total number of portfolios that pass the SPA test is equal to 21 for the NS-BEKK model. This number, 21, is the largest among the 8 (the S-DCC), 2 (the NS-DCC), 21 (the NS-BEKK), and 2 (the NS-ADCC). These results indicate that irrespective of the weight combination of the portfolios, the NS-BEKK is the most suitable model to be used in the stock- and currency-stock-based portfolio by the bank risk manager. In addition, we are surprised that the NS-BEKK model is selected from the efficiency evaluation test for both the stock- and currency-stock-based portfolios, whereas the S-DCC model is chosen from the accuracy tests only for the stock-based portfolio. The reason we guess for this is that the three accuracy tests are based on the one-day VaR, whereas the efficiency evaluation test is based on the MRC that depends on the 10-day VaR at the 99\% confidence level and the MRA's multiplication factor. As to the other reasons, they are left for future investigations.

20 Due to the limited space, the results of the efficiency evaluation test based on MRC for the other two weight combinations stock and currency-stock portfolios are omitted here and are available upon request. However, the summary results of the above results are also listed in Table 12. 
Table 8. All the summary results of the out-of-sample VaR forecast performances for the three weight combinations stock portfolios.

\begin{tabular}{|c|c|c|c|c|c|c|c|c|c|c|c|c|c|c|c|c|c|}
\hline \multicolumn{18}{|c|}{ Panel A. $w_{1}=50 \%$, and $w_{2}=50 \%$ bi-component portfolios } \\
\hline & \multicolumn{4}{|c|}{$90 \%$ Level } & \multicolumn{4}{|c|}{ 95\% Level } & \multicolumn{4}{|c|}{ 99\% Level } & \multicolumn{4}{|c|}{ 99.5\% Level } & \multirow{2}{*}{ SUM } \\
\hline & $\mathbf{L R}_{\mathrm{uc}}$ & $\mathbf{L R}_{\mathrm{cc}}$ & DQ & Sum & $\mathbf{L R}_{\mathrm{uc}}$ & $\mathbf{L R}_{\mathrm{cc}}$ & DQ & Sum & $\mathbf{L R}_{\mathrm{uc}}$ & $\mathbf{L R}_{\mathrm{cc}}$ & DQ & Sum & $\mathbf{L R}_{\mathrm{uc}}$ & $\mathbf{L R}_{\mathrm{cc}}$ & DQ & Sum & \\
\hline S-CCC & 18 & 8 & 7 & 33 & 5 & 6 & 7 & 18 & 3 & 1 & 1 & 5 & 3 & 0 & 0 & 3 & 59 \\
\hline NS-CCC & 19 & 11 & 8 & 38 & 9 & 8 & 10 & $\underline{27}$ & 2 & 2 & 2 & 6 & 2 & 0 & 0 & 2 & 73 \\
\hline S-DCC & 21 & 18 & 13 & $\underline{52}$ & 20 & 18 & 17 & $\underline{55}$ & 13 & 7 & 6 & $\underline{26}$ & 15 & 1 & 4 & $\underline{20}$ & $\underline{153}$ \\
\hline NS-DCC & 20 & 14 & 8 & $\underline{42}$ & 7 & 7 & 9 & 23 & 1 & 2 & 2 & 5 & 5 & 0 & 0 & $\underline{5}$ & $\underline{75}$ \\
\hline S-BEKK & 21 & 14 & 8 & $\overline{43}$ & 9 & 8 & 9 & 26 & 5 & 4 & 3 & 12 & 7 & 1 & 2 & $\overline{10}$ & $\overline{91}$ \\
\hline NS-BEKK & 18 & 13 & 7 & 38 & 7 & 7 & 11 & 25 & 3 & 4 & 2 & $\underline{9}$ & 3 & 0 & 0 & 3 & $\underline{75}$ \\
\hline NS-ADCC & 20 & 13 & 7 & 40 & 9 & 8 & 9 & 26 & 0 & 0 & 0 & $\overline{0}$ & 6 & 0 & 1 & 7 & $\overline{73}$ \\
\hline \multicolumn{18}{|c|}{ Panel B. $w_{1}=25 \%$, and $w_{2}=75 \%$ bi-component portfolios } \\
\hline & \multicolumn{4}{|c|}{$90 \%$ Level } & \multicolumn{4}{|c|}{$95 \%$ Level } & \multicolumn{4}{|c|}{$99 \%$ Level } & \multicolumn{4}{|c|}{ 99.5\% Level } & SUM \\
\hline & $\mathbf{L R}_{\mathrm{uc}}$ & $\mathbf{L R}_{\mathrm{cc}}$ & DQ & Sum & $\mathbf{L R}_{\mathrm{uc}}$ & $\mathbf{L R}_{\mathrm{cc}}$ & DQ & Sum & $\mathbf{L R}_{\mathrm{uc}}$ & $\mathbf{L R}_{\mathrm{cc}}$ & DQ & Sum & $\mathbf{L R}_{\mathrm{uc}}$ & $\mathbf{L R}_{\mathrm{cc}}$ & DQ & Sum & \\
\hline S-CCC & 10 & 5 & 3 & 18 & 7 & 6 & 7 & 20 & 1 & 0 & 0 & 1 & 2 & 0 & 0 & 2 & 41 \\
\hline NS-CCC & 20 & 14 & 11 & $\underline{45}$ & 13 & 11 & 11 & $\underline{35}$ & 2 & 1 & 1 & $\underline{4}$ & 3 & 0 & 3 & $\underline{6}$ & $\underline{90}$ \\
\hline S-DCC & 21 & 16 & 14 & $\underline{51}$ & 18 & 12 & 14 & $\underline{44}$ & 11 & 5 & 4 & $\underline{20}$ & 12 & 2 & 6 & $\underline{20}$ & $\underline{135}$ \\
\hline NS-DCC & 20 & 14 & 11 & $\underline{45}$ & 13 & 11 & 11 & $\underline{35}$ & 1 & 1 & 1 & 3 & 2 & 0 & 3 & 5 & 88 \\
\hline S-BEKK & 19 & 11 & 11 & $\overline{41}$ & 15 & 8 & 9 & $\overline{32}$ & 0 & 0 & 0 & 0 & 5 & 1 & 4 & 10 & 83 \\
\hline NS-BEKK & 17 & 14 & 11 & 42 & 11 & 11 & 12 & 34 & 0 & 0 & 1 & 1 & 1 & 0 & 1 & 2 & 79 \\
\hline NS-ADCC & 19 & 14 & 11 & 44 & 13 & 11 & 11 & 35 & 1 & 1 & 1 & 3 & 2 & 0 & 3 & 5 & 87 \\
\hline \multicolumn{18}{|c|}{ Panel C. $w_{1}=75 \%$, and $w_{2}=25 \%$ bi-component portfolios } \\
\hline & \multicolumn{4}{|c|}{$90 \%$ Level } & \multicolumn{4}{|c|}{$95 \%$ Level } & \multicolumn{4}{|c|}{$99 \%$ Level } & \multicolumn{4}{|c|}{ 99.5\% Level } & \\
\hline & $\mathbf{L R}_{\mathrm{uc}}$ & $\mathbf{L R}_{\mathrm{cc}}$ & DQ & Sum & $\mathbf{L R}_{\mathrm{uc}}$ & $\mathbf{L R}_{\mathrm{cc}}$ & DQ & Sum & $\mathbf{L R}_{\mathrm{uc}}$ & $\mathbf{L R}_{\mathrm{cc}}$ & DQ & Sum & $\mathbf{L R}_{\mathrm{uc}}$ & $\mathbf{L R}_{\mathrm{cc}}$ & DQ & Sum & $501 \mathrm{~N}$ \\
\hline S-CCC & 16 & 15 & 10 & 41 & 12 & 11 & 10 & 33 & 7 & 2 & 0 & 9 & 8 & 0 & 0 & 8 & 91 \\
\hline NS-CCC & 20 & 17 & 14 & $\underline{51}$ & 16 & 16 & 13 & 45 & 1 & 2 & 1 & 4 & 4 & 0 & 1 & $\underline{5}$ & 105 \\
\hline S-DCC & 21 & 19 & 17 & $\underline{57}$ & 20 & 19 & 17 & $\underline{56}$ & 13 & 5 & 2 & $\underline{20}$ & 11 & 3 & 4 & $\underline{18}$ & $\underline{151}$ \\
\hline NS-DCC & 21 & 16 & 14 & $\underline{51}$ & 17 & 16 & 14 & $\underline{47}$ & 3 & 2 & 1 & $\underline{6}$ & 4 & 0 & 0 & 4 & $\underline{108}$ \\
\hline
\end{tabular}


Table 8. Cont.

\begin{tabular}{|c|c|c|c|c|c|c|c|c|c|c|c|c|c|c|c|c|c|}
\hline \multicolumn{18}{|c|}{ Panel C. $w_{1}=75 \%$, and $w_{2}=25 \%$ bi-component portfolios } \\
\hline & \multicolumn{4}{|c|}{$90 \%$ Level } & \multicolumn{4}{|c|}{ 95\% Level } & \multicolumn{4}{|c|}{ 99\% Level } & \multicolumn{4}{|c|}{ 99.5\% Level } & \multirow{2}{*}{ SUM } \\
\hline & $\mathbf{L R}_{\mathrm{uc}}$ & $\mathbf{L R}_{\mathrm{cc}}$ & DQ & Sum & $\mathbf{L R}_{\mathrm{uc}}$ & $\mathbf{L R}_{\mathrm{cc}}$ & DQ & Sum & $\mathbf{L R}_{\mathrm{uc}}$ & $\mathbf{L R}_{\mathrm{cc}}$ & DQ & Sum & $\mathbf{L R}_{\mathrm{uc}}$ & $\mathbf{L R}_{\mathrm{cc}}$ & DQ & Sum & \\
\hline S-BEKK & 21 & 17 & 14 & 52 & 19 & 18 & 16 & 53 & 6 & 3 & 2 & 11 & 7 & 1 & 1 & 9 & 125 \\
\hline NS-BEKK & 20 & 16 & 12 & 48 & 18 & 15 & 12 & 45 & 2 & 1 & 1 & 4 & 3 & 0 & 0 & 3 & 100 \\
\hline NS-ADCC & 21 & 16 & 14 & 51 & 18 & 15 & 14 & 47 & 2 & 2 & 1 & 5 & 3 & 0 & 0 & 3 & 106 \\
\hline
\end{tabular}

Note: (1) Refer to note 2 of Table 3. (2) The numbers in columns $\mathrm{LR}_{\mathrm{uc}}, \mathrm{LR}_{\mathrm{cc}}$, and DQ underneath the $90 \%$ level at panel A are the numbers in columns $\mathrm{S}_{90, \mathrm{uc}}, \mathrm{S}_{90, \mathrm{cc}}$, and $\mathrm{S}_{90, \mathrm{dq}}$ underneath the 90\% level in Table 7. Similarly, the numbers in column Sum underneath the $90 \%$ level at panel A are the numbers in columns $\mathbf{S}_{\mathbf{9 0}}$ underneath the $90 \%$ level case in Table 7 . As to the numbers in columns $\mathrm{LR}_{\mathrm{uc}}, \mathrm{LR}_{\mathrm{cc}}, \mathrm{DQ}$, and Sum underneath the $95 \%, 99 \%, 99.5 \%$ levels in panel A, they are defined as the $90 \%$ level. (3) The numbers in the column Sum at each panel denote the total sum of three corresponding numbers in columns $\mathrm{LR}_{\mathrm{uc}}, \mathrm{LR}_{\mathrm{cc}}$, and DQ. (4) The numbers in the column SUM at each panel denote the total sum of the four corresponding numbers in the columns Sum of the $90 \%, 95 \%, 99 \%$, and $99.5 \%$ levels. (5) The bold font in the columns Sum, and SUM denotes the greater number when two numbers corresponding to two models are compared with each other and these two models have the same bivariate variance-covariance specification but a different parameter estimate approach (i.e., the S-CCC vs. NS-CCC; the S-DCC vs. NS-DCC; and the S-BEKK vs. NS-BEKK). (6) The underlined font in the columns Sum, and SUM denotes the greatest number when three numbers corresponding to three models are compared with each other and these three models have the same parameter estimate approach but with different bivariate variance-covariance specifications (i.e., the S-CCC, S-DCC, and S-BEKK; NS-CCC, NS-DCC, and NS-BEKK). (7) The shaded font in the columns Sum, and SUM denotes the greatest number when seven numbers corresponding to even models are compared with each other. (8) The italic font in the columns Sum, and SUM denotes the greater number when two numbers corresponding to two models are compared with each other, and these two models are the NS-DCC and NS-ADCC.

Table 9. The out-of-sample VaR forecasts performance of the equal weight currency-stock portfolios based on alternative accuracy tests for the $90 \%$ level.

\begin{tabular}{|c|c|c|c|c|c|c|c|c|}
\hline & Udi-Ny & Udi-Sp & Udi-Na & Udi-Ca & Udi-Da & Udi-Ft & Udi-Sm & Sum \\
\hline \multicolumn{9}{|c|}{ Panel A. The $\mathrm{LR}_{\mathrm{uc}}$ test } \\
\hline S-CCC & $0.3643[0.5461]$ & $\mathbf{0 . 0 8 9 9}[0.7642]$ & $\mathbf{0 . 0 0 0 0 [ 1 . 0 0 0 0 ]}$ & $\mathbf{1 . 7 1 1 9}[0.1907]$ & $5.8681[0.0154]$ & $0.0000[1.0000]$ & $\mathbf{1 . 0 4 6 6 [ 0 . 3 0 6 2 ] ~}$ & 6 \\
\hline NS-CCC & $\mathbf{0 . 0 2 2 0}[0.8818]$ & $\mathbf{0 . 0 2 2 3}[0.8811]$ & $\mathbf{0 . 0 2 2 0}[0.8818]$ & $\mathbf{1 . 3 5 9 7}[0.2435]$ & $5.8681[0.0154]$ & $\mathbf{0 . 0 8 7 8}[0.7669]$ & $\mathbf{0 . 3 4 7 4}[0.5555]$ & 6 \\
\hline S-DCC & $\mathbf{0 . 0 8 9 9}[0.7642]$ & $1.1375[0.2861]$ & $\mathbf{0 . 8 3 0 3}[0.3621]$ & $0.0000[1.0000]$ & $1.3597[0.2435]$ & $\mathbf{0 . 0 2 2 3}[0.8811]$ & $\mathbf{0 . 8 3 0 3}[0.3621]$ & 7 \\
\hline NS-DCC & $0.2036[0.6517]$ & $1.9058[0.1674]$ & $\mathbf{0 . 0 8 9 9}[0.7642]$ & $\mathbf{0 . 0 2 2 0}[0.8818]$ & $1.3597[0.2435]$ & $\mathbf{0 . 0 2 2 3}[0.8811]$ & $\mathbf{0 . 5 7 2 9}[0.4491]$ & 7 \\
\hline S-BEKK & $\mathbf{0 . 0 8 7 8 [ 0 . 7 6 6 9 ]}$ & $0.0000[1.0000]$ & $\mathbf{0 . 0 2 2 0}[0.8818]$ & $2.5309[0.1116]$ & $7.2612[0.0070]$ & $\mathbf{0 . 1 9 6 5}[0.6575]$ & $1.3597[0.2435]$ & 6 \\
\hline NS-BEKK & $\mathbf{0 . 0 8 9 9}[0.7642]$ & $1.9058[0.1674]$ & $0.0000[1.0000]$ & $\mathbf{0 . 1 9 6 5}[0.6575]$ & $1.7119[0.1907]$ & $\mathbf{0 . 0 8 7 8}[0.7669]$ & $\mathbf{0 . 2 0 3 6}[0.6517]$ & 7 \\
\hline NS-ADCC & $\mathbf{0 . 2 0 3 6}[0.6517]$ & $1.9058[0.1674]$ & $\mathbf{0 . 0 8 9 9}[0.7642]$ & $\mathbf{0 . 0 2 2 0}[0.8818]$ & $1.3597[0.2435]$ & $\mathbf{0 . 0 2 2 3}[0.8811]$ & $\mathbf{0 . 3 6 4 3 [ 0 . 5 4 6 1 ]}$ & 7 \\
\hline
\end{tabular}


Table 9. Cont.

\begin{tabular}{|c|c|c|c|c|c|c|c|c|}
\hline & Udi-Ny & Udi-Sp & Udi-Na & Udi-Ca & Udi-Da & Udi-Ft & Udi-Sm & Sum \\
\hline \multicolumn{9}{|c|}{ Panel B. The $\mathrm{LR}_{\mathrm{cc}}$ test } \\
\hline S-CCC & $\mathbf{0 . 5 2 2 1}[0.7702]$ & $\mathbf{0 . 1 2 7 9}[0.9380]$ & $2.4 \times 10^{-5}[0.9999]$ & $2.4195[0.2982]$ & $6.0139[0.0494]$ & $5.0545[0.0798]$ & $6.0584[0.0483]$ & 5 \\
\hline NS-CCC & $\mathbf{0 . 1 6 4 3 [ 0 . 9 2 1 1 ]}$ & $\mathbf{0 . 0 3 1 3}[0.9844]$ & $\mathbf{0 . 0 3 2 9}[0.9836]$ & $2.2588[0.3232]$ & $6.0139[0.0494]$ & $4.1640[0.1246]$ & $7.0446[0.0295]$ & 5 \\
\hline S-DCC & $\mathbf{0 . 5 6 1 7}[0.7551]$ & $\mathbf{1 . 1 6 5 0}[0.5584]$ & $\mathbf{0 . 8 3 4 7}[0.6587]$ & $1.9366[0.3797]$ & $3.1793[0.2039]$ & $3.7804[0.1510]$ & $7.1652[0.0278]$ & 6 \\
\hline NS-DCC & $0.2911[0.8645]$ & $2.0396[0.3606]$ & $\mathbf{0 . 1 2 7 9}[0.9380]$ & $2.9583[0.2278]$ & $2.2588[0.3232]$ & $3.7804[0.1510]$ & $6.3292[0.0422]$ & 6 \\
\hline S-BEKK & $\mathbf{0 . 1 6 3 4}[0.9215]$ & $\mathbf{2} \times 10^{-5}[0.9999]$ & $0.0329[0.9836]$ & $2.9262[0.2315]$ & $7.2906[0.0261]$ & $5.5319[0.0629]$ & $5.8702[0.0531]$ & 6 \\
\hline NS-BEKK & $\mathbf{0 . 1 2 7 9}[0.9380]$ & $2.0396[0.3606]$ & $2 \times 10^{-5}[0.9999]$ & $\mathbf{1 . 3 3 3 9}[0.5132]$ & $2.4195[0.2982]$ & $2.6549[0.2651]$ & $9.3299[0.0094]$ & 6 \\
\hline NS-ADCC & $\mathbf{0 . 2 9 1 1}[0.8645]$ & $2.0396[0.3606]$ & $\mathbf{0 . 1 2 7 9}[0.9380]$ & $2.9583[0.2278]$ & $2.2588[0.3232]$ & $3.7804[0.1510]$ & $5.5747[0.0615]$ & 7 \\
\hline \multicolumn{9}{|c|}{ Panel C. The DQ test } \\
\hline S-CCC & 1.9277[0.9637] & $\mathbf{1 . 1 7 8 7}[0.9914]$ & $2.3263[0.9395]$ & $5.2358[0.6312]$ & $\mathbf{9 . 1 6 3 5 [ 0 . 2 4 1 1 ]}$ & $8.9207[0.2583]$ & $14.5328[0.0424]$ & 6 \\
\hline NS-CCC & $2.5911[0.9200]$ & $1.3865[0.9859]$ & $2.4799[0.9286]$ & $6.1659[0.5205]$ & $\mathbf{9 . 1 2 4 0}[0.2438]$ & $7.4978[0.3789]$ & $13.0912[0.0699]$ & 7 \\
\hline S-DCC & $3.5911[0.8254]$ & $2.1972[0.9481]$ & $4.8508[0.6781]$ & $8.3832[0.3000]$ & $13.7697[0.0554]$ & $7.4171[0.3867]$ & $\mathbf{1 1 . 3 0 5 8 [ 0 . 1 2 5 8 ]}$ & 7 \\
\hline NS-DCC & $\mathbf{2 . 7 0 4 2 [ 0 . 9 1 0 9 ]}$ & $2.7454[0.9075]$ & $\mathbf{2 . 4 1 4 9 [ 0 . 9 3 3 3 ]}$ & $\mathbf{8 . 0 6 0 7}[0.3272]$ & $\mathbf{1 0 . 8 3 6 4 [ 0 . 1 4 5 9 ]}$ & $6.9173[0.4375]$ & 9.9127[0.1935] & 7 \\
\hline S-BEKK & $2.4411[0.9314]$ & $2.3166[0.9402]$ & $2.5963[0.9196]$ & $7.0117[0.4276]$ & $\mathbf{1 1 . 5 0 4 3 [ 0 . 1 1 8 0 ]}$ & $\mathbf{9 . 6 5 4 0 [ 0 . 2 0 9 0 ]}$ & $12.9049[0.0744]$ & 7 \\
\hline NS-BEKK & $2.3700[0.9365]$ & $2.3697[0.9365]$ & $\mathbf{2 . 2 1 4 2}[0.9470]$ & $6.5538[0.4767]$ & $9.2576[0.2346]$ & $6.5970[0.4720]$ & $12.8241[0.0765]$ & 7 \\
\hline NS-ADCC & $2.6933[0.9118]$ & $3.0184[0.8832]$ & $2.5772[0.9211]$ & $\mathbf{8 . 0 6 0 7}[0.3272]$ & $10.8363[0.1459]$ & $6.9173[0.4375]$ & $\mathbf{1 1 . 0 3 4 2}[0.1371]$ & 7 \\
\hline
\end{tabular}

Note: (1) Refer to notes 1-2 of Table 3. In addition, the symbol Udi denotes the US dollar index. (2) The numbers in this table denote the values of three accuracy tests (i.e., LR $\mathrm{R}_{\mathrm{uc}}$, LR $\mathrm{R}_{\mathrm{cc}}$, and DQ) at the $90 \%$ level for equal weight bi-component currency-stock portfolios. On the contrary, the numbers in the bracket beside the preceding numbers denote the corresponding $p$-values of those test statistics. (3) The bold font indicates that the null hypotheses of the $\mathrm{LR}_{\mathrm{uc}}, \mathrm{LR}_{\mathrm{cc}}$, and DQ tests statistics are accepted at the $5 \%$ significance level. (4) The LR $\mathrm{uc}_{\mathrm{uc}}\left(\right.$ respectively, $\mathrm{LR} \mathrm{R}_{\mathrm{cc}}$ ) test statistic is asymptotically distributed $\chi^{2}(1)$ (respectively, $\chi^{2}(2)$ ) and its corresponding critical value at the $5 \%$ significance level is 3.841 (respectively, 5.991$)$. Conversely, the DQ test statistic is asymptotically distributed $\chi^{2}(7)$ and its corresponding critical value at the $5 \%$ significance level is 14.067 . (5) The numbers in column Sum denote the total number of portfolios passing the above the three accuracy tests at the $5 \%$ significance level. 
Table 10. All the summary results of the out-of-sample VaR forecast performance for the three weight combinations of currency-stock-based portfolios.

\begin{tabular}{|c|c|c|c|c|c|c|c|c|c|c|c|c|c|c|c|c|c|}
\hline \multicolumn{18}{|c|}{ Panel A. $w_{1}=50 \%$, and $w_{2}=50 \%$ bi-component portfolios } \\
\hline & \multicolumn{4}{|c|}{$90 \%$ Level } & \multicolumn{4}{|c|}{$95 \%$ Level } & \multicolumn{4}{|c|}{$99 \%$ Level } & \multicolumn{4}{|c|}{ 99.5\% Level } & \multirow{2}{*}{ SUM } \\
\hline & $\mathbf{L R}_{\mathrm{uc}}$ & $\mathbf{L R}_{\mathrm{cc}}$ & DQ & Sum & $\mathbf{L R}_{\mathrm{uc}}$ & $\mathbf{L R}_{\mathrm{cc}}$ & DQ & Sum & $\mathbf{L R}_{\mathrm{uc}}$ & $\mathbf{L R}_{\mathrm{cc}}$ & DQ & Sum & $\mathbf{L R}_{\mathrm{uc}}$ & $\mathbf{L R}_{\mathrm{cc}}$ & DQ & Sum & \\
\hline S-CCC & 6 & 5 & 6 & 17 & 5 & 3 & 4 & 12 & 1 & 0 & 0 & 1 & 0 & 0 & 0 & 0 & 30 \\
\hline NS-CCC & 6 & 5 & 7 & 18 & 5 & 3 & 4 & 12 & 0 & 0 & 0 & 0 & 0 & 0 & 0 & 0 & 30 \\
\hline S-DCC & 7 & 6 & 7 & $\underline{20}$ & 6 & 7 & 5 & $\underline{18}$ & 1 & 2 & 0 & $\underline{3}$ & 0 & 1 & 1 & $\underline{2}$ & $\underline{43}$ \\
\hline NS-DCC & 7 & 6 & 7 & $\underline{20}$ & 6 & 7 & 5 & $\overline{18}$ & 1 & 2 & 1 & $\underline{4}$ & 0 & 1 & 2 & $\underline{3}$ & $\underline{45}$ \\
\hline S-BEKK & 6 & 6 & 7 & $\overline{19}$ & 3 & 5 & 4 & 12 & 0 & 0 & 0 & 0 & 0 & 0 & 0 & 0 & 31 \\
\hline NS-BEKK & 7 & 6 & 7 & $\underline{20}$ & 6 & 7 & 6 & $\underline{19}$ & 1 & 2 & 1 & $\underline{4}$ & 0 & 0 & 1 & 1 & 44 \\
\hline NS-ADCC & 7 & 7 & 7 & 21 & 6 & 6 & 5 & 17 & 1 & 1 & 1 & 3 & 0 & 1 & 2 & 3 & 44 \\
\hline \multicolumn{18}{|c|}{ Panel B. $w_{1}=25 \%$, and $w_{2}=75 \%$ bi-component portfolios } \\
\hline & \multicolumn{4}{|c|}{$90 \%$ Level } & \multicolumn{4}{|c|}{ 95\% Level } & \multicolumn{4}{|c|}{$99 \%$ Level } & \multicolumn{4}{|c|}{ 99.5\% Level } & SUM \\
\hline & $\mathbf{L R}_{\mathrm{uc}}$ & $\mathbf{L R}_{\mathrm{cc}}$ & DQ & Sum & $\mathbf{L R}_{\mathrm{uc}}$ & $\mathbf{L R}_{\mathrm{cc}}$ & DQ & Sum & $\mathbf{L R}_{\mathrm{uc}}$ & $\mathbf{L R}_{\mathrm{cc}}$ & DQ & Sum & $\mathbf{L R}_{\mathrm{uc}}$ & $\mathbf{L R}_{\mathrm{cc}}$ & DQ & Sum & soivt \\
\hline S-CCC & 0 & 0 & 0 & 0 & 0 & 0 & 0 & 0 & 0 & 0 & 0 & 0 & 0 & 0 & 0 & 0 & 0 \\
\hline NS-CCC & 7 & 6 & 6 & 19 & 6 & 6 & 6 & $\underline{18}$ & 0 & 1 & 1 & 2 & 0 & 0 & 0 & 0 & 39 \\
\hline S-DCC & 7 & 6 & 7 & $\underline{20}$ & 7 & 5 & 5 & $\underline{17}$ & 2 & 1 & 1 & $\underline{4}$ & 3 & 0 & 0 & $\underline{3}$ & $\underline{44}$ \\
\hline NS-DCC & 7 & 6 & 7 & $\underline{20}$ & 7 & 5 & 5 & 17 & 0 & 2 & 1 & $\underline{3}$ & 0 & 0 & 1 & $\underline{1}$ & $\underline{41}$ \\
\hline S-BEKK & 7 & 6 & 6 & 19 & 5 & 4 & 4 & 13 & 0 & 0 & 1 & 1 & 0 & 0 & 0 & 0 & 33 \\
\hline NS-BEKK & 7 & 6 & 6 & 19 & 7 & 5 & 4 & 16 & 0 & 1 & 1 & 2 & 0 & 0 & 1 & $\underline{1}$ & 38 \\
\hline NS-ADCC & 7 & 6 & 7 & 20 & 7 & 5 & 5 & 17 & 0 & 2 & 1 & 3 & 0 & 0 & 1 & 1 & 41 \\
\hline \multicolumn{18}{|c|}{ Panel C. $w_{1}=75 \%$, and $w_{2}=25 \%$ bi-component portfolios } \\
\hline & \multicolumn{4}{|c|}{$90 \%$ Level } & \multicolumn{4}{|c|}{ 95\% Level } & \multicolumn{4}{|c|}{$99 \%$ Level } & \multicolumn{4}{|c|}{ 99.5\% Level } & SUIM \\
\hline & $\mathrm{LR}_{\mathrm{uc}}$ & $\mathrm{LR}_{\mathrm{cc}}$ & DQ & Sum & $\mathrm{LR}_{\mathrm{uc}}$ & $\mathrm{LR}_{\mathrm{cc}}$ & $\mathrm{DQ}$ & Sum & $\mathrm{LR}_{\mathrm{uc}}$ & $\mathrm{LR}_{\mathrm{cc}}$ & $\mathrm{DQ}$ & Sum & $\mathrm{LR}_{\mathrm{uc}}$ & $\mathrm{LR}_{\mathrm{cc}}$ & DQ & Sum & \\
\hline S-CCC & 0 & 1 & 4 & 5 & 2 & 2 & 6 & 10 & 7 & 4 & 4 & $\underline{15}$ & 7 & 3 & 4 & $\underline{14}$ & 44 \\
\hline NS-CCC & 7 & 7 & 7 & $\underline{21}$ & 7 & 7 & 7 & 21 & 3 & 2 & 0 & 5 & 3 & 0 & 0 & 3 & 50 \\
\hline S-DCC & 7 & 5 & 6 & 18 & 7 & 6 & 7 & $\underline{20}$ & 5 & 2 & 2 & 9 & 4 & 0 & 2 & 6 & $\underline{53}$ \\
\hline
\end{tabular}


Table 10. Cont.

\begin{tabular}{|c|c|c|c|c|c|c|c|c|c|c|c|c|c|c|c|c|c|}
\hline \multicolumn{18}{|c|}{ Panel C. $w_{1}=75 \%$, and $w_{2}=25 \%$ bi-component portfolios } \\
\hline & \multicolumn{4}{|c|}{$90 \%$ Level } & \multicolumn{4}{|c|}{$95 \%$ Level } & \multicolumn{4}{|c|}{ 99\% Level } & \multicolumn{4}{|c|}{ 99.5\% Level } & \multirow{2}{*}{ SUM } \\
\hline & $\mathbf{L R}_{\mathrm{uc}}$ & $\mathbf{L R}_{\mathrm{cc}}$ & DQ & Sum & $\mathbf{L R}_{\mathrm{uc}}$ & $\mathbf{L R}_{\mathrm{cc}}$ & DQ & Sum & $\mathbf{L R}_{\mathrm{uc}}$ & $\mathbf{L R}_{\mathrm{cc}}$ & DQ & Sum & $\mathrm{LR}_{\mathrm{uc}}$ & $\mathbf{L R}_{\mathrm{cc}}$ & DQ & Sum & \\
\hline NS-DCC & 7 & 5 & 6 & 18 & 7 & 7 & 7 & 21 & 7 & 3 & 3 & $\underline{13}$ & 6 & 0 & 2 & $\underline{8}$ & $\underline{60}$ \\
\hline S-BEKK & 7 & 7 & 7 & $\underline{21}$ & 7 & 7 & 6 & $\underline{20}$ & 3 & 2 & 0 & 5 & 3 & 0 & 0 & 3 & 49 \\
\hline NS-BEKK & 7 & 5 & 6 & 18 & 7 & 7 & 7 & 21 & 5 & 2 & 3 & 10 & 5 & 0 & 2 & 7 & 56 \\
\hline NS-ADCC & 7 & 6 & 6 & 19 & 7 & 7 & 7 & 21 & 7 & 3 & 3 & 13 & 6 & 0 & 2 & 8 & 61 \\
\hline
\end{tabular}

Note: (1) Refer to note 2 of Table 3. (2) The numbers in columns $\mathrm{LR}_{\mathrm{uc}}, \mathrm{LR}_{\mathrm{cc}}$, and DQ underneath the $90 \%$ level at panel A are the numbers in the columns Sum at Panels A, B, and C in Table 9. The numbers in the column Sum underneath the $90 \%$ level at panel A are the total sum of three corresponding numbers in columns $L R_{u c}, R_{c c}$, and DQ. As to the numbers in columns $\mathrm{LR}_{\mathrm{uc}}, \mathrm{LR}_{\mathrm{cc}}, \mathrm{DQ}$, and Sum underneath the $95 \%, 99 \%, 99.5 \%$ levels at panel A, they are defined as the $90 \%$ level case. (3) As to the other notes, please refer to the notes 3-8 in Table 8 .

Table 11. The efficiency evaluation test based on the market risk capital for equal weight stock and currency-stock portfolios.

\begin{tabular}{|c|c|c|c|c|c|c|c|c|}
\hline \multicolumn{9}{|c|}{ Panel A. The bi-component stock portfolios } \\
\hline & Ny-Sp & $\mathrm{Ny}-\mathrm{Na}$ & $\mathrm{Ny}-\mathrm{Ca}$ & Ny-Da & $\mathrm{Ny}-\mathrm{Ft}$ & $\mathrm{Ny}-\mathrm{Sm}$ & $\mathrm{Sp}-\mathrm{Na}$ & Sum \\
\hline S-DCC & 7.8910(1.724) & 8.0044(2.008) & 8.2003(2.348) & 8.4113(1.788) & $6.8843(1.994)$ & $6.9209(2.080)$ & 8.0728(2.027) & 1 \\
\hline \multirow[b]{2}{*}{ NS-DCC } & $\begin{array}{c}{[0.000]} \\
7.2111(2.455)\end{array}$ & $\begin{array}{c}{[0.000]} \\
7.5252(2.501)\end{array}$ & $\begin{array}{c}{[0.000]} \\
7.9801(2.340)\end{array}$ & $\begin{array}{c}{[0.000]} \\
8.0803(2.160)\end{array}$ & $\begin{array}{c}{[0.510]} \\
7.0083(2.383)\end{array}$ & $\begin{array}{c}{[0.010]} \\
6.8579(2.166)\end{array}$ & $\begin{array}{c}{[0.000]} \\
7.6419(2.577)\end{array}$ & \multirow[b]{2}{*}{0} \\
\hline & [0.000] & [0.004] & [0.000] & {$[0.000]$} & [0.000] & [0.000] & [0.007] & \\
\hline \multirow{2}{*}{ NS-BEKK } & $7.0659(2.337)$ & $7.3937(2.269)$ & $7.8118(2.146)$ & $7.8791(1.923)$ & $6.8751(2.120)$ & $6.6864(1.885)$ & $7.4977(2.295)$ & \multirow{2}{*}{7} \\
\hline & [0.498] & {$[0.528]$} & {$[0.568]$} & [0.619] & {$[0.557]$} & [0.523] & {$[0.535]$} & \\
\hline \multirow{3}{*}{ NS-ADCC } & $7.2111(2.455)$ & $7.5250(2.501)$ & $7.9720(2.367)$ & $8.0878(2.163)$ & $7.0207(2.425)$ & $6.8287(2.112)$ & $7.6419(2.577)$ & \multirow{2}{*}{0} \\
\hline & [0.000] & [0.001] & [0.000] & [0.000] & [0.001] & [0.000] & [0.004] & \\
\hline & $\mathrm{Sp}-\mathrm{Ca}$ & Sp-Da & Sp-Ft & Sp-Sm & $\mathrm{Na}-\mathrm{Ca}$ & $\mathrm{Na}-\mathrm{Da}$ & Na-Ft & \\
\hline \multirow{2}{*}{ S-DCC } & $7.8820(2.256)$ & $8.2991(1.942)$ & $6.8906(2.186)$ & $6.9046(2.072)$ & $8.3522(1.901)$ & $8.3967(1.829)$ & 7.0895(1.999) & \multirow{2}{*}{2} \\
\hline & [0.037] & [0.000] & [0.104] & [0.000] & {$[0.019]$} & [0.073] & {$[0.634]$} & \\
\hline \multirow{2}{*}{ NS-DCC } & $7.8908(2.339)$ & $8.0216(2.170)$ & $6.9040(2.405)$ & $6.7965(2.182)$ & $8.1983(2.369)$ & $8.3949(2.230)$ & $7.2283(2.402)$ & \multirow{2}{*}{0} \\
\hline & [0.000] & [0.000] & [0.003] & [0.000] & {$[0.031]$} & [0.000] & [0.011] & \\
\hline \multirow{2}{*}{ NS-BEKK } & $7.7161(2.116)$ & $7.8271(1.902)$ & $6.7619(2.113)$ & $6.6260(1.868)$ & $8.1093(2.122)$ & $8.2155(1.924)$ & $7.1130(2.097)$ & \multirow{2}{*}{7} \\
\hline & {$[0.520]$} & {$[0.665]$} & [0.917] & {$[0.523]$} & {$[0.733]$} & {$[0.945]$} & [0.442] & \\
\hline \multirow{2}{*}{ NS-ADCC } & $7.8820(2.368)$ & $8.0500(2.172)$ & $6.8929(2.407)$ & $6.7560(2.148)$ & $8.2153(2.413)$ & $8.4142(2.221)$ & $7.2187(2.453)$ & \multirow{2}{*}{0} \\
\hline & [0.000] & {$[0.000]$} & [0.006] & [0.000] & [0.013] & [0.000] & {$[0.066]$} & \\
\hline
\end{tabular}


Table 11. Cont.

\begin{tabular}{|c|c|c|c|c|c|c|c|c|}
\hline \multicolumn{9}{|c|}{ Panel A. The bi-component stock portfolios } \\
\hline & $\mathrm{Na}-\mathrm{Sm}$ & Ca-Da & Ca-Ft & Ca-Sm & Da-Ft & Da-Sm & Ft-Sm & \\
\hline S-DCC & $\begin{array}{c}7.5970(1.947) \\
{[0.000]}\end{array}$ & $\begin{array}{c}10.2190(2.242) \\
{[0.822]}\end{array}$ & $\begin{array}{c}9.2129(1.436) \\
{[0.140]}\end{array}$ & $\begin{array}{c}8.8354(1.232) \\
{[0.465]}\end{array}$ & $\begin{array}{c}8.5388(0.915) \\
{[0.889]}\end{array}$ & $\begin{array}{c}9.3045(1.837) \\
{[0.548]}\end{array}$ & $\begin{array}{c}8.1860(2.395) \\
{[0.000]}\end{array}$ & $5(8)$ \\
\hline NS-DCC & $\begin{array}{c}7.0929(2.193) \\
{[0.000]}\end{array}$ & $\begin{array}{c}10.6129(2.697) \\
{[0.000]}\end{array}$ & $\begin{array}{c}9.1373(2.960) \\
{[0.005]}\end{array}$ & $\begin{array}{c}9.1406(2.709) \\
{[0.000]}\end{array}$ & $\begin{array}{c}9.1602(2.746) \\
{[0.889]}\end{array}$ & $\begin{array}{c}9.1858(2.414) \\
{[0.548]}\end{array}$ & $\begin{array}{c}\text { 7.9692(2.715) } \\
{[0.002]}\end{array}$ & $2(2)$ \\
\hline NS-BEKK & $\begin{array}{c}6.9765(1.852) \\
{[0.856]}\end{array}$ & $\begin{array}{c}10.3884(2.538) \\
{[\mathbf{0 . 1 7 8}]}\end{array}$ & $\begin{array}{c}8.9687(2.588) \\
{[0.889]}\end{array}$ & $\begin{array}{c}8.7994(2.439) \\
{[0.548]}\end{array}$ & $\begin{array}{c}9.0521(2.563) \\
{[0.889]}\end{array}$ & $\begin{array}{c}8.7474(2.143) \\
{[0.548]}\end{array}$ & $\begin{array}{c}7.7521(2.266) \\
{[0.521]}\end{array}$ & $7(21)$ \\
\hline NS-ADCC & $\begin{array}{c}7.0177(2.155) \\
{[0.144]}\end{array}$ & $\begin{array}{c}10.6069(2.707) \\
{[0.000]}\end{array}$ & $\begin{array}{c}9.1373(2.960) \\
{[0.008]}\end{array}$ & $\begin{array}{c}9.1406(2.709) \\
{[0.000]}\end{array}$ & $\begin{array}{c}9.1602(2.746) \\
{[0.889]}\end{array}$ & $\begin{array}{c}9.1864(2.415) \\
{[0.548]}\end{array}$ & $\begin{array}{c}7.9690(2.715) \\
{[0.001]}\end{array}$ & $2(2)$ \\
\hline \multicolumn{9}{|c|}{ Panel B. The bi-component currency-stock portfolios } \\
\hline & Udi-Ny & Udi-Sp & Udi-Na & Udi-Ca & Udi-Da & Udi-Ft & Udi-Sm & Sum \\
\hline S-DCC & $\begin{array}{c}4.1895(1.214) \\
{[0.002]}\end{array}$ & $\begin{array}{c}4.2479(1.338) \\
{[0.433]}\end{array}$ & $\begin{array}{c}4.7965(1.348) \\
{[0.028]}\end{array}$ & $\begin{array}{c}6.2143(1.543) \\
{[0.115]}\end{array}$ & $\begin{array}{c}6.3642(1.361) \\
{[0.388]}\end{array}$ & $\begin{array}{c}4.8727(1.547) \\
{[0.315]}\end{array}$ & $\begin{array}{c}5.1948(1.394) \\
{[0.297]}\end{array}$ & 5 \\
\hline NS-DCC & $\begin{array}{c}4.1493(1.220) \\
{[0.005]}\end{array}$ & $\begin{array}{c}4.2775(1.272) \\
{[0.000]}\end{array}$ & $\begin{array}{c}4.7987(1.332) \\
{[0.000]}\end{array}$ & $\begin{array}{c}6.2952(1.528) \\
{[0.000]}\end{array}$ & $\begin{array}{c}6.4516(1.314) \\
{[0.000]}\end{array}$ & $\begin{array}{c}4.9358(1.567) \\
{[0.000]}\end{array}$ & $\begin{array}{c}5.2512(1.328) \\
{[0.001]}\end{array}$ & 0 \\
\hline NS-BEKK & $\begin{array}{c}4.1102(1.214) \\
{[0.649]}\end{array}$ & $\begin{array}{c}4.2392(1.233) \\
{[0.634]}\end{array}$ & $\begin{array}{c}4.7541(1.236) \\
{[0.927]}\end{array}$ & $\begin{array}{c}6.1904(1.469) \\
{[0.885]}\end{array}$ & $\begin{array}{c}6.3584(1.270) \\
{[0.612]}\end{array}$ & $\begin{array}{c}4.8605(1.536) \\
{[0.685]}\end{array}$ & $\begin{array}{c}5.1756(1.149) \\
{[0.703]}\end{array}$ & 7 \\
\hline NS-ADCC & $\begin{array}{c}4.1486(1.223) \\
{[0.002]}\end{array}$ & $\begin{array}{c}4.2577(1.276) \\
{[0.049]}\end{array}$ & $\begin{array}{c}4.7742(1.341) \\
{[0.129]}\end{array}$ & $\begin{array}{c}\text { 6.2952(1.528) } \\
{[0.000]}\end{array}$ & $\begin{array}{c}6.4516(1.315) \\
{[0.000]}\end{array}$ & $\begin{array}{c}4.9358(1.567) \\
{[0.000]}\end{array}$ & $\begin{array}{c}5.2512(1.328) \\
{[0.001]}\end{array}$ & 1 \\
\hline
\end{tabular}

Note: (1) The symbols Ny, Sp, Na, Ca, Da, Ft, Sm, and Udi denote the USNYSE, S\&P500, and Nasdaq; France CAC40; Germany DAX; United Kingdom FTSE; Swiss SMI stock indices; and the US dollar index, respectively. (2) S-DCC and NS-DCC respectively denote the standard and non-standard (i.e., the two-step) dynamic conditional correlation models; NS-BEKK denotes the non-standard (i.e., the simplified) BEKK model derived by Su (2014a), whereas NS-ADCC denotes the non-standard (i.e., the two-step) asymmetric type of dynamic conditional correlation models. (3) The numbers in this table and parentheses ' ( )' denote the mean values and standard deviation of market risk capital, respectively. The numbers in the brackets ' []$^{\prime}$ denote the reality check $p$-value of the Hansen's consistent test for the market risk capital-based loss function. In the SPA test, each competing model has to take turns to be the benchmark model and the null hypothesis is that none of the models is better than the benchmark. The number of bootstrap replications to calculate the $p$-values is 1000 and the dependency parameter $\mathrm{q}$ is 0.5 . (4) The bold font in brackets ' []$^{\prime}$ ' denotes a $p$-value greater than $10 \%$ level, indicating that the above null hypothesis is accepted or that the benchmark model has a better performance than the other competing model. (5) The numbers in the column Sum denote the total number of bi-component portfolios that adopt the SPA test for a specified model. (6) The bold font in the column Sum denotes the greatest number among the four numbers in an alternative subpanel. (7) The numbers in the parentheses ' ( )' of the column Sum at the third subpanel of panel A denote the total number of portfolios that adopt the SPA test for a specified model when taking 21 bi-component stock portfolios as a whole. 
Table 12. The summary results of the efficiency evaluation test based on the market risk capital (MRC) for the three weight combinations of the stock and currency-stock portfolios.

\begin{tabular}{|c|c|c|c|c|c|c|c|c|c|c|c|c|}
\hline & \multicolumn{6}{|c|}{ Stock Portfolios } & \multicolumn{6}{|c|}{ Currency-Stock Portfolios } \\
\hline & $w_{1}$ & $\mathbf{w}_{2}$ & $w_{1}$ & $\mathbf{w}_{2}$ & $\mathbf{w}_{1}$ & $\mathbf{w}_{2}$ & $w_{1}$ & $w_{2}$ & $w_{1}$ & $w_{2}$ & $w_{1}$ & $\mathbf{w}_{2}$ \\
\hline & 0.5 & 0.5 & 0.25 & 0.75 & 0.75 & 0.25 & 0.5 & 0.5 & 0.25 & 0.75 & 0.75 & 0.25 \\
\hline S-DCC & \multicolumn{2}{|c|}{8} & \multicolumn{2}{|c|}{8} & \multicolumn{2}{|c|}{7} & \multicolumn{2}{|c|}{5} & \multicolumn{2}{|c|}{4} & \multicolumn{2}{|c|}{0} \\
\hline NS-DCC & \multicolumn{2}{|c|}{2} & \multicolumn{2}{|c|}{0} & \multicolumn{2}{|c|}{1} & \multicolumn{2}{|c|}{0} & \multicolumn{2}{|c|}{1} & \multicolumn{2}{|c|}{0} \\
\hline NS-BEKK & \multicolumn{2}{|c|}{21} & \multicolumn{2}{|c|}{19} & \multicolumn{2}{|c|}{20} & \multicolumn{2}{|c|}{7} & \multicolumn{2}{|c|}{7} & \multicolumn{2}{|c|}{7} \\
\hline NS-ADCC & \multicolumn{2}{|c|}{2} & \multicolumn{2}{|c|}{0} & \multicolumn{2}{|c|}{1} & \multicolumn{2}{|c|}{1} & \multicolumn{2}{|c|}{1} & \multicolumn{2}{|c|}{0} \\
\hline
\end{tabular}

Note: (1) S-DCC and NS-DCC respectively denote the standard and non-standard (i.e., the two-step) dynamic conditional correlation models; NS-BEKK denotes the non-standard (i.e., the simplified) BEKK model derived by $\mathrm{Su}$ (2014a), whereas NS-ADCC denotes the non-standard (i.e., the two-step) asymmetric type of dynamic conditional correlation model. (2) $w_{1}$ and $w_{2}$ are the weights of the two component assets of portfolios. (3) The numbers are summarized from those in the column Sum of Table 11 and denote the total number of bi-component portfolios that adopt the SPA test for a specified model. Notably, there are 21 bi-component stock portfolios and 7 bi-component currency-stock portfolios. (4) The bold font denotes the greatest number among the four numbers in each column.

\section{Conclusions}

In this study, the seven bivariate GARCH models were mainly used to forecast the out-of-sample $\mathrm{VaR}$ of 21 equal-weight bi-component portfolios composed of alternative two indices among seven stock indices in America and Europe. The seven bivariate GARCH models were composed of four bivariate variance-covariance specifications with two parameter estimate approaches. Subsequently, the out-of-sample forecast results were used to investigate which bivariate variance-covariance specification and which parameter estimate approach has a better VaR forecast performance and whether the asymmetric DCC model has a better forecast performance than its corresponding symmetric one. To explore whether a different portfolio (different components with different weights) has the same comparison results with the equal-weight portfolio, two additional sub-issues were explored. First, we added two other weight combinations $\left(\mathrm{w}_{1}=25 \%, \mathrm{w}_{2}=75 \%\right.$; and $\mathrm{w}_{1}=75 \%$, $\mathrm{w}_{2}=25 \%$ ) for the original 21 stock-based portfolios to investigate whether the different weight combinations would affect the comparison results. Second, we also considered the US dollar index (Udi) as the new component asset to construct seven currency-stock-based bi-component portfolios to investigate whether the different component combinations of portfolios would affect the comparison results. Finally, via combining the MRC under the 1996 MRA to the Basel Capital Accord, we used the two-stage selection procedure of Sarma et al. (2003) to select a suitable model to manage the institutional risk.

The empirical findings can be summarized as follows. Regarding the stock portfolios, we find the following findings irrespective of weight combinations. First, the standard approach has a better $\mathrm{VaR}$ forecast performance for the DCC and BEKK types of bivariate variance-covariance specification, whereas the non-standard approach has a better VaR forecast performance only for the CCC type of bivariate variance-covariance specification. Second, the DCC type of bivariate variance-covariance specification has the best VaR forecast performance only for the standard approach, whereas three types of bivariate variance-covariance specification seem to have the same VaR forecast performance for the non-standard approach. Third, the DCC type of bivariate variance-covariance specification with the standard approach shows the best VaR forecast performance among the seven bivariate GARCH models. This result is one of the most significant findings in this study. Fourth, the NS-ADCC and NS-DCC models have almost the same VaR forecast performance. Hence, the different weight combinations of portfolios seem to not affect the comparison results for the stock-based portfolio. On the other hand, regarding the currency-stock portfolios, all seven models seem to have the same $\mathrm{VaR}$ forecast performance irrespective of weight combinations, indicating that the different weight combinations seem not to affect the comparison results for the currency-stock-based portfolio. Hence, regarding the accuracy test, the VaR forecast performance comparison results vary with the component 
combination of the portfolio but do not vary with the weight combinations of the portfolios. Finally, regarding the efficiency evaluation test via market risk capital, we find that the NS-BEKK is the most suitable model to be used in stock- and currency-stock-based portfolios for the bank risk manager, irrespective of the weight combination of portfolios. This is another of the most significant findings in this study.

Based on these findings, one important policy implication is proposed: the bank risk manager should select the NS-BEKK model to forecast the VaR of both the stock and currency-stock portfolios because the BEKK type of bivariate variance-covariance specification with the non-standard approach (i.e., with simplified parameters) produces the smallest value of MRC among all competing models' MRCs.

Author Contributions: Both authors contributed equally to this article.

Funding: This research received no external funding.

Acknowledgments: The authors appreciate the editors and two anonymous referees for their helpful comments and suggestions.

Conflicts of Interest: The authors declare no conflict of interest.

\section{References}

Baba, Yoshi, Robert F. Engle, Dennis Kraft, and Kenneth F. Kroner. 1990. Multivariate Simultaneous Generalized $A R C H$. Oakland: University of California, unpublished manuscript.

Baldi, Lucia, Massimo Peri, and Daniela Vandone. 2016. Stock markets' bubbles burst and volatility spillovers in agricultural commodity markets. Research in International Business and Finance 38: 277-85. [CrossRef]

Bams, Dennis, Gildas Blanchard, and Thorsten Lehnert. 2017. Volatility measures and Value-at-Risk. International Journal of Forecasting 33: 848-63. [CrossRef]

Bauwens, Luc, Sebastien Laurent, and Jeroen V. K. Rombouts. 2006. Multivariate GARCH models: A survey. Journal of Applied Econometrics 21: 79-109. [CrossRef]

Bayer, Sebastian. 2018. Combining Value-at-Risk forecasts using penalized quantile regressions. Econometrics and Statistics 8: 56-77. [CrossRef]

Bollerslev, Tim. 1986. Generalized autoregressive conditional heteroscedasticity. Journal of Econometrics 31: 307-27. [CrossRef]

Bollerslev, Tim. 1990. Modeling the coherence in short-run nominal exchange rates: A multivariate generalized ARCH model. Review of Economics and Statistics 72: 498-505. [CrossRef]

Caporale, Guglielmo Maria, John Hunter, and Faek Menla Ali. 2014. On the linkages between stock prices and exchange rates: Evidence from the banking crisis of 2007-2010. International Review of Financial Analysis 33: 87-103. [CrossRef]

Cappiello, Lorenzo, Robert F. Engle, and Kevin Sheppard. 2006. Asymmetric Dynamics in the Correlations of Global Equity and Bond Returns. Journal of Financial Econometrics 4: 537-72. [CrossRef]

Chang, Chia-Lin, Hui-Kuang Hsu, and Michael McAleer. 2013. Is small beautiful? Size effects of volatility spillovers for firm performance and exchange rates in tourism. North American Journal of Economics and Finance 26: 519-34. [CrossRef]

Christoffersen, Peter. 1998. Evaluating interval forecasts. International Economic Review 39: 841-62. [CrossRef]

Engle, Robert. 2002. Dynamic conditional correlation: A simple class of multivariate generalized autoregressive conditional heteroskedasticity models. Journal of Business and Economic Statistics 20: 339-50. [CrossRef]

Engle, Robert, and Kenneth F. Kroner. 1995. Multivariate simultaneous GARCH. Econometric Theory 11: 122-50. [CrossRef]

Engle, Robert F., and Simone Manganelli. 2004. CAViaR: Conditional autoregressive value at risk by regression quantiles. Journal of Business and Economic Statistics 22: 367-81. [CrossRef]

Hansen, Peter Reinhard. 2005. A test for superior predictive ability. Journal of Business E Economic Statistics 23: 365-80.

Hansen, Peter R., and Asger Lunde. 2005. A forecast comparison of volatility models: Does anything beat a GARCH(1,1)? Journal of Applied Econometrics 20: 873-89. [CrossRef] 
Jarque, Carlos M., and Anil K. Bera. 1987. A test for normality of observations and regression residuals. International Statistics Review 55: 163-72. [CrossRef]

Jorion, Philippe. 2000. Value at Risk: The New Benchmark for Managing Financial Risk. New York: McGraw-Hill.

Kupiec, Paul H. 1995. Techniques for verifying the accuracy of risk measurement models. Journal of Derivatives 3 : 73-84. [CrossRef]

Laporta, Alessandro G., Luca Merlo, and Lea Petrella. 2018. Selection of Value at Risk models for energy commodities. Energy Economics 74: 628-43. [CrossRef]

Lee, Cheng-Few, and Jung-Bin Su. 2012. Alternative statistical distributions for estimating Value-at-Risk: Theory and evidence. Review of Quantitative Finance and Accounting 39: 309-31. [CrossRef]

Li, Hong. 2012. The impact of China's stock market reforms on its international stock market linkages. Quarterly Review of Economics and Finance 52: 358-68. [CrossRef]

Lin, Boqiang, and Jianglong Li. 2015. The spillover effects across natural gas and oil markets: Based on the VEC-MGARCH framework. Applied Energy 155: 229-41. [CrossRef]

Liu, Xueyong, Haizhong An, Shupei Huang, and Shaobo Wen. 2017. The evolution of spillover effects between oil and stock markets across multi-scales using a wavelet-based GARCH-BEKK model. Physica A 465: 374-83. [CrossRef]

Lopez, Jose A. 1999. Regulatory evaluation of Value-at-Risk Models. Journal of Risk 1: 37-64. [CrossRef]

McAleer, Michael. 2018. Stationarity and invertibility of a dynamic correlation matrix. Kybernetika 54: 363-74. [CrossRef]

Moore, Tomoe, and Ping Wang. 2014. Dynamic linkage between real exchange rates and stock prices: Evidence from developed and emerging Asian markets. International Review of Economics and Finance 29: 1-11. [CrossRef]

Moschini, Gian Carlo, and Robert J. Myers. 2002. Testing for constant hedge ratios in commodity markets: A multivariate GARCH approach. Journal of Empirical Finance 9: 589-603. [CrossRef]

Ozkan, Ibrahim, and Lutfi Erden. 2015. Time-varying nature and macroeconomic determinants of exchange rate pass-through. International Review of Economics \& Finance 38: 56-66.

Politis, Dimitris N., and Joseph P. Romano. 1994. The stationary bootstrap. Journal of the American Statistical Association 89: 1303-13. [CrossRef]

Sarma, Mandira, Susan Thomas, and Ajay Shah. 2003. Selection of value-at-risk models. Journal of Forecasting 22: 337-58. [CrossRef]

Silvennoinen, Annastiina, and Timo Teräsvirta. 2009. Multivariate GARCH Models. Handbook of Financial Time Series. New York: Springer, pp. 201-29.

$\mathrm{Su}$, Jung-Bin. 2014a. How to mitigate the impact of inappropriate distributional settings when the parametric value-at-risk approach is used? Quantitative Finance 14: 305-25. [CrossRef]

$\mathrm{Su}$, Jung-Bin. 2014b. Empirical analysis of long memory, leverage, and distribution effects for stock market risk estimates. North American Journal of Economics and Finance 30: 1-39. [CrossRef]

$\mathrm{Su}$, Jung-Bin. 2014c. The interrelation of stock markets in China, Taiwan and Hong Kong and their constructional portfolio's value-at-risk estimate. Journal of Risk Model Validation 8: 69-127. [CrossRef]

$\mathrm{Su}$, Jung-Bin. 2015. Value-at-risk estimates of the stock indices in developed and emerging markets including the spillover effects of currency market. Economic Modelling 46: 204-24. [CrossRef]

$\mathrm{Su}$, Jung-Bin, and Jui-Cheng Hung. 2011. Empirical analysis of jump dynamics, heavy-tails and skewness on value-at-risk estimation. Economic Modelling 28: 1117-30. [CrossRef]

$\mathrm{Su}$, Jung-Bin, Ming-Chih Lee, and Chien-Liang Chiu. 2014. Why does skewness and the fat-tail effect influence value-at-risk estimates? Evidence from alternative capital markets. International Review of Economics $\mathcal{E}$ Finance 31: 59-85.

Tamakoshi, Go, and Shigeyuki Hamori. 2014. Co-movements among major European exchange rates: A multivariate time-varying asymmetric approach. International Review of Economics and Finance 31: 105-13. [CrossRef]

Turhan, M. Ibrahim, Ahmet Sensoy, Kevser Ozturk, and Erk Hacihasanoglu. 2014. A view to the long-run dynamic relationship between crude oil and the major asset classes. International Review of Economics E Finance 33: 286-99.

Wang, Ping, and Peijie Wang. 2010. Price and volatility spillovers between the Greater China Markets and the developed markets of US and Japan. Global Finance Journal 21: 304-17. [CrossRef] 
Wang, Kai-Li, Jau-Rong Li, and Meng-Jou Hsiao. 2010. A further investigation of dynamic information transmission between DRs and their underlying stocks with exchange rate threshold effects. Journal of Financial Studies 18: 93-130.

Weber, Enzo. 2013. Simultaneous stochastic volatility transmission across American equity markets. Quarterly Review of Economics and Finance 53: 53-60. [CrossRef]

Yaya, OlaOluwa S., Mohammed M. Tumala, and Christopher G. Udomboso. 2016. Volatility persistence and returns spillovers between oil and gold prices: Analysis before and after the global financial crisis. Resources Policy 49: 273-81. [CrossRef]

Yu, Wenhua, Kun Yang, Yu Wei, and Likun Lei. 2018. Measuring Value-at-Risk and Expected Shortfall of crude oil portfolio using extreme value theory and vine copula. Physica A 490: 1423-33. [CrossRef]

C 2018 by the authors. Licensee MDPI, Basel, Switzerland. This article is an open access article distributed under the terms and conditions of the Creative Commons Attribution (CC BY) license (http:// creativecommons.org/licenses/by/4.0/). 